\title{
IV. Die deutsche Entnazifizierung - Das Dilemma der Spruchkammern
}

\section{Das Befreiungsgesetz}

Die amerikanische Säuberungspolitik geriet im Herbst 1945 in eine Sackgasse. Die zahllosen Entlassungen aufgrund rein formaler Belastungen drohten, wie gezeigt ${ }^{1}$, Verwaltung und Wirtschaft zugrunde zu richten. So wie bisher, darin stimmten Deutsche und Amerikaner überein, konnte es nicht weitergehen. Die Verhaftung der höheren NS-Chargen unmittelbar nach der Besetzung war auf volles Verständnis der Bevölkerung gestoßen und weithin sogar begrüßt worden. Viele hielten es auch für richtig, daß belastete Parteigenossen keine Spitzenpositionen in der Verwaltung behalten konnten. Als die Entnazifizierung nach Erlaß der Direktive vom 7. Juli 1945 aber immer weitere Kreise zog und auch viele kleine Parteigenossen aus dem öffentlichen Dienst entlassen wurden, traf das fast nur noch auf Mißbilligung. Besonderen Unmut erregte das Gesetz Nr. 8 vom 29. September 1945 über die Entnazifizierung der Wirtschaft, das viele kleine Geschäftsleute und Handwerker zwang, ihre Läden und Betriebe zu schließen oder sie - häufig auswärtigen und branchenfremden - Treuhändern anzuvertrauen ${ }^{2}$. Dieses Gesetz sah aber zugleich eine beratende deutsche Mitwirkung vor und leitete damit eine Zuständigkeitsverlagerung ein, die langfristig eher einen Entlastungseffekt hatte. Weil es den Amerikanern gerade auf dem Gebiet der Wirtschaft an genügenden Personalunterlagen und -kenntnissen fehlte, wurden in den Städten und Landkreisen Vorprüfungsausschüsse aus mindestens drei politisch unbelasteten Deutschen bestellt, die mit ihren Empfehlungen die Militärregierung beraten sollten. Auf eine solche Mitwirkung hatten alle verantwortlichen deutschen Politiker gehofft, die sich seit dem Sommer 1945 Gedanken machten, wie die bisherige Säuberungspraxis korrigiert werden könne.

Auch auf lokaler Ebene entstanden deutsche Gegenentwürfe zur amerikanischen Entnazifizierungspolitik. Die wirklichen Nationalsozialisten sollten unnachsichtig bestraft werden; wer ein überzeugter Parteigenosse gewesen war, könnten allein die Deutschen beurteilen, die mit den örtlichen Verhältnissen während der NS-Zeit vertraut seien, erklärte zum Beispiel der Fürther Landrat Hörndlein in einer ausführlichen, „aus der Praxis heraus“ erarbeiteten Denkschrift vom Februar 1946, die er der örtlichen Militärregierung und auch dem bayerischen Ministerpräsidenten Wilhelm

Vgl. dazu S. 99-102.

„The publication of Law No. 8“, so schrieb die Fürther Militärregierung in ihrem Jahresbericht vom 20. Juni 1946, „caused the greatest consternation of any order of the occupying forces to date. Reports from German sources at this time were to the effect that although the population generally was in favor of Denazification it had not been expected that Denazification would reach down to such ,little people ““. Annual Hist. Rep., 20. Juni 1946, Det. Fürth, in: NA, RG 260, 10/81-1/5. Vgl. auch S. 245-249. 
Hoegner unterbreitete ${ }^{3}$. Eine „wesentliche Vereinfachung und Beschleunigung der Entnazifizierung" könne garantiert werden, wenn die Entnazifizierung ganz in deutsche Hände gelange. Der Fürther Landrat glaubte dafür ein unkompliziertes Verfahren vorschlagen zu können: In allen Gemeinden bis zu 3000 Einwohnern sollte ein Prüfungsausschuß unter der Leitung des Bürgermeisters, in den größeren Städten in jedem Stadtteil ein solcher Ausschuß mit einem politisch zuverlässigen Distriktvorsteher an der Spitze eingerichtet werden. Im Rahmen einer Gesamtüberprüfung sollten die Ausschüsse die „wirklichen Aktivisten namentlich feststellen und der Aufsichtsbehörde melden“. Fehlurteile seien dabei weitgehend ausgeschlossen, so Hörndlein, „da ja in einer Gemeinde jede einzelne Person dem Ausschuß persönlich bekannt ist". Die Aktivisten sollten dann vor ein Schöffengericht gebracht werden, die „übrigen Volksgenossen die ihnen gebührenden allgemeinen Lebensrechte" zurückerhalten. Die Entnazifizierung, glaubte Hörndlein, könne so „in 8-14 Tagen für die gesamte amerikanische Zone durchgeführt werden “4.

So illusionär Hörndleins Vorschläge waren, sie trafen sich mit vielen ähnlichen 1945/46 kursierenden deutschen Vorstellungen von einem vernünftigen Entnazifizierungsverfahren. Von ähnlichen Auffassungen war auch das bayerische Kabinett unter der Leitung Hoegners ausgegangen, als es schon am 24. November 1945 ein „Gesetz zur Reinigung Bayerns vom Nationalsozialismus und Militarismus" der Militärregierung zur Genehmigung vorlegte. Das Gesetz sah in Anlehnung an die ordentliche Strafverfolgung vor, daß nur beim Vorliegen einer persönlichen Schuld Sanktionen erfolgen sollten. Die Aussichten, den ebenfalls vor allem auf die Rehabilitierung der Masse der kleinen Parteigenossen abzielenden Gesetzentwurf durchzubringen, wurden in bayerischen Regierungskreisen anscheinend günstig beurteilt. Das am 22. Oktober eingerichtete Sonderministerium für Entnazifizierung forderte schon Anfang Dezember 1945 die Landräte und Oberbürgermeister auf, sich auf einen baldigen Start der Säuberungsmaschinerie einzurichten und noch vor Weihnachten Vorschlagslisten für das Personal der Entnazifizierungsausschüsse einzureichen'.

Die Militärregierung dachte aber nicht daran, den bayerischen Gesetzentwurf zu genehmigen, obwohl wesentliche Elemente des Entwurfs Überlegungen nahekamen, die im Herbst 1945 auch im Kreise der führenden Mitarbeiter ${ }^{6}$ General Clays zur Revision des harten Entnazifizierungskurses angestellt worden waren. Clay blieb sich aber der politisch heiklen Materie zu sehr bewußt, als daß er solchen Vorstellungen ohne weiteres Raum zu geben bereit gewesen wäre. Zunächst reagierte die Militärregierung bloß formalistisch: Ein bayerischer Alleingang komme nicht in Frage, angestrebt sei

3 LR Fürth an MinPräs Hoegner, 12. Februar 1946, in: LRA Fürth, EAP 150/11.

4 Ebenda.

s Vgl. Anordnung des bayerischen Staatsministeriums für Sonderaufgaben, 10. Dezember 1945, in: Ebenda. Kaum hatte der Fürther Oberbürgermeister die Anweisung des Ministeriums erhalten, rief er die Vorsitzenden der Parteien zusammen und drängte sie, aus ihren Reihen Kandidaten für die Positionen der Spruchkammervorsitzenden und Beisitzer zu benennen. Mit Erfolg, denn bereits am 19. Dezember 1945 konnte er dem Sonderminister eine komplette Liste überreichen. Vgl. Vorschlagsliste der KPD, DDP, SPD sowie Schreiben des OB an Staatsminister für Sonderaufgaben, 19. Dezember 1945, in: Stadtverwaltung Fürth, EAP 2. In Ansbach war man dagegen etwas langsamer. „Eine Vorschlagsliste wird“, so klagte Oberbürgermeister Ernst Körner vor dem Beratenden Ausschuß der Stadt, „kaum eingereicht werden können, weil die Männer fehlen." Prot. des Beratenden Ausschuß vom 15. Januar 1946, in: Stadtverwaltung Ansbach: Registratur des $\mathrm{OB}$.

6 Vgl. Niethammer, Entnazifizierung, S. $272 \mathrm{f}$. 
eine zonale Lösung des Entnazifizierungsproblems ${ }^{7}$. Als daraufhin wiederum unter Hoegners maßgeblicher Initiative im Länderrat des amerikanischen Besatzungsgebietes in Stuttgart im Dezember 1945 ein Entnazifizierungsausschuß ein zoneneinheitliches Säuberungsgesetz erarbeitete, das wesentliche Punkte des bayerischen Entwurfes übernahm (Abkehr von rein formalen Belastungskriterien zugunsten des Kriteriums faktischer individueller Verantwortlichkeit), mußte die Militärregierung Farbe bekennen. Hoegners Kollegen, Reinhold Maier (Württemberg-Baden) und Karl Geiler (Hessen), die dem Gesetz am 8. Januar 1946 ebenfalls zustimmten, erfuhren aber schnell, daß die Amerikaner sich die Initiative nicht aus der Hand nehmen lassen wollten und auch nicht mehr konnten. Denn zur gleichen Zeit waren im Alliierten Kontrollrat in Berlin Verhandlungen im Gange mit dem Ziel, ein Säuberungsgesetz für alle vier Zonen zu schaffen. Am 12. Januar gelangten die auf der Basis eines amerikanischen Vorschlags geführten Verhandlungen nach monatelangen Beratungen zum Abschluß. Der Alliierte Kontrollrat erließ die Direktive Nr.24, die weiter an der Formalität der Parteimitgliedschaft als Hauptkriterium der Belastung festhielt ${ }^{8}$.

Die Ministerpräsidenten waren tief bestürzt, als Clay ihnen eröffnete, die Kontrollratsdirektive sei für die gesamte US-Zone bindend und müsse in den vom Länderrat verabschiedeten Gesetzentwurf eingearbeitet werden. Es blieb ihnen aber keine Wahl, als sich dem Diktat zu unterwerfen. Am Faschingsdienstag, 5. März 1946, hatten sich Deutsche und Amerikaner endlich auf ein Säuberungsgesetz "geeinigt“. Während die Narren auf dem Münchener Marienplatz den ersten Fasching nach Kriegsende feierten, trafen sich die Mitglieder des Länderrats ein paar Schritte weiter zu einer Sondersitzung im festlich geschmückten Rathaus und unterzeichneten in Anwesenheit von General Clay das "Gesetz zur Befreiung von Nationalsozialismus und Militarismus“".

Als die Presse am nächsten Tag die neue Entnazifizierungsrichtlinie vorstellte, war das Erstaunen groß. Das sogenannte Befreiungsgesetz enthielt zwei Bestimmungen, die der deutschen Rechtstradition zuwiderliefen. Der Angeklagte - nicht der Kläger hatte die Beweislast. Nach Ansicht deutscher Juristen verletzte das Gesetz außerdem das Rückwirkungsverbot. Das Gesetz sah justizförmige Spruchkammern vor, die über jeden einzelnen Fall zu entscheiden hatten. An der Spitze der Spruchkammer standen ein Vorsitzender und einige Beisitzer, die ihre Entscheidungen per Abstimmung fällten. Die Funktion des Staatsanwalts übernahm der sogenannte öffentliche Kläger. Das Gesetz unterschied fünf Stufen politischer Belastung: Hauptschuldige (I), Belastete oder Aktivisten (II), Minderbelastete (III), Mitläufer (IV), Entlastete (V). Für jede dieser Gruppen waren spezielle Sühnemaßnahmen vorgesehen, die von geringfügigen Geldstrafen bis zu langjähriger Arbeitslagerhaft reichten.

Mit dem Befreiungsgesetz war niemand glücklich. Am besten damit leben konnte wohl General Clay, denn das Gesetz war ein weiterer Schritt seiner in den eigenen Reihen nicht unumstrittenen Politik des „Turn-it-over-to-the-Germans“. Es ließ sich zudem in den Vereinigten Staaten, wo man immer noch auf eine durchgreifende Säu-

8 Die Kontrollratsdirektive Nr. 24 spiegelte zwar nicht die neuesten Überlegungen im Umkreis von Clay wider, wurde aber von der amerikanischen Militärregierung dennoch als Erfolg verbucht, denn immerhin hatte sich der Kontrollrat, dessen Arbeit öfter gestockt hatte, als arbeitsfähig erwiesen.

9 Vgl. Gesetzestext, in: Erich Schullze (Hrsg.), Gesetz zur Befreiung von Nationalsozialismus und Militarismus, München 1946. 
berung erpicht war, gut präsentieren, und stellte zugleich vorsichtig die Weichen für die Rehabilitierung der Masse der kleinen Parteigenossen. Die Deutschen waren weniger zufrieden. Sie erreichten zwar, daß die Entnazifizierung endlich in ihre Zuständigkeit überging und die einzelnen Fälle von den Spruchkammern unter „Würdigung der Gesamtpersönlichkeit" individuell beurteilt werden konnten. Zu ihrem Leidwesen hatten die Amerikaner aber auf einer vollständigen Ubernahme der Kontrollratsdirektive $\mathrm{Nr} .24$ bestanden und so die unselige Tradition pauschaler Disqualifikation fortgeführt, die mit dem Erlaß der USFET-Direktive vom 7. Juli 1945 begründet worden war. In der Praxis hatten die Kläger deshalb die Pflicht, alle Betroffenen aufgrund formaler Belastungen in die Klassen I bis $\mathrm{V}$ einzustufen. Für die Betroffenen hatte das gravierende Folgen: So mußte z. B. jeder Parteigenosse, der vor 1937 der NSDAP beigetreten war, automatisch in die Gruppe II der Belasteten eingereiht werden. Er galt bis zur Widerlegung der Schuldvermutung, also bis zum Abschluß der Verhandlungen seines Falles vor der Spruchkammer, als Belasteter und konnte solange keine berufliche Position einnehmen, die höher rangierte als „gewöhnliche Arbeit“. Für die große Mehrheit der 1945 entlassenen Beamten und Angestellten kam das einem Berufsverbot bis zum Verhandlungstag gleich ${ }^{10}$.

Als Voraussetzung der neuen Säuberungsprozedur mußte im Frühjahr 1946 jeder Deutsche über 18 Jahre die Kurzfassung des sogenannten Fragebogens, einen Meldebogen mit 14 Fragen zur Person, zur Mitgliedschaft in NS-Organisationen und zum beruflichen Werdegang seit 1932 ausfüllen und auf der Polizei oder im Bürgermeisteramt einreichen. Eine sinnreiche Erfindung sorgte dafür, daß sich kaum einer um die Meldung herumdrücken konnte. Dem Meldebogen war nämlich ein kleiner Abschnitt beigegeben, der bei der Abgabe abgestempelt und dem „Kunden“ wieder ausgehändigt wurde. Nur wer diesen abgestempelten Abschnitt vorzuweisen vermochte, konnte weiter Lebensmittelmarken beziehen.

\section{Die Spruchkammern 1946-1949: Aufbau, Personal, Tätigkeit, Ansehen in der Öffentlichkeit}

\section{a. Feblstart 1946}

Der Beginn der Spruchkammertätigkeit war von großen Hoffnungen und schlimmen Befürchtungen begleitet. Die Deutschen, so berichtete die Intelligence Division der Militärregierung im April 1946, „sind wie ein kranker Mann, der vor einer schweren und überaus kitzligen Operation steht, die aber notwendig ist, wenn er jemals wieder genesen will ... Die wichtigsten Fragen, die sich die Deutschen stellen ... kann man ebenfalls in medizinischen Ausdrücken umschreiben: Wie kräftig ist der Patient? Wie fähig ist der Chirurg? Wie lange wird es dauern, bis der Patient wieder arbeiten kann? Wird das die letzte Operation sein?" ${ }^{\prime 11}$ Die meisten Deutschen erwarteten vor allem

10 Vgl. Erich Schullze (Hrsg.), Gesetz zur Befreiung von Nationalsozialismus und Militarismus mit den Ausführungsvorschriften und Formularen, München 1946. Vgl. auch die Ausführungen von Staatssekretär Hans Ehard in einer Versammlung der Spruch- und Berufungskammern Ober- und Mittelfrankens in Ansbach am 27. März 1946, Prot. in: Stadtverwaltung Fürth, EAP 2.

" OMGB, Periodic Report for Week Ending 24 April 1946, an Director of Intelligence, OMGUS (künftig Wochenbericht der Intelligence Division von OMGB), in: NA, RG 260, 10/85-3/1. 
eine baldige Rehabilitierung der ihrer Meinung nach im Zuge der rigorosen amerikanischen Entnazifizierung zu Unrecht entlassenen Beamten und Angestellten und eine Lockerung der Maßnahmen zur Säuberung der Wirtschaft nach den Bestimmungen des Gesetzes Nr.8. Der Fürther Landrat hoffte, daß „durch die Spruchkammern das Entnazifizierungsverfahren nunmehr beschleunigt zur Ausführung gebracht werden kann und damit die bisherige Lähmung der Wirtschaft beseitigt ${ }^{\text {" }}$ wird ${ }^{12}$, sowie, daß nach „erfolgreicher“ Säuberung „eine größere Anzahl von geschulten Verwaltungsbeamten in ihre früheren Dienststellen " zurückgeführt werden könne ${ }^{13}$. In den Kreisen der ehemaligen Parteigenossen war die Stimmung geteilt. Manche erblickten in dem neuen Gesetz ein Zeichen, daß der bisherige harte Kurs unverändert fortgesetzt werde und die Amerikaner noch immer nicht zum Einlenken bereit seien; andere hofften, die „Zeit für eine allgemeine Toleranz“ sei gekommen, Strafen seien wahrlich genug verhängt worden ${ }^{14}$.

Die Hoffnung auf ein schnelles Verfahren zerschlug sich aber schnell, denn der Aufbau des Säuberungsapparates erwies sich als schwierig. Es dauerte bis zum Sommer bzw. Herbst 1946, bis die Spruchkammern ihre ersten Entnazifizierungsfälle anpacken konnten. An Richtlinien fehlte es nicht. Das Staatsministerium für Sonderaufgaben wies die Regierungspräsidenten, Oberbürgermeister und Landräte schon wenige Tage nach Erlaß des Gesetzes zur Befreiung von Nationalsozialismus und Militarismus an, für eine schleunige Besetzung der Spruch- und Berufungskammern zu sorgen. „Ankläger wie Vorsitzende der Spruchkammer sollen“, so hieß es im Rundbrief des Sonderministeriums vom 11. März 1946, „müssen jedoch nicht Juristen sein. Alle Mitglieder der Spruchkammer müssen einwandfreie Antifaschisten sein, dürfen also nicht Mitglieder der NSDAP oder einer ihrer angeschlossenen Gliederungen gewesen sein. Sie dürfen in den betreuten oder anderen Naziorganisationen keine Funktion gehabt haben." ${ }^{15}$ Die Parteien wurden aufgefordert, aus ihren Reihen eine bestimmte Anzahl von Beisitzern zu benennen. Die vorgeschlagenen Kandidaten mußten den großen Fragebogen und einen Lebenslauf beim Sonderministerium und bei der Militärregierung einreichen. Erst nachdem von beiden Stellen grünes Licht gegeben war, konnten sie vereidigt werden und ihren Dienst antreten.

Es zeigte sich aber bald, daß der Kreis derjenigen, die jetzt in den Spruchkammern das „Feuer eines politischen Purgatoriums“ entfachen sollten, verschwindend klein war $^{16}$. Am „fühlbarsten“ machte sich, so Regierungspräsident Schregle an die bayerische Staatsregierung, „der Mangel an unbelasteten Juristen“ bemerkbar, die für die Posten der Spruchkammervorsitzenden und Ankläger in Frage kamen ${ }^{17}$. Den wenigen Juristen, die nicht mit dem Makel der Parteimitgliedschaft belastet waren, fehle es an „Zivilcourage“, sie schreckten vor den Spruchkammern zurück, „als wären sie etwas Schmutziges "18, und zögen es stattdessen vor, im sicheren Justizdienst zu bleiben, wo

12 LR Fürth an RegPrās, Monatsbericht für März 1946, in: StA Nürnberg, LRA Fürth (1962), Nr. 40/2.

13 Monatsbericht für April 1946, in: Ebenda.

14 So RegPräs Schregle auf der Versammlung der Spruch- und Berufungskammern Ober- und Mittelfrankens am 27. März 1946, Prot. in: StA Nürnberg, LRA Scheinfeld, Nr. 367.

15 Rundbrief des bayerischen Sonderministeriums, 11. März 1946, in: LRA Fürth, EAP 150/11.

16 Henke, Die Grenzen der politischen Säuberung in Deutschland nach 1945, S.127.

17 RegPräs an bay. Staatsregierung, 15. Juni 1946, in: BayHStA, Reg von Mittelfranken, Berichterstattung 1946, AZ 1-64, Bd. 6.

18 Dorn, Inspektionsreisen, S. 115. 
ihnen jetzt alle Türen offen standen. Vielfach mußte man deshalb auf alte, bereits pensionierte Juristen zurückgreifen. Damit konnten sich aber die Linksparteien SPD und KPD nur schwer anfreunden, hatten sie doch mit dieser Generation von Juristen, der sie nicht zu Unrecht vorwarfen, auf dem rechten Auge blind zu sein, in der Weimarer Zeit denkbar schlechte Erfahrungen gemacht. Im Landkreis Fürth kam es deshalb zu erbitterten Auseinandersetzungen, als die SPD, die aus den Kommunalwahlen als stärkste Partei hervorgegangen war, den vom Landrat vorgeschlagenen Spruchkammervorsitzenden, den parteilosen Rechtsrat und ehemaligen Oberbürgermeister von Selb, Victor Häublein (Jg. 1872), nicht akzeptieren wollte. Sie gab ihren Widerstand gegen Häublein erst auf, als ihr vom Sonderministerium in München zugesichert worden war, daß der stellvertretende Vorsitzende und der öffentliche Kläger aus ihren Reihen bestellt würden ${ }^{19}$.

Heftig umstritten war der Vorsitz der Spruchkammer auch im Stadtkreis Fürth. Die tonangebende SPD hatte überraschenderweise darauf verzichtet, einen eigenen Kandidaten zu benennen, so daß sie sich vor die heikle Wahl zwischen dem 75 jährigen ehemaligen Amtsgerichtsdirektor und CSU-Vorsitzenden Karl Drechsel und dem Emigranten und KZ-Häftling Fritz Sauber von der KPD gestellt sah. Sie entschied sich schließlich für den Vorsitzenden der CSU und erteilte Sauber, der sich durch heftige Angriffe auf Oberbürgermeister Schmidt viele Feinde in der SPD gemacht hatte („Der Sauber ist nicht ganz sauber"), eine Absage ${ }^{20}$. Im Zweifelsfall war den Sozialdemokraten ein alter Amtsgerichtsdirektor doch lieber als ein vielleicht allzu parteiischer Kommunist $^{21}$. Unproblematisch verlief die Suche nach einem Vorsitzenden im Landkreis Ansbach. Die Parteien einigten sich hier auf den politisch integeren 78jährigen Botschafter a. D. Ernst-Arthur Voretzsch, wie Drechsel und Häublein ausgebildeter Jurist, den die CSU als stärkste Partei ins Spiel gebracht hatte.

Anders als im Stadt- und Landkreis Fürth und im Landkreis Ansbach, wo die politischen Parteien großes Interesse zeigten, in die führenden Positionen der Spruchkammern „ihre“ Leute hineinzusetzen, schoben sich die Parteien in der Stadt Ansbach die Verantwortung gegenseitig zu. In der evangelischen Beamtenstadt, wo große Teile des örtlichen Beamtentums vor 1945 der NSDAP angehört oder ihr nahegestanden hatten, war die Spruchkammer offenbar besonders unpopulär. Die CSU schlug zwar im Frühjahr 1946 mit Hans Hufnagel einen Kandidaten vor, der auch gewillt schien, das schwere Amt zu übernehmen. Hufnagel bestand auch alle Prüfungen der Militärregierung und des Sonderministeriums und war am 13. Juli 1946 im Sitzungssaal des Ansbacher Schlosses vom Stellvertreter des Staatsministers für Sonderaufgaben feierlich vereidigt worden. Doch dann überlegte er es sich anders und erklärte, ohne in Aktion getreten zu sein, seinen Rücktritt. Als sich der Oberbürgermeister daraufhin erneut an die örtliche CSU wandte und bat, einen Ersatzmann für Hufnagel zu benennen, teilte diese lapidar mit, sie sehe sich dazu nicht imstande ${ }^{22}$. Daß sich die lokale CSU gar nicht ernsthaft um einen Vorsitzenden aus ihren Reihen bemühte, geht aus einem

19 Zu den Modalitäten des Aufbaus der Spruchkammer Fürth-Land vgl. LRA Fürth, EAP 150/11.

20 Mündliche Mitteilung von Konrad Grünbaum vom 29. November 1984.

21 Vgl. Stadtverwaltung Fürth, EAP 2.

$22 \mathrm{OB}$ Ansbach an Sonderbeauftragten für Ober- und Mittelfranken für das Staatsministerium für Sonderaufgaben, 1. August 1946, Amtsgericht Ansbach, Registratur S: Verwaltungsakten. Vgl. auch OB Ansbach an MilReg, Stimmungsbericht vom 2. August 1946, in: Stadtverwaltung Ansbach, EAP 022-95/19. 
vertraulichen Bericht der Militärregierung hervor: „Aus verschiedenen Quellen wird deutlich“, so urteilte sie über die Ansbacher Verhältnisse, „daß die CSU alles andere als erpicht darauf ist, daß einer aus ihren Reihen Vorsitzender der Spruchkammer wird, denn die Verbindung eines CSU-Mitglieds mit einer solchen Position schmälert womöglich die Popularität der CSU.“23 Die SPD hielt sich mit einigem Recht ebenfalls zurück. Sie war in der Spruchkammer bereits mit dem stellvertretenden Kläger, einigen Beisitzern und dem Personal des Ermittlungsdienstes vertreten; zur Angelegenheit einer Partei sollte die Entnazifizierung denn noch nicht werden.

Oberbürgermeister Körner bat deshalb den Regierungspräsidenten, einen Juristen aus der Regierungsbezirksverwaltung als Spruchkammervorsitzenden abzustellen. Aber auch von dort war keine Unterstützung zu erwarten. Die Stadt mußte also selbst Abhilfe schaffen. Im September schien mit dem stellvertretenden Vorsitzenden der Spruchkammer Gerolzhofen/Unterfranken tatsächlich ein Vorsitzender gefunden ${ }^{24}$. Aber auch der Plan einer Lösung von „außen“ zerschlug sich; der Stadtrat mußte sich deshalb im September und Oktober 1946 erneut mit der leidigen Angelegenheit befassen. Um die Spruchkammer endlich funktionsfähig zu machen, schlug Oberbürgermeister Körner jetzt vor, einen bisher bei der Militärregierung beschäftigten Angestellten zum Kläger und ein Mitglied der KPD zum Vorsitzenden zu machen. Körner, der dem linken Flügel der SPD angehörte, war der Meinung, daß „ein kommunistischer Vorsitzender nichts schaden“ könne, „wenn die Beisitzer auf der Höhe“ seien, denn letzten Endes werde über jeden Fall abgestimmt. „Nachdem keine der Parteien Vorschläge gemacht“ habe, sei er gezwungen, „die ihm noch geeignet erscheinenden Leute heranzuziehen“ - das letzte Aufgebot also ${ }^{25}$.

Die bürgerliche Mehrheit des Stadtrats konnte sich jedoch für den Vorschlag Körners nicht erwärmen, und schließlich versagte auch die Militärregierung ihre Zustimmung ${ }^{26}$. Neun Monate nach Erlaß des Gesetzes zur Befreiung von Nationalsozialismus und Militarismus vom 5. März 1946 war damit Ansbach noch immer ohne Spruchkammervorsitzenden.

Bei der Suche nach stellvertretenden Vorsitzenden, Klägern und Beisitzern sowie der Einrichtung eines Ermittlungsdienstes, der dem Kläger bei der Vorbereitung der einzelnen Fälle zuarbeiten sollte, ergaben sich im allgemeinen weniger Schwierigkeiten als bei der Auswahl der Vorsitzenden. Die öffentlichen Kläger kamen in den Spruchkammern der Stadt- und Landkreise Fürth und Ansbach fast sämtlich aus den Reihen der Linksparteien SPD und KPD - ein auffallender Kontrast zur politischen Einstellung der Vorsitzenden, die sich entweder zur CSU bekannten oder parteilos waren. Die meisten Kläger hatten während der NS-Zeit Monate oder Jahre in Schutzhaft oder im Konzentrationslager verbracht und konnten so gleichsam einen moralischen Anspruch auf das Amt geltend machen. Keiner war für die übernommene Aufgabe juristisch qualifiziert, so daß schon zu Beginn der politischen Säuberung ein be-

23 Denazification Field Inspection Report, Det. Ansbach, 12. Februar 1947, in: NA, RG 260, 15/119-1/7.

$24 \mathrm{Vgl}$. OB Ansbach an MilReg, Stimmungsbericht vom 11. September 1946, in: Stadtverwaltung Ansbach, EAP 022-95/19.

25 Prot. der Sitzung des Ansbacher Stadtrats vom 8. Oktober 1946, in: Stadtverwaltung Ansbach, Registratur des OB. Vgl. auch OB Ansbach an Sonderministerium, 28. September 1946, in: Amtsgericht Ansbach, Registratur $\mathrm{S}$ : Verwaltungsakten.

26 Vgl. OB Ansbach an MilReg, Stimmungsbericht vom 4. Dezember 1946, in: Stadtverwaltung Ansbach, EAP $022-95 / 19$. 
trächtliches Qualifikationsgefälle zwischen den Vorsitzenden, die durchwegs eine juristische Ausbildung genossen hatten und im Umgang mit Paragraphen und Verordnungen geübt waren, und den Laien im Anklägeramt bestand.

Während sich die Bestellung der Kläger in ganz Mittel- und Oberfranken schnell und relativ problemlos vollzog, gehörte Ansbach auch hier zu den Nachzüglern. Die Spruchkammer Ansbach-Land war noch im August 1946 ohne Kläger $^{27}$. Und in Ansbach-Stadt kam es wegen der Bestellung des öffentlichen Anklägers zu einer Affäre, die - so undurchsichtig sie im ganzen ist - doch deutlich macht, daß es auch in den Linksparteien zu unschönen Intrigen kommen konnte, wenn ein ihnen nicht genehmer, unberechenbarer Außenseiter diese Stellung beanspruchte. Um einen solchen Mann ging es bei Ernst Woop, der sich am 27. März 1946 um das Amt des öffentlichen Klägers beworben hatte ${ }^{28}$. Woop schien dafür die besten Voraussetzungen mitzubringen: Er gehörte der KPD an, hatte mehrere Jahre im $\mathrm{KZ}$ gesessen, war Mitglied der Liga für Menschenrechte gewesen und hatte ein Jüdin zur Frau. Oberbürgermeister Körner unterstützte die Kandidatur Woops zunächst uneingeschränkt. Aber der Mann stammte nicht aus der Ansbacher Gegend, sondern aus Berlin und hatte sich offenbar vorgenommen, ohne Rücksicht auf Personen ordentlich „aufzuräumen“ und hierfür schon, während seine Bewerbung noch lief, einen außerordentlichen Eifer an den Tag zu legen begonnen, der selbst vielen NS-Gegnern suspekt erschien. Es kam deshalb offenbar innerhalb der Ansbacher SPD und KPD zu einer Verschwörung gegen Woop, in die auch Oberbürgermeister Körner verwickelt wurde. Während die Militärregierung Ende Juni 1946 mitteilte, sie habe gegen Woop nichts einzuwenden, hatte Körner mit dem persönlich umgänglicheren und politisch weniger radikalen Kommunisten Julius Gäbel überraschend einen Ersatzmann in Vorschlag gebracht, der sich freilich zu einer Kandidatur nur unter der Bedingung bereitfand, daß sein Genosse Woop von den Amerikanern nicht angenommen würde. Daraufhin scheuten sich Körner und die Ansbacher SPD anscheinend nicht, Woops Vergangenheit bei der Militärregierung ins $Z$ wielicht zu rücken. Im Juli erhielt dieser die Nachricht, daß er als Kläger abgelehnt sei. Er selbst erklärte zu der Entscheidung: „Ich habe das Gefühl, als wenn Kräfte innerhalb der SPD bemüht sind, ihre belasteten Freunde und Bekannten zu schonen und sie zu decken." Die SPD-Spitze habe deshalb der Militärregierung souffliert, er habe im KZ Auschwitz eng mit der SS zusammengearbeitet. Damit sei seine Karriere natürlich beendet gewesen ${ }^{29}$.

Die Beisitzer sollten nach den Bestimmungen des Befreiungsgesetzes zu etwa gleichen Teilen von den Parteien gestellt werden. Davon erhofften sich die Väter des Gesetzes zweierlei: Einmal sollte damit die politische Kontrolle der Spruchkammern gewährleistet werden. Zum anderen sollten alle Parteien in die Verantwortung genommen und es ihnen so unmöglich gemacht werden, gegen die politische Säuberung offen Sturm zu laufen. Im Land- und Stadtkreis Fürth, wo die Parteien im April und Mai jeweils sechs Kandidaten benannten, verfuhr man nach der Anregung, die Beisit-

27 Amtsgericht Ansbach, Registratur S: Verwaltungsakten.

28 Die Akten zum Fall "Woop“ finden sich ebenda.

29 Kurz zuvor hatte es ganz anders geheißen: „Die Vereidigung“, schrieb der Sonderbeauftragte am 28. Juni 1946 an Woop, sei „nur noch eine Frage technischer Bedeutung. Ich ersuche Sie ... beim Oberbürgermeister, Herrn Körner, vorzusprechen und die organisatorischen Vorarbeiten für die Tätigkeit der Spruchkammer des Stadtkreises Ansbach sofort aufzunehmen." Ebenda. 
zerposten paritätisch zu besetzen. Im Landkreis Ansbach wichen die Parteien nur geringfügig davon ab: Die beiden großen Parteien CSU und SPD stellten jeweils fünf, die beiden kleinen Parteien FDP und KPD jeweils drei Beisitzer. Die Stadt Ansbach machte dagegen eine krasse Ausnahme. Während SPD und FDP im August mit jeweils sechs Beisitzern vertreten waren, kam aus den Reihen der KPD kein Beisitzer und aus der CSU nur einer. Die politische Säuberung in Ansbach mußte so fast ohne Mithilfe der CSU beginnen, die in den Wahlen zur Verfassunggebenden Landesversammlung in der Stadt über 40 Prozent der Stimmen erhalten hatte. Die neugegründete CSU hatte zwar einige Kandidaten benannt, sie waren aber fast alle wegen ihrer NS-Vergangenheit von der Militärregierung abgelehnt worden. Absagen der Militärregierung handelten sich aber auch Freie Demokraten und Kommunisten und einige Sozialdemokraten ein, die ebenfalls eine nicht ganz weiße Weste hatten. Die Parteien, so schilderte Ansbachs Stadtoberhaupt vor der Versammlung der Landräte und Oberbürgermeister Ober- und Mittelfrankens seine diesbezüglichen Erfahrungen, gingen „teilweise mit einem sträflichen Leichtsinn an die Benennung der Beisitzer“ heran und schlugen Leute vor, die schon „vom Fragebogen her" nicht einwandfrei waren ${ }^{30}$.

Der mit den Voruntersuchungen beauftragte Ermittlungsdienst der Spruchkammer sollte, so hieß es in einer Rundmeldung der Regierung in Ansbach vom April 1946, aus „politisch und charakterlich tadellose(n) Personen mit kriminalistischen Fähigkeiten und betonter antinationalsozialistischer und antimilitaristischer Gesinnung ... im Alter etwa zwischen 25 und 45 Jahren “ bestehen ${ }^{31}$. Die Spruchkammern konnten sich anfangs über einen Mangel an Bewerbern nicht beklagen. Ermittler zu sein, so berichtete das bayerische Sonderministerium am 15. Juni 1946 an die Militärregierung, war ein begehrter Posten: „Es herrscht vielfach die Ansicht, daß dies eine denkbar einfache, angenehme und gut bezahlte Stellung ist. Bei der Überprüfung ihres Könnens zeigte sich aber dann schon meist, daß ihr Wissen für einen Ermittler, der vor allen Dingen politische und geschichtliche Kenntnisse aus der Vergangenheit haben muß, gleich Null ist." ${ }^{\text {32 }}$ Diese Erfahrung mußte auch der Fürther Landrat machen, der große Mühe hatte, entsprechend qualifizierte Leute zu finden. Am 18. April schlug er deshalb dem Sonderbeauftragten des Sonderministeriums nur vier Kandidaten vor, die bis dahin nicht durch besondere kriminalistische Fähigkeiten aufgefallen waren: einen 70jährigen Pensionär, einen Schuhmachermeister, den Bürgermeister von Stadeln, der gelernter Bierbrauer war, und einen Oberwachtmeister, der zwischen 1942 und 1945 der Schutzpolizei in Fürth bzw. Burgfarrnbach angehört hatte. Mit Ausnahme des Pensionärs waren die künftigen Ermittler Mitglieder der SPD ${ }^{33}$. Auch im Stadtkreis Ansbach hatten sich nur Laien ohne kriminalistische Ausbildung für den Ermittlungsdienst finden lassen: 1948 und 1949 bestand er aus drei Kaufleuten und einem Friseur. Zwei Mitglieder waren von der SPD benannt worden, je einer von den Gewerkschaften und der KPD. Die bürgerlichen Parteien CSU und FDP waren unter den Ermittlern, die, wie sich bald herausstellte, eine von der Öffentlichkeit nicht gerade hoch

30 So OB Ansbach in der Besprechung des RegPräs mit den OB und LR, 8. Juli 1946, Prot. in: StA Nürnberg, LRA Scheinfeld, Nr. 367. Vgl. auch LRA Fürth, EAP 150/11.

31 Rundmeldung der Regierung für Ober- und Mittelfranken, 9. April 1946, in: LRA Fürth, EAP 150/11.

32 Bayerisches Sonderministerium an MilReg, 15. Juni 1946, in: BayHStA, Bestand Sonderministerium: Militärregierung 1946-1950, AZ 2-82, Bd. 1.

33 Vgl. LRA Fürth, EAP 150/11. 
geschätzte Aufgabe zu erfüllen hatten, ebensowenig vertreten wie unter den sonstigen Angestellten der Spruchkammer ${ }^{34}$.

In der Berufungskammer für Ober- und Mittelfranken, die im September 1946 soweit intakt war, daß sie die Aufsicht über die Spruchkammern des Regierungsbezirks übernehmen konnte, spielten Repräsentanten der Parteien dagegen kaum eine Rolle. Die zweite Instanz war fest in der Hand parteiloser Juristen. Präsident der Berufungskammer, die ihren Sitz in Ansbach hatte, war der Vorsitzende des Landgerichts in Ansbach, der 58jährige Heinrich Wehrl, der allerdings keinen übertriebenen Entnazifizierungseifer an den Tag legte. Mit dem Befreiungsgesetz konnte er sich nie recht anfreunden. Gegenüber der Fränkischen Landeszeitung vertrat er die Meinung, die NSWeltanschauung sei bereits durch den Ausgang des Krieges ausgetilgt worden ${ }^{35}$.

Daß der Aufbau der Spruchkammern solche Schwierigkeiten bereitete und selbst im Herbst 1946 noch nicht ganz abgeschlossen war, lag auch an der Militärregierung, die der Aufgabe, das vorgeschlagene Personal zu überprüfen, zunächst nicht ganz gewachsen war. Sie beklagte sich zwar laufend über die Verzögerungen, sorgte aber nicht dafür, daß die von den Landräten und Oberbürgermeistern eingereichten Unterlagen schnellstens bearbeitet wurden ${ }^{36}$. „Es wäre unsere Pflicht“, forderte Schregle die Oberbürgermeister und Landräte seines Regierungsbezirks auf, die Militärregierung zu einem etwas höheren Tempo anzutreiben und „sich bei den Dienststellen der Besatzungsmacht mit Nachdruck dafür einzusetzen, daß die Fragebogen rascher durchgeprüft werden “ ${ }^{\text {37 }}$. Vorerst aber war mit solchen Appellen nur wenig zu erreichen, denn die Militärregierung, die bisher die Entnazifizierung in eigener Regie ohne deutsche Mithilfe durchgeführt hatte, paßte ihren Apparat erst im Sommer 1946 den veränderten Bedingungen an und hatte bis dahin alle Mühe, die anfallenden Arbeiten einigermaßen zu bewältigen ${ }^{38}$.

Wenn es - wie in Ansbach-Stadt - zum Teil auch nicht gelungen war, die Spruchkammern parteipolitisch repräsentativ zu besetzen, so entsprach doch das Sozialprofil der Spruchkammerangehörigen weitgehend der Sozialstruktur des Milieus, das sie entnazifizieren sollten. In Fürth, dessen Erwerbsleben hauptsächlich von mittleren Handwerksbetrieben und einigen größeren Industriebetrieben mit einer entsprechend großen Zahl von Arbeitern und Angestellten geprägt war, setzte sich die aus 28 Mitgliedern bestehende Spruchkammer am 22. Mai 1946 überwiegend aus Handwerkern, Industriearbeitern und selbständigen Händlern zusammen. Die Beamtenschaft war fast nicht vertreten. Der Spruchkammer der Beamten- und Angestelltenstadt Ansbach gehörten am 24. Februar 1947 neben einem Arbeiter und einigen wenigen Handwerkern und kleineren Händlern hauptsächlich Angestellte und Beamte an. Und auf dem

34 Vgl. Amtsgericht Ansbach, Spruchkammerakten: Verwaltungsakten. Niethammer, Entnazifizierung, S. 526, kommt bei der Untersuchung der parteipolitischen Zusammensetzung des Ermittlungsdienstes zu ganz ähnlichen Ergebnissen.

35 Vgl. Fränkische Landeszeitung vom 21. August 1948. Vgl. auch bay. Sonderministerium an OB Fürth, 16 September 1946, in: Stadtverwaltung Fürth, EAP 2; Frānkische Landeszeitung vom 2. November 1946 und Amtsgericht Ansbach, Registratur S: Verwaltungsakten.

${ }^{36} \mathrm{Vgl}$. Wochenbericht der Intelligence Division vom OMGB, 17. Mai 1946, in: NA, RG 260, 10/85-3/1

${ }_{37}$ Besprechung des RegPräs mit den OB und LR, 3. Juni 1946, Prot. in: StA Nürnberg, Reg von Mittelfranken (1978, Zusatz), Nr. 25.

38 Vgl. MilReg für Ober- und Mittelfranken an Directors of all Military Government Liaison and Security Offices, Regierungsbezirk Ober- und Mittelfranken, 25. September 1946, in: NA, RG 260, 9/114-3/20; vgl. auch Wochenbericht der Intelligence Division von OMGB, 16. August 1946, in: NA, RG 260, 10/85-3/1. 
Lande standen sich vor und hinter den Schranken der Spruchkammer fast durchweg Bauern gegenüber. Solche Übereinstimmung bestand, wie schon dargelegt, in politischer Hinsicht nicht. Die Linksparteien SPD und KPD waren nicht nur in ihrer Hochburg Fürth überproportional vertreten, sondern auch in den Landkreisen mit einer eher konservativ gesinnten Bevölkerung, die in den Wahlen des Jahres 1946 überwiegend für die CSU gestimmt hatte. Das linke Übergewicht wurde allerdings dadurch wettgemacht, daß die Schlüsselpositionen des Spruchkammervorsitzenden meist mit CSU-Mitgliedern oder Parteilosen besetzt waren, wie auch dadurch, daß die Berufungskammern eine Domäne parteiloser bzw. bürgerlicher Juristen darstellte.

Die Parteien der Region Ansbach und Fürth entsandten 1946 in aller Regel ihre besten Leute in die Spruchkammern. Von den 24 Beisitzern der Spruchkammer FürthStadt vom Mai 1946 gehörten 16 dem Stadtrat bzw. Beratenden Ausschuß der Stadt an. Nicht viel anders war es im Landkreis Ansbach, wo 9 von 16 Beisitzern im Kreistag oder Gemeinderat vertreten waren. Die Entnazifizierung war also keineswegs in die „Hände von ,Minderwertigen' geraten, weil sie die einzigen Unbelasteten sind“, wie Clays Entnazifizierungsberater, Professor Walter L. Dorn, nach einem Besuch der Spruchkammer in Bad Kissingen im Frühjahr 1947 in seinem Tagebuch notierte. „Wir müssen Leute finden“, so Dorn weiter, „die den großen Nazis intellektuell und sozial die Waage halten können, wenn diese Aufgabe gelöst werden soll - oder sie

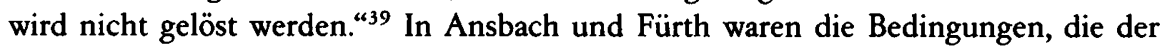
amerikanische Professor vielleicht mit etwas zu viel Respekt vor den großen Nazis stellte, im großen und ganzen durchaus erfüllt ${ }^{40}$.

Trotz vielfältiger Schwierigkeiten beim Aufbau der Spruchkammern war es im Juni 1946 in Fürth so weit. „Erster Spruchkammertag 26. Juni. Entnazifizierung in Fürth beginnt", meldeten die Nürnberger Nachrichten. Die ersten Spruchkammern in Bayern hatten schon etwa einen Monat früher zu arbeiten begonnen. Den Anfang hatte am 20. Mai die Spruchkammer in Fürstenfeldbruck gemacht, wo sich aus Anlaß des historischen Ereignisses auch führende Vertreter der Militärregierung und Sonderminister Schmitt einfanden ${ }^{41}$. Die Fürther Spruchkammer, so hieß es in der Zeitung, „nimmt ihre Tätigkeit am kommenden Mittwoch, den 26. Juni in Fürth, Hornschuchpromenade 6, 2. Stock, Zimmer 27 auf ... Im allgemeinen werden zunächst die schweren Fälle der Gruppen I und II zur Aburteilung kommen. Es werden aber auch auf ministerielle Anordnung hin als vorrangig bezeichnete Fälle minderbelasteter Personen aus wirtschaftlichen Gründen ... bevorzugt rasch an die Reihe kommen. Auch soziale Umstände können für eine raschere Abfertigung maßgebend sein.“‘2

39 Dorn, Inspektionsreisen, S. 106.

40 Für die Untersuchung standen zur Verfügung: die Liste des Personals der Spruchkammer Fürth-Stadt I vom 22. Mai 1946, ein Vorschlag für die personelle Besetzung der Spruchkammer Fürth-Land vom 17. April 1946, eine Liste des Personals der Spruchkammer Ansbach-Land vom 17. August 1946, eine Liste des Personals der Spruchkammer Ansbach-Land vom 20. August 1946 sowie Listen des Personals der Berufungskammer Ansbach vom 4. Mai 1948 und 2. Mai 1949. Die Listen enthalten in der Regel Angaben über Parteizugehörigkeit, Beruf und Geburtsjahr der Kammerangehörigen. Wo diese fehlten, konnten sie häufig durch verstreute Angaben in den Sachakten ergänzt werden. Die Listen finden sich in: Amtsgericht Ansbach, Registratur S: Verwaltungsakten; LRA Fürth, EAP 150/11; Stadtverwaltung Fürth, EAP 2.

41 Vgl. Süddeutsche Zeitung vom 21. Mai 1946.

42 Nürnberger Nachrichten, Fürther Ausgabe, vom 19. Juni 1946. 
Der Spruchkammervorsitzende Drechsel eröffnete am 26. Juni 1946, 8.00 Uhr, die erste öffentliche Sitzung. Der erste Angeklagte war der 57jährige Schmied Gerhard König, Pg seit 1933 und von 1944-1945 Blockleiter. Die Verhandlung glich von Beginn an einem politischen Tribunal. Der Kläger, offenbar ein engagierter Verfechter eines harten Säuberungskurses, agierte wie ein scharfer Staatsanwalt und faßte den Betroffenen nicht mit Glacehandschuhen an. Er bezeichnete ihn als „König der Denunzianten“ und als einen der 10000 „kleinen Hitler“, die es durch Terror und Druck auf ihre Umgebung ermöglicht hatten, daß das verbrecherische Regime zwölf Jahre dauern konnte. Auch sonst sei König ein „eifriger Mundpropagandist des Nazitums“, ein „Droher“, „Aushorcher“ und „Zungenzieher“ gewesen. Das Urteil war entsprechend: Einreihung in die Gruppe I der Hauptschuldigen, vier Jahre Arbeitslager und laufende Abgaben an Wiedergutmachungsfonds ${ }^{43}$. Im Landkreis Ansbach begann die Entnazifizierung nicht weniger spektakulär. Auch hier stand als erster ein bekannter Denunziant, ein ehemaliger Verwaltungsoberinspektor beim evangelischen Landeskirchenrat, vor der Spruchkammer. Es zeigte sich dabei, daß die Wahl des energischen Botschafters a.D. Ernst-Arthur Voretzsch zum Vorsitzenden ein Glückgriff gewesen war. Der alte NS-Gegner ließ sich nicht sonderlich beeindrucken, als der Denunziant mit einigen wohlwollenden Entlastungsschreiben von prominenten evangelischen Kirchenmännern (u.a. von Landesbischof Hans Meiser) aufwartete und verurteilte den Oberinspektor als Aktivist der Gruppe II zu eineinhalb Jahren Arbeitslager und 50-prozentigem Vermögenseinzug ${ }^{44}$.

Dieser Auftakt entsprach allem Anschein nach den Erwartungen der Öffentlichkeit. So hatte man sich in weiten Kreisen der Bevölkerung die Entnazifizierung vorgestellt und nicht so, wie sie die Militärregierung 1945 durchführte. Denunziation galt als die klassische NS-Missetat („Der schlimmste Mann im ganzen Land, das ist und bleibt der Denunziant"), sie konnte gar nicht hart genug bestraft werden. Die Erwartungen, die der Auftakt geweckt hatte, erfüllten sich aber nicht. Die Spruchkammern in Ansbach und Fürth beschäftigten sich in den folgenden Wochen und Monaten zwar noch einige Male mit windigen Denunzianten, meistens standen aber kleinere Parteigenossen vor den Schranken der Kammer. „Tag der Mitläufer“, meldeten die Nürnberger Nachrichten, Fürther Ausgabe, am 20. Juli. „Wettlauf der Mitläufer“, war ein Artikel am 24. Juli überschrieben. Und am 18. September hieß es: „Die Spruchkammern verhandeln ,Nominelle“." Es war deshalb durchaus berechtigt, wenn die Nürnberger Nachrichten im Herbst 1946 fragten: „Wann kommen ,wirkliche Nazis“?“45 Für Ansbach-Stadt hätte die Frage lauten können: Wann kommen endlich die ersten öffentlichen Verfahren? Dort hatte man im Sommer 1946 immer noch keinen Vorsitzenden gefunden, so daß bislang keine mündlichen Verfahren abgewickelt werden konnten. Seit August arbeitete aber immerhin der kleine Senat, der sich aus der stellvertretenden Vorsitzenden Eva Reiner, dem stellvertretenden Kläger Josef Otta und zwei Beisitzern zusammensetzte.

In der Öffentlichkeit war vom kleinen Senat der Spruchkammer, der in scbriftlichen Verfahren die vielen kleinen Fälle erledigen durfte, wenig zu spüren. Er beschränkte

43 Nürnberger Nachrichten, Fürther Ausgabe, vom 29. Juni 1946 und Amtsgericht München, Registratur S: Nr. 2.

44 Vgl. Fränkische Landeszeitung vom 21. August 1946 und Amtsgericht Ansbach, Registratur S: Nr. 9.

45 Nürnberger Nachrichten, Fürther Ausgabe, vom 25. September 1946. 
sich darauf, die „notwendigen Vorarbeiten und Vorerhebungen zum Zwecke der Durchführung der schriftlichen oder mündlichen Verfahren“ durchzuführen ${ }^{46}$. Das hieß beileibe nicht Untätigkeit. Im Frühsommer 1946 wurde die Spruchkammer mit etwa 22000 Meldebogen überflutet. Diese mußten nun gesichtet und je nach den Belastungen der Beschuldigten geordnet werden. Die Nichtbetroffenen wurden sofort ausgeschieden und darüber informiert, daß sie von der Spruchkammer nichts zu befürchten hatten. In allen übrigen Fällen begannen dann die Ermittlungen. Dabei war in jedem einzelnen Fall ein regelrechter Papierkrieg zu führen. Der öffentliche Kläger fragte bei insgesamt sieben Stellen nach, ob gegen den Beschuldigten etwas vorliege: Bei der Stadtpolizei und beim Ausschuß der politischen Parteien, bei den örtlichen Gewerkschaften und im Rathaus, beim Arbeits- und Finanzamt und bei der Berufsvertretung. Außerdem bat er Special Branch, die im Meldebogen angegebenen Daten zu überprüfen. Wenn diese Routineprüfungen abgeschlossen waren, wurden die Beschuldigten in die Büros der Spruchkammer zitiert und vom stellvertretenden Kläger verhört. Danach kam der Ermittlungsdienst an die Reihe. Dieser sah - soweit vorhanden - in der Regel die Personalakten durch und befragte einige Ansbacher Bürger über die Vergangenheit des Beschuldigten. Dort, wo es gelungen war, Dokumente der NS-Stellen vor dem Feuer zu retten, wurden natürlich auch diese in die Ermittlungen miteinbezogen. Die Ansbacher Spruchkammer bereitete 1946 so eine ganze Reihe von Fällen vor, die der Vorsitzende - sollte denn je einer gefunden werden - sofort nach Amtsantritt anpacken konnte. Über diesen Vorarbeiten kamen aber die eigentlichen Aufgaben des kleinen Senats, nämlich schriftliche Verfahren durchzuführen, zu kurz. Ende des Jahres waren kaum 8 Prozent aller Verfahren abgeschlossen. Die Spruchkammer Fürth-Land, eine der besten in ganz Nordbayern, meldete dagegen zu Weihnachten 1946: Landkreis Fürth zu 38,5 Prozent entnazifiziert ${ }^{47}$.

Daß sich die Spruchkammern zunächst fast ausschließlich mit „kleinen Fischen“ befaßten, lag nicht in der Absicht der Väter des Befreiungsgesetzes. Es war auch kein Versagen der Spruchkammern, sondern unter den herrschenden Bedingungen fast unvermeidlich: Ganze Heerscharen von Beamten, Angestellten und Freiberuflern hatten 1945 im Zuge der pauschalen amerikanischen Säuberungspolitik ihre Posten verloren, in die sie erst nach „erfolgreicher“ Entnazifizierung durch die Spruchkammern wieder zurückkehren konnten. Sie mußten sich nun anderweitig durchschlagen und hofften, daß das ihnen angetane Unrecht bald rückgängig gemacht würde. Als die Spruchkammern im Sommer 1946 ihre Pforten öffneten, wurden sie mit Bittbriefen bombardiert, in denen die Bittsteller lang und breit begründeten, wieso gerade ihr Fall einer raschen Behandlung bedürfe. Außerdem hatte sich mittlerweile eine Reihe von Sachzwängen ergeben, die die Verantwortlichen in Sachen Entnazifizierung zunehmend mehr bekümmerten. Überall fehlte es an Lehrern, Richtern, Ärzten und vor allem an erfahrenem Verwaltungspersonal. Gleichzeitig standen aber zahllose Angehörige dieser Berufsgruppen, die 1945 vielfach nur aufgrund von formalen Belastungen entlassen worden waren, auf der Straße. Was lag für die Behördenchefs und Stadtoberhäupter also näher, als die Spruchkammern zu bestürmen, diese Berufsgruppen bevorzugt zu ent-

46 OB Ansbach an MilReg, Stimmungsbericht vom 18. September 1946, in: Stadtverwaltung Ansbach, EAP 022-95/19.

47 Nürnberger Nachrichten, Fürther Ausgabe, vom 28. Dezember 1946. 
nazifizieren? Der Stadtrat von Ansbach beispielsweise sandte Bittschreiben um Bittschreiben an die Spruchkammer. Allein am 2. August 1946 erstellte er eine Liste mit den Namen von zehn entlassenen Beamten, die der Spruchkammer „mit der Bitte um bevorzugte Durchschleusung “ zugeleitet wurde ${ }^{48}$. Der Druck aus allen Verwaltungszweigen auf die Spruchkammern nahm im Herbst 1946 derartig zu, daß die bayerische Regierung ausdrücklich anordnete, daß Fälle mit geringer Belastung bevorzugt an die Reihe kommen sollten, während schwerer Belastete für den Augenblick grundsätzlich zurückgestellt werden müßten ${ }^{49}$. Zunächst sollten also die Fehler der amerikanischen Säuberungspolitik ausgebügelt werden. Daß man die Fälle der Kleinen aus solchen Gründen vorzog, schuf freilich die fatale Optik, als sollten die schweren Fälle bis zum Sankt Nimmerleinstag hinausgezögert werden.

Die Spruchkammern konnten der Anweisung aus München mit umso ruhigerem Gewissen folgen, als die prominentesten Nationalsozialisten ihrer Zuständigkeit ohnehin entzogen waren. Die am schwersten belasteten Personen hatten sich in den alliierten Kriegsverbrecherprozessen zu verantworten. Die Kreis- und Ortsgruppenleiter sowie zahlreiche SS-Führer waren 1945 vom CIC aufgespürt und in Internierungslager gesteckt worden, wo sie ihren Verfahren vor den Lagerspruchkammern entgegensahen. Die „Heimat“-Spruchkammern rechneten offenbar nicht damit, mit diesen Fällen befaßt zu werden und trafen daher kaum Vorbereitungen. Ihnen blieb nur die undankbare Aufgabe, die ganze deutsche Bevölkerung durchzukämmen, um gleichsam die dritte und vierte Garnitur der Nationalsozialisten ausfindig zu machen: die Denunzianten und engstirnigen kleinen Fanatiker, die in der NSDAP kaum höhere Posten innegehabt, im Dorf bzw. in der Nachbarschaft aber teilweise erhebliches Unheil angerichtet hatten. Ansonsten waren die Spruchkammern von vornherein nur „Spezialisten für Zweitrangiges“ ${ }^{\text {"50 }}$, in der Öffentlichkeit genossen sie nur geringes Ansehen. Größere Aufmerksamkeit hätten sie gewiß erlangen können, wenn ihre Tätigkeit mit einer Reihe von wirklichen Paukenschlägen begonnen, wenn es etwa geheißen hätte: April 1946 - Oberbürgermeister und Kreisleiter Richard Hänel vor der Ansbacher Spruchkammer. Mai 1946 - Kreisleiter Wilhelm Seitz als Hauptschuldiger angeklagt. So wie die Dinge lagen, standen sich aber politische, rechtliche und pragmatische Zwänge unvereinbar gegenüber. Der Konzentration auf überzeugende Fälle von NSAktivisten, die um der politisch-moralischen Glaubwürdigkeit der Kammern willen zu wünschen gewesen wäre, widersprach die aufgrund der Wiederherstellung der Gerechtigkeit und der Behebung des Personalmangels im öffentlichen Dienst nicht minder erwünschte schnelle Abwicklung der vielen kleinen Fälle.

Die große Masse der kleinen Pgs, die noch immer auf ein Verfahren wartete, wurde immer unzufriedener. Sie hatten besonders unter Art. 58 des Befreiungsgesetzes zu leiden, wonach „Personen, die in Klasse I oder II ... aufgeführt sind oder die sonst Mitglieder der NSDAP oder einer ihrer Gliederungen ... waren, in der öffentlichen Verwaltung, in Privatunternehmungen, in gemeinnützigen Unternehmen und Wohlfahrtseinrichtungen sowie in freien Berufen nicht anders als in gewöhnlicher Arbeit

48 Prot. der Sitzung des Stadtrats von Ansbach vom 2. August 1946, in: Stadtverwaltung Ansbach, Registratur des OB.

$49 \mathrm{Vgl}$. Nürnberger Nachrichten, Fürther Ausgabe, vom 18. September 1946.

so Niethammer, Entnazifizierung, S. 549. 
beschäftigt werden“ durften. Dieses Beschäftigungsverbot galt bis zur rechtskräftigen Entscheidung durch die Spruchkammer. Gerade die ließ aber auf sich warten. Viele kleine Pgs standen deshalb bereits mehr als ein Jahr auf der Straße. Niemand wußte, wann die Warterei zu Ende sein würde. Der Ansbacher Landrat Richard Neff schilderte die Situation der kleinen Parteigenossen in einem Bericht an die Militärregierung zutreffend so: „Das, was an dem Säuberungsgesetz am einschneidensten für die große Masse der Bevölkerung war und ist ... sind nicht die Folgen der endgültigen Entscheide, sondern die Auswirkungen der vorläufigen Maßnahmen, insbesondere des Beschäftigungsverbotes ... Die Folgen dieser Ungerechtigkeit werden aber immer gröBer und schwerwiegender, je länger es dauert, bis die Entscheidung ergehen kann. Die wichtigste Entscheidung eines öffentlichen Klägers oder der Spruchkammer überhaupt ist heute nicht mehr die, welche Strafe sie einem Betroffenen auferlegen soll, sondern die, welcher Betroffene zuerst zur Verhandlung kommen, und welcher noch weiter zuwarten soll. Mir ist nicht bekannt, daß für diese wichtige Entscheidung der Spruchkammern irgendwelche Vorschriften gegeben sind, und die Folge ist, daß die Entscheidung über die Reihenfolge tatsächlich mehr oder minder dem Zufall überlassen wird. Ich habe noch von keinem Betroffenen gehört, der sich bei mir über den Spruch beklagt hätte, wohl aber alltäglich kommt die Klage zu mir, daß es zu lange dauere und ob nicht der eine oder andere bevorzugt zur Verhandlung kommen könnte. “51

Der Unmut unter den kleinen Pgs wurde noch größer, als man in der zweiten Hälfte des Jahres 1946 in der Zeitung lesen konnte, daß manch einer, der im Dritten Reich im Rampenlicht gestanden hatte, vor der Spruchkammer recht glimpflich davongekommen war. Die Zeitungen waren zwar voll mit Meldungen über drastische Spruchkammerurteile. Doch nicht diese blieben im Gedächtnis haften, sondern die auffallend milden Urteile. So machte es im Oktober 1946 Schlagzeilen, daß der Star des nazistischen Tendenzfilms „SA-Mann Brand“, der Schauspieler Manfred Kömpel, im unterfränkischen Bad Brückenau als Mitläufer eingereiht worden war ${ }^{52}$. Im selben Monat meldete die Presse, daß der bekannte Textilfabrikant Josef Witt aus Weiden, der der NSDAP enorme Summen gespendet hatte, in seiner Heimatstadt zum Mitläufer gestempelt worden sei. Gerade dieses Urteil löste in ganz Nordbayern, wo man Witt ja überall kannte, heftige Diskussionen aus. „Es lohnt sich nicht, über eine solche Komödie auch nur ein Wort zu verlieren“, so der ätzende Kommentar des Herausgebers der Nürnberger Nachrichten Dr. Joseph E. Drexel. „Da kann man nur sagen: macht Schluß mit dieser Komödie! Wir haben uns schon lächerlich genug gemacht. ${ }^{\text {" } 33}$ Ebenso regte man sich in den Reihen der kleinen Parteigenossen über die Freisprüche von Hjalmar Schacht, Franz von Papen und Hans Fritzsche durch das Internationale Militärgericht in Nürnberg auf, und vor allem darüber, daß Schacht sich weigerte, anschließend vor einer bayerischen Spruchkammer zu erscheinen. ,Jede Aktion der bayerischen Spruchkammer betrachte ich als ungesetzlich“, so Schacht, der lieber in der britischen oder französischen Zone entnazifiziert werden wollte, wo in

31 LR Ansbach an MilReg, 17. September 1947, in: NA, RG 260, 9/144-2/2.

32 Süddeutsche Zeitung vom 25. Oktober 1946.

53 Nürnberger Nachrichten, Fürther Ausgabe, vom 9. Oktober 1946. Vgl. auch Süddeutsche Zeitung vom 5. November 1946. 
der Regel viel mildere Urteile gefällt wurden. Manche kleinen Pgs fragten sich, ob der "große" Schacht sich die Spruchkammer selbst aussuchen könne ${ }^{54}$.

Der Verdacht breitete sich aus, es würde mit zweierlei Maß gemessen. Diese Meinungen erhielten durch eine Reihe von skandalösen Urteilen der Berufungskammer für Ober- und Mittelfranken in Ansbach noch weiter Auftrieb. Die den bürgerlichen Parteien angehörenden bzw. parteilosen Juristen der Berufungskammer empfanden die politische Säuberung als überflüssig und lehnten vor allem das Befreiungsgesetz, das in wesentlichen Punkten der von ihnen hochgeschätzten deutschen Rechtstradition zuwiderlief, ab. Sie taten alles, um das Befreiungsgesetz zu unterlaufen und es seines politischen Charakters zu entkleiden. Sie hatten dabei oft leichtes Spiel, denn die Urteilsbegründungen der mit juristischen Laien besetzten ersten Instanz ließen häufig zu wünschen übrig. Außerdem richteten sich die Augen der Öffentlichkeit mehr auf die Spruchkammer in der eigenen Stadt. Die Berufungskammer für den Regierungsbezirk Ober- und Mittelfranken stand dagegen im Schatten solcher Aufmerksamkeit und konnte ihre Verfahren fast unbehelligt von öffentlichen Stimmungen und Erwartungen abwickeln.

Die wenigen größeren Nationalsozialisten, die im Sommer und Herbst 1946 in der ersten Instanz zu schweren Strafen verurteilt wurden, gingen aus den Berufungsverfahren meist als Minderbelastete oder Mitläufer hervor. Einer der Vorsitzenden der zweiten Instanz, der frühere Direktor des Amtsgerichts Ansbach, Friedrich Stöhr, trieb es aber anscheinend zu weit; einmal stufte er sogar einen KZ-Aufseher, der Häftlinge geschlagen hatte, als vom Gesetz nicht betroffen ein ${ }^{55}$. Er mußte entlassen werden, weil „seine systematische Herabstufung ein öffentlicher Skandal geworden“ war $^{56}$. Viele Spruchkammervorsitzende waren über die weiche Linie der Berufungskammer, die ihre bescheidenen Erfolge bei der politischen Säuberung vielfach wieder zunichte machte, so verärgert, daß sie, wie Dorn nach einer Rundreise durch Franken in seinen Erinnerungen schrieb, „zum Rücktritt geneigt“ waren ${ }^{57}$.

Es waren freilich nicht nur restaurative Stimmungen, die das Ansehen der Entnazifizierung weiter herabsetzten, je mehr die Fragwürdigkeit der ganzen Säuberungsprozedur zutage trat. Das Befreiungsgesetz war den Deutschen aufgenötigt worden, viele sahen es als ein Gesetz der Amerikaner an, auch deshalb, weil es ihren Gerechtigkeitsvorstellungen so wenig entsprach. Es gebe nicht wenige Menschen, schrieb im Oktober 1946 der Ansbacher Oberbürgermeister in seinem Stimmungsbericht an die Militärregierung, „die den Spruchkammern direkt ablehnend gegenüberstehen “58. Biedere ehemalige kleine Pgs mißbilligten die Pauschalität der Säuberung ebenso wie viele ihrer unbelasteten Nachbarn und Berufskollegen, die zwischen „solchen“ und „solchen“ Nationalsozialisten während der zwölf Jahre des Dritten Reiches wohl zu unterscheiden gewußt hatten. Entscheidend für sie war, ob einer anständig geblieben war oder

54 Vgl. Nürnberger Nachrichten, Fürther Ausgabe, vom 26. Oktober 1946. Vgl. auch Opinion Surveys, Report Number 33, Information Control Division, OMGUS, Washington National Records Center, Washington D. C. 1970 und Wochenbericht der Intelligence Division von OMGB, 11. Oktober 1946, in: NA, RG 260, $10 / 85-3 / 1$.

35 Vgl. Fränkische Landeszeitung vom 8. März 1947.

s6 Dorn, Inspektionsreisen, S. 108.

57 Ebenda, S. 107.

s8 OB Ansbach an MilReg, Stimmungsbericht vom 30. Oktober 1946, in: Stadtverwaltung Ansbach, EAP 022 95/19. 
nicht. Die Frage der nominellen Mitgliedschaft oder Nichtmitgliedschaft in der NSDAP, oft vor allem bedingt durch die berufliche Situation, hatte dagegen viel geringere Bedeutung als die meisten Amerikaner oder auch manche Antifaschisten annahmen. Die nachbarschaftlichen und sonstigen sozialen Beziehungen waren davon meist nicht gestört worden. Gerade im mittelstädtischen und dörflichen Milieu, wo jeder jeden kannte, war das Netz dieser sozialen Beziehungen, waren die oft gravierenden Unterschiede zwischen den Anschauungen des Mannes auf der Straße und den Einstufungen der persönlich bekannten Fälle durch die Spruchkammer meist entscheidend für die Einstellung gegenüber der Entnazifizierung insgesamt. Obwohl die Kammern ihre Arbeit noch gar nicht richtig begonnen hatten, versackte ihre Überzeugungskraft so zunehmend im Geflecht dieser nachbarschaftlichen, kollegialen und gesellschaftlichen Beziehungen. Davon profitierten zunächst vor allem die kleinen und mittleren Nationalsozialisten, nicht aber die prominenten Repräsentanten des NS-Regimes, die in ihren Heimatorten meist unbeliebt oder gar verhaßt waren.

Als die Fälle der kleinen Pgs zur Behandlung anstanden, sandten die Betroffenen meist gleich ganze Pakete von Entlastungszeugnissen, sogenannte Persilscheine, von Freunden, Nachbarn und Kollegen an die Spruchkammer, in denen sie im günstigsten Licht erschienen: als ganz und gar unpolitische Menschen, die auch in der NS-Zeit völlig integer geblieben und nur auf ihr privates Fortkommen bedacht gewesen seien. Das meist tatsächlich wohl untadelige Verhalten des Betroffenen als Nachbar, Berufskollege oder Familienvater wurde ganz in den Vordergrund gerückt, die politische Tätigkeit als Blockwart oder SA-Führer dagegen weitgehend unterschlagen. Ein Ansbacher Postbetriebswart animierte fast die ganze Gneisenaustraße, in der er als Briefträger bekannt war, Persilscheine für ihn auszustellen ${ }^{59}$. Ein kleiner Geschäftsmann, Pg seit 1935, der vor allem den Vorwurf zu entkräften hatte, während seiner Tätigkeit als Blockwalter NS-Propaganda betrieben zu haben, machte sich mit einer vorgetippten Bescheinigung auf den Weg, die jeder in seinem früheren Block unterschreiben sollte. Ein schwerer Gang durch die Nachbarschaft war das für den Geschäftsmann anscheinend nicht. Insgesamt 29 Unterschriften brachte er auf diese Weise zusammen ${ }^{60}$. Auch ein nicht weiter belasteter „Alter Kämpfer", Pg seit 1925, hatte keine Mühe, in der Ansbacher Blumenstraße eine Reihe von Persilscheinen zu bekommen. Da er noch im Interniertenlager Nürnberg-Langwasser einsaß, schickte er im Dezember 1946 anscheinend einen Vertrauensmann los. Dieser hatte gleich seine Schreibmaschine mit dabei und verfaßte zusammen mit wohlmeinenden Nachbarn jeweils kurze Entlastungszeugnisse. Recht einfallsreich war er nicht. In fast jedem Persilschein tauchten die gleichen Wendungen auf ${ }^{61}$ : „Soviel mir bekannt ist, war er Mitglied der Allgemeinen SS. Über seine politische Tätigkeit ist mir nichts bekannt. Herr Beble hat sich immer als hilfsbereiter und entgegenkommender Mensch gezeigt und auch politisch anders Gesinnten stets geholfen.“ Oder: „Mir ist bekannt, daß er Mitglied der Allgemeinen SS war. Über seine politische Tätigkeit ist mir nichts bekannt. Herr Beble war stets ein zuvorkommender und hilfsbereiter Mensch, der sich auch für Nicht-Parteigenossen jeder Zeit einsetzte und behilflich war.“

\footnotetext{
99 Amtsgericht Ansbach, Registratur S: Nr. 10.

60 Ebenda: Nr. 11.

61 Ebenda: Nr. 12.
} 
Je angesehener der Betroffene in der Stadt war, desto sicherer war er im sozialen Geflecht aufgehoben. Ein Paradebeispiel dafür war der Fall des Geschäftsführers der Gewerbebank Ansbach, Hans Bamm - einer von den „besseren Leuten“ der Stadt. Bamm hatte die Geschäftsführung der Bank 1919 übernommen und war 1933 der NSDAP beigetreten, weil er , so schrieb er der Spruchkammer, sonst seine Existenz gefährdet hätte. Außerdem wollte er die „unparteiliche Fortführung der Genossenschaft" gewährleisten. Seine insgesamt 14 Persilscheine stammten von den besten Adressen Ansbachs. Der stellvertretende Leiter der Landeszentralbank von Bayern, ein Reichsbankrat, der Bamm seit 1920 kannte, versicherte: „Jeder, der Herrn Bamm näher kannte und Gelegenheit hatte, mit ihm öfter zu sprechen, wußte, daß er ausgesprochener Nazigegner war. Wenn er trotzdem der Partei beitreten mußte, so geschah dies, um die Bank nicht unter nationalsozialistische Führung kommen zu lassen und damit sein Lebenswerk zu gefährden. Nie hatte Herr Bamm sich für die Partei propagandistisch betätigt.“ Dem stimmten eine praktische Ärztin, ein Kaufmann und der Vorstand der Vereinigten Innungen von Ansbach und Umgebung zu. Sie hoben besonders hervor, daß Herr Bamm ,in der gesamten Geschäftswelt ... eine beliebte Persönlichkeit“ sei, „die allseits das größte Vertrauen genießt“. Ein Buchbindermeister und eine Klavierlehrerin, beide Nachbarn von Bamms, betonten, daß der Betroffene „als schlichter und einfacher Mann ... stets beste nachbarliche Beziehungen“ unterhalten habe. „Er benützte vielfach“, so der Buchbindermeister, die Anrede „Grüß Gott Herr Nachbar!“62 Das mußte überzeugend wirken.

Unter den Honoratioren, Nachbarn und Kollegen, die so bereitwillig Persilscheine ausstellten, befanden sich nicht nur Leute mit politisch weißer Weste, sondern auch viele Parteigenossen, die eben erst selbst entnazifiziert worden waren oder noch auf ihr Verfahren warteten. Die früheren Pgs fanden offenbar nichts dabei, sich untereinander diesen Gefallen zu tun. Diese Art der Hilfe von $\mathrm{Pg}$ zu Pg war auch in den Kreisen der höheren Ansbacher Beamtenschaft weit verbreitet. Der schon mehrfach genannte frühere Stadtrechtsrat, Friedrich Böhner, gab über den früheren Oberinspektor und Leiter des Polizeiamtes, Albert Aker, zu Protokoll: „Durch die jahrelange Zusammenarbeit kamen wir uns natürlich auch persönlich näher und trugen bei dem gegenseitig herrschenden Vertrauen auch keine Bedenken, uns über die Verhältnisse im sogenannten 3. Reich offenherzig auszusprechen ... Herr Aker brachte dabei immer wieder seine Abneigung gegen die Ziele und Methoden der Partei deutlich zum Ausdruck und teilte meine Meinung, daß das alles zu keinem guten Ende führen könne.“ Als dann Böhners Fall vor der Spruchkammer verhandelt wurde, war Aker an der Reihe: Er habe „in der ganzen Zeit des sogenannten 3. Reiches fast täglich mit ihm (Böhner) dienstliche Angelegenheiten besprochen. Dabei wurden häufig auch politische Fragen erörtert, und weil wir gegenseitig unsere übereinstimmende Gesinnung kannten, sehr offenherzig behandelt. Ich weiß daher sehr wohl, daß Herr Böhner der Partei gegenüber beginnend schon bald nach seinem Eintritt, eine schroff ablehnende Haltung einnahm und von sich aus nichts unternahm, um ihre Ziele zu fördern." Die beiden Schreiben glichen sich im Tenor und waren anscheinend auf derselben Schreibmaschine getippt worden ${ }^{63}$. Eine Hand wusch eben die andere. 
Einer der wichtigsten Produzenten von Persilscheinen war die evangelische Kirche. Der Rat der Evangelischen Kirche in Deutschland meldete schon im Juni 1946 in einem ausführlichen Schreiben an die amerikanische Militärregierung ,schwerwiegende Bedenken“ gegen die Grundauffassung des ganzen Befreiungsgesetzes an. Die Kirche beanstandete vor allem, daß durch das Gesetz Handlungen bestraft würden, die lange vor dem Erlaß des Gesetzes lagen. Es handle sich außerdem vielfach um Verstöße gegen die "göttliche Gerechtigkeit", so die EKD, eine menschliche Obrigkeit könne nicht zu strafen unternehmen, was allein nach göttlichem Recht als Unrecht zu gelten habe ${ }^{64}$. Selbst der Ansbacher Oberkirchenrat Kern, ein beherzter Gegner der Nationalsozialisten und ein über die Grenzen Ansbachs hinaus bekannter Meinungsführer im evangelischen Kirchenkampf, teilte diesen Standpunkt. In seinen Sonntagspredigten hieß es: „Die Menschen haben nicht zu richten, sondern nur Gott.“ Oberbürgermeister Körner reagierte darauf mit der bissigen Bemerkung: „Die Erklärungen von ihm in Bezug auf die Spruchkammer ... sind nicht gerade angetan, das an sich nicht einfache Entnazifizierungswerk zu erleichtern und noch viel weniger das $\mathrm{m}$. E. künstlich geschürte Mißtrauen gegen diese Einrichtung zu beseitigen ... "65 Es zirkulierte sogar ein „richtiggehender Führer für Geistliche mit Hinweisen, wie sie vor der Spruchkammer zugunsten ihrer Gemeindemitglieder aussagen können"66.

Die Vertreter der evangelischen Kirche in Ansbach hatten immer ein offenes Ohr für die Bitten um politische Leumundszeugnisse. Ihre Barmherzigkeit kannte dabei keine gesellschaftlichen Grenzen. Oberkirchenrat Kern, Dekan Eckhardt, Landesbischof Meiser und die Stadtpfarrer schrieben schon 1946 zahllose Persilscheine, in denen sie vor allem die kirchliche Bindung der Beschuldigten hervorhoben: Der Betroffene, so schrieb etwa Meiser über einen prominenten Arzt Ansbachs, „gehört mit seiner Familie der Familie der evang.-luther. Kirche in Bayern an. Seine Ehe ist kirchlich getraut, seine Kinder sind getauft und konfirmiert. Dr. Faber hat sich mit seiner Familie von der Kirche auch dann nicht gelöst, als die Partei einen immer stärkeren weltanschaulichen Druck ausübte, sondern sich nach wie vor am kirchlichen Leben beteiligt. ${ }^{667}$ Christliches Bekenntnis wurde damit zum Attest der politischen Unbedenklichkeit ${ }^{68}$.

Selbst einer Reihe von schwererbelasteten Nationalsozialisten stand die evangelische Kirche vor der Spruchkammer bei, sofern sie während der NS-Zeit nicht aus der Kirche ausgetreten waren. Während die neue Stadtspitze und die Honoratiorenschaft noch eine gewisse Scheu zeigten, prominenten Nationalsozialisten beizuspringen, kannte die Kirche kaum solche Berührungsängste. Obersteuerinspektor Hans Bebel, $\mathrm{Pg}$ seit 1923 und nach Auskunft des örtlichen Gewerkschaftsbundes ein überzeugter $\mathrm{Pg}$, konnte zu seiner Entlastung ein Schreiben des Pfarrers der 3. Evangelisch-Lutherischen Pfarrstelle St. Gumbertus vorlegen, das einer Expertise über die Kinder des Betroffenen glich: „Seine älteste Tochter Herta war damals meine Schülerin; sie gehörte

64 Süddeutsche Zeitung vom 4. Juni 1946.

65 OB Ansbach an MilReg, Stimmungsbericht vom 25. September 1946, in: Stadtverwaltung Ansbach, EAP 022-95/19.

66 Dorn, Inspektionsreisen, S. 115.

67 Amtsgericht Ansbach, Registratur S: Nr. 14.

${ }^{68}$ Vgl. dazu Niethammer, Entnazifizierung, S.612f. Seines Erachtens gehörten die Kirchen nicht zu den Hauptproduzenten von Persilscheinen. Dieser Eindruck ergibt sich aus den Akten der Spruchkammer Ansbach nicht. Dort wimmelt es von Persilscheinen von Geistlichen. 
einer Klasse der evangelischen Bekenntnisschule an, ein Zeichen dafür, daß es der Familie Bebel ein Anliegen war, ihre Kinder in christlich-kirchlichem Sinn erziehen zu lassen. Die Art des Kindes und seine Treue in der Mitarbeit, zumal auch später im Konfirmandenunterricht (1940) ließen mich einen Einblick in den christlichen Geist ihres Elternhauses gewinnen ... Die beiden jüngeren Töchter Gerlinde und Mechthild waren in den Jahren vor ihrem Schulbesuch in einem kirchlich geleiteten evangelischen Kindergarten untergebracht; die Eltern lehnten es ab, sie einem, in erreichbarer Nähe befindlichen, im Sinne der Partei geführten NSV-Kindergarten anzuvertrauen. Ebenso waren sie regelmäßig Besucher des Kindergottesdienstes, wie auch die Familie am gottesdienstlichen Leben der Gemeinde teilnahm, alles Tatsachen, die mit einer national-sozialistischen Geisteshaltung nichts zu tun hatten“69.

Der Kreis der Befürworter einer politischen Säuberung wurde demgegenüber immer kleiner. Die Parteien, die noch im Juni 1946 versichert hatten, entschlossen und rückhaltlos hinter dem Befreiungsgesetz zu stehen und alles in ihrer Macht stehende zu tun, um seine „rasche und reibungslose Durchführung zu gewährleisten“, rückten von dieser Erklärung langsam wieder $a b^{70}$. Sie brauchten Stimmen, und es konnte wahlentscheidend sein, welche Partei in den Reihen der kleinen Parteigenossen den größten Anklang fand. Am weitesten wagte sich die Wirtschaftliche Aufbau-Vereinigung vor, deren Vorsitzender Loritz die Spruchkammern als einen „Schlag ins Gesicht des deutschen Volkes“ bezeichnete ${ }^{71}$. Der Kurs der CSU war weniger eindeutig. Während die Landesleitung, um die Militärregierung zu besänftigen, ihren Entnazifizierungswillen beteuerte, zogen die Kreisverbände nach und nach ihre Mitglieder aus den Spruchkammern zurück und warben gleichzeitig offen um die Stimmen der kleinen Pgs. „Briefe aus kleineren Gemeinden scheinen anzudeuten“, so die Erkenntnis der Intelligence Division der Militärregierung im August 1946, „daß die CSU den früheren Pgs sehr häufig Hilfe und Beistand leistet. In mehreren Briefen wird die CSU deshalb CNSU genannt, d.h. Christlich Nationalsozialistische Union. “72 Auch in der SPD tauchten Zweifel auf, ob die Befürwortung des Entnazifizierungsgesetzes noch länger opportun sei. Der Bezirksvorsitzende der fränkischen SPD forderte seine Parteifreunde sogar ausdrücklich auf, die Mitarbeit in den Spruchkammern einzustellen, was den Parteivorsitzenden Wilhelm Hoegner zeitweise fürchten ließ, die Amerikaner könnten deshalb in Franken die SPD verbieten ${ }^{73}$.

Selbst viele entschiedene Gegner des Nationalsozialismus, die auf eine gerechte Entnazifizierung gehofft hatten, distanzierten sich vom Befreiungsgesetz, das in ihren Augen nur neue Ungerechtigkeiten schuf ${ }^{74}$. Man machte höchstens noch bittere Witze, in denen die von den Spruchkammern verhängten Bußgelder mit den kirchlichen Ablässen am Vorabend der Reformation verglichen wurden: „Zu Zeiten von

69 Amtsgericht Ansbach, Registratur S: Nr. 15.

70 Wilhelm Hoegner, Der schwierige Außenseiter. Erinnerungen eines Abgeordneten, Emigranten und Ministerpräsidenten, München 1959, S. $234 \mathrm{f}$.

71 Hans Woller, Die Loritz-Partei. Geschichte, Struktur und Politik der Wirtschaftlichen Aufbau-Vereinigung (WAV) 1945-1955, Stuttgart 1982, S. 44.

72 Wochenbericht der Intelligence Division von OMGB, 30. August 1946, in: NA, RG 260, 10/85-3/1.

73 Vgl. Henke/Woller, Lehrjahre der CSU, S.76. Vgl. auch Dorn, Inspektionsreisen, S. 98.

74 Vgl. Niethammer, Entnazifizierung, S.662; Walter Dirks, Folgen der Entnazifizierung. Ihre Auswirkungen in kleinen und mittleren Gemeinden der 3 westlichen Zonen, in: Sociologica, Festschrift für Max Horkheimer, Frankfurt/Main 1953, S. 446 f. 
Martin Luther konnte man sich von seinen Sünden reinigen, wenn man einen bestimmten Betrag an die Kirche entrichtete. Ein zeitgenössischer bayerischer Vers parodiert dieses Thema in bezug auf die Entnazifizierung:

,Wenn das Geld im Kasten klingt, die Seele in den Himmel springt.

Wenn das Geld im Kasten klingt, der Nazi aus dem Braunhemd springt'“" ${ }^{75}$

So war es kein Wunder, daß das nie besonders große Ansehen der Spruchkammern weiter abnahm. Die Vorsitzenden und Kläger fühlten sich isoliert und als „Diener der Amerikaner" mißachtet ${ }^{76}$. Die Ermittler galten als Schnüffler und Spitzel, denen man am besten aus dem Weg ging. Um nicht allzuweit ins gesellschaftliche Abseits zu geraten, überlegte es sich mancher von ihnen sicher zweimal, ob er überhaupt etwas entdecken sollte. Die Vorsicht der Ermittler war schon so stark ausgeprägt, daß sie auch der Militärregierung nicht verborgen blieb. Sie „kommen deshalb oft mit positiven Berichten über die Betroffenen zurück, weil sie ihre Befragungen auf Personen beschränkten, die ihnen vom Betroffenen selbst benannt wurden", hieß es in einem Bericht der Militärregierung vom Februar $1947^{77}$.

Das bedeutete nun aber andererseits nicht, daß die schlimmen Ereignisse der NSZeit gänzlich vergessen und vergeben gewesen wären. Wann immer in der Öffentlichkeit bekannt wurde, daß Verfahren gegen prominente Nationalsozialisten oder verhaßte Denunzianten anstünden, meldeten sich genug Belastungszeugen. So wurde die Spruchkammer Ansbach-Land im Sommer 1946 mit Briefen und Anzeigen regelrecht bombardiert, die den ehemaligen Ortsgruppenleiter von Flachslanden, Friedrich Strobel, als um „kein Haar besser als Streicher" charakterisierten ${ }^{78}$. Über den früheren Ortsgruppenleiter von Windsbach, Hans Hagelauer, hieß es, er sei „Nazi mit Leib und Seele“ gewesen und habe die Schuld daran, „daß jetzt soviel Leid aufgrund des Entnazifizierungsgesetzes in verschiedenen Familien unserer Gemeinde einzieht" ${ }^{\text {"79 }}$.

Unter dem Eindruck des allgemeinen Ansehensverlustes der Spruchkammern schien sich allerdings auch hier eine Änderung anzubahnen. Die Zahl der Belastungszeugen wurde kleiner, was freilich auch andere Gründe hatte: „Ein großer Teil der Bevölkerung“, so die etwas übertriebene Beobachtung der Militärregierung vom Oktober 1946, „der die Rückkehr der Nazis an die Macht fürchtet, schreckt mehr und mehr davor zurück, als Belastungszeuge aufzutreten, sogar dann, wenn es sich um stadtbekannte Nazis handelt. In einigen Fällen haben einflußreiche Nazis tatsächlich moralischen Druck ausgeübt, um Zeugen davon abzuhalten, belastende Aussagen zu machen. “80 Die Mehrzahl der Verfahren gegen kleine Pgs mußte so ohne Belastungszeugen stattfinden. „Soll ausgerechnet ich den Denunzianten machen? Das fällt mir ja gar nicht ein, sagten sich viele. ${ }^{\text {(81 }}$ Die Bevölkerung, so hieß es in einem Bericht des Ans-

\footnotetext{
75 Wochenbericht der Intelligence Division von OMGB, 19. April 1946, in: NA, RG 260, 10/85-3/1.

76 Dorn, Inspektionsreisen, S.98.

77 Denazification Field Inspection Report, Det. Ansbach, 12. Februar 1947, in: NA, RG 260, 15/119-1/7.

${ }^{78}$ Urteil der Spruchkammer Ansbach-Land vom 27. Juli 1948, in: Amtsgericht Ansbach, Registratur S: Nr. 16.

79 Bericht des Landjägereikommissars aus Windsbach, 6. September 1946, in: Ebenda: Nr. 17.

80 Wochenbericht der Intelligence Division von OMGB, 25. Oktober 1946, in: NA, RG 260, 10/85-3/2.

81 Fränkische Landeszeitung vom 6. November 1946.
} 
bacher Ermittlungsdienstes, „ist allgemein sehr kontra gegen die ganze Entnazifizierung eingestellt, so daß die Ermittlungen erschwert (waren) und kein besseres Ergebnis zeitigten ${ }^{\text {(82 }}$.

\section{b. Clays Donnerwetter 1946 und die Folgen - "White-washing“ im Zeichen der Amnestien}

Die Entnazifizierung steckte bereits ein halbes Jahr nach Erlaß des Gesetzes zur Befreiung von Nationalsozialismus und Militarismus in einer ernsten Krise. Wie sollte man sie meistern? Die Ministerpräsidenten und Parteiführer forderten - auf einen einfachen Nenner gebracht - die Abkehr vom Befreiungsgesetz und eine Generalamnestie für alle kleinen Nationalsozialisten, damit den Spruchkammern ausreichend Zeit bliebe, sich mit den schweren Fällen zu befassen. An eine Generalamnestie war aber nicht zu denken, denn die amerikanische Militärregierung bestand auf der strikten Einhaltung des Gesetzes. Schon im Sommer 1946 ließ sie keinen Zweifel daran, daß sie die dauernden Verzögerungen beim Aufbau der Spruchkammern nicht durchgehen lassen werde. Ministerpräsident Wilhelm Hoegner informierte im Juni 1946 seine Kabinettskollegen im Ministerrat über Unterredungen mit Militärgouverneur Walter J. Muller, der ihm unverblümt mitgeteilt hatte, daß General Clay über die Lage in Bayern bestürzt sei: „Wenn die bayerische Regierung die Entnazifizierung nicht rasch und zufriedenstellend durchführen könne, werde die Militärregierung einschreiten und das Besatzungsheer zur Denazifizierung heranziehen. ${ }^{83}$ Zugleich würden die Deutschen das Recht zur Selbstregierung, das sie erst wenige Monate vorher erworben hatten, wieder verlieren ${ }^{84}$. Durch diese unzweideutigen Drohungen ließen sich die Spruchkammern in den Städten und Landkreisen aber nicht beeindrucken. Sie hielten auch weiterhin an ihrem Kurs fest, zunächst die große Zahl der 1945 zu Unrecht entlassenẹn kleinen Pgs zu rehabilitieren und erst dann die schweren Fälle auf die Tagesordnung zu setzen.

In der zweiten Hälfte des Jahres 1946 wuchsen in den Reihen der Militärregierung deshalb die Zweifel am deutschen Entnazifizierungswillen. Die „Falken“ wollten von den Spruchkammern endlich Taten sehen; sie übersahen aber völlig, daß sie ja selbst die Suppe miteingebrockt hatten, die die Spruchkammern jetzt auslöffeln mußten. Bei nicht wenigen von ihnen galt die Hauptsorge aber auch nicht so sehr der "Rache“ selbst als der Besänftigung ihrer Vorgesetzten in Washington, die, so fürchteten sie, wohl kaum zufrieden sein würden, wenn sie erfuhren, daß bisher fast ausschließlich kleine Pgs vor den Spruchkammern gestanden hatten. Außerdem konnten sie es nur schweren Herzens mitansehen, wie die Spruch- bzw. Berufungskammern in der gesamten Besatzungszone reihenweise solche Parteigenossen zu Mitläufern stempelten, die sie selbst ein Jahr zuvor aufgrund von formalen Belastungen als "gefährliche Nazis“ angesehen und aus den Ämtern entlassen hatten. Die „Falken“ hatten es von Anfang an für verfehlt gehalten, die Entnazifizierung nach Erlaß des Befreiungsgesetzes ganz den Deutschen zu überlassen, sich mit dieser Meinung aber nicht durchsetzen können. Offizielle Politik der Militärregierung war, so versicherte Oberst Whitaker von 
der Ansbacher Militärregierungseinheit dem Landrat Richard Neff, daß die Militärregierung keinen „Einfluß auf die Entscheidungen der Spruchkammer nimmt ${ }^{\text {“85 }}$.

Nachdem diese Großzügigkeit aber in den Augen vieler Militärregierungsoffiziere ausgenützt worden war, gewannen die Verfechter einer harten Entnazifizierungslinie wieder Oberwasser. Sie drängten darauf, die politische Säuberung in amerikanische Hände zurückzulegen oder zumindest die Spruchkammern unter ihre Kontrolle zu bringen. Im Sommer 1946 wurde deshalb das „Delinquency and Error Report System" aufgebaut, das jede Entscheidung der Spruchkammern der Nachprüfung durch die Besatzungsmacht unterwarf. Stellte man dabei Verfahrens- oder Beurteilungsfehler der Kammern fest, so wurde das Befreiungsministerium eingeschaltet und der Spruch einstweilen stornier ${ }^{86}$. Außerdem schuf man für jeden Regierungsbezirk sogenannte Special Branch Advisory Teams, die den amerikanischen Säuberungsapparat vor Ort inspizieren und dazu anhalten sollten, den Spruchkammern etwas mehr auf die Finger zu sehen. Die ersten Berichte dieser Teams, die im Sommer 1946 in den amerikanischen Zentralen einliefen, übertrafen noch die Befürchtungen, die zu ihrem Einsatz geführt hatten ${ }^{87}$. In einem Memorandum von Special Branch über den Stand der Entnazifizierung in Bayern vom 17. September 1946 hieß es, die Spruchkammern hätten sich darauf spezialisiert, ein großangelegtes ,white-washing“ zu betreiben. Nur ein verschwindend geringer Prozentsatz der Betroffenen sei in die Gruppen I bis III eingestuft worden ${ }^{88}$. Wieder verdichtete sich die Stimmung zu der Überzeugung: So kann es nicht weitergehen. Ein Zusammenstoß mit den verantwortlichen Deutschen war unvermeidlich.

Clay tobte, als ihm die Berichte zu Gesicht kamen. Er hatte für das Befreiungsgesetz sein ganzes politisches Prestige eingesetzt und wollte unter allen Umständen an ihm festhalten. Voraussetzung aber war, daß es so durchgeführt wurde, daß es ihm den Rücken freihielt gegen alle Angriffe der in Sachen Entnazifizierung nicht gerade zimperlichen amerikanischen Presse. Nichts wäre ihm im Herbst 1946 ungelegener gekommen als eine neue Entnazifizierungsdebatte. Eine Änderung des Befreiungsgesetzes, wie es die Deutschen forderten, kam aber auch deshalb nicht in Frage, weil die Amerikaner ihr Gesetz gerade erst im Alliierten Kontrollrat eingebracht und als Modell für alle anderen Besatzungszonen empfohlen hatten ${ }^{89}$. Clay wußte $z w a r$, daß ein wesentliches Ziel des Befreiungsgesetzes die Rehabilitierung der im ersten Jahr der Besatzung Entlassenen war. Das durfte aber keinesfalls so weit gehen, daß, wie es jetzt an der Tagesordnung zu sein schien, selbst Schwerbelastete zu Mitläufern des Nationalsozialismus gestempelt würden. Einen Ausweg aus dieser Zwickmühle gab es nur, wenn es gelang, die Deutschen zu härterem Durchgreifen zu veranlassen.

Diesen Versuch unternahm Clay am 5. November 1946 anläßlich der 14. Tagung des Länderrats der amerikanischen Zone in Stuttgart. Die Ministerpräsidenten und Minister, die sich in der Villa Reitzenstein versammelt hatten, befanden sich in bester Stimmung. Der württembergisch-badische Kabinettschef Reinhold Maier hatte gerade eine Rückschau auf ein Jahr Länderratsarbeit gegeben und dabei mit Lobesworten

85 So gab Neff den Chef der örtlichen Militärregierung in einer Kreisausschußsitzung wieder. Prot. der Kreisausschußsitzung vom 25. September 1946, in: LRA Ansbach, EAP 01-014.

86 Vgl. Niethammer, Entnazifizierung, S. 407.

87 Vgl. dazu die Berichte, in: NA, RG 260, 13/92-1 und 13/92-2.

88 Vgl. Niethammer, Entnazifizierung, S. 410.

89 Ebenda, S. 417. 
nicht gespart, da setzte Clay zu einer ebenso kurzen wie schneidenden Philippika an: Er sei „tief enttäuscht“ über die Art der Durchführung des Befreiungsgesetzes. Was bisher geschehen sei, zeige, daß die Deutschen noch nicht fähig seien, sich selbst zu regieren, und offenbare einen beträchtlichen Mangel an Willen zur Demokratie: „Ich habe Ihnen schon bei mehreren Gelegenheiten gesagt, daß die Militärregierung fest entschlossen ist, ihre Besatzungszone zu entnazifizieren. Wir beabsichtigen, alle jene aus einflußreichen Positionen zu entlassen, die sich verschworen hatten, um die Welt in Ruin und Zerstörung zu stürzen. Wir sind in unserem Entschluß nicht wankend geworden. Wenn das deutsche Volk diese Aufgabe nicht übernehmen will, kann und wird die Militärregierung die Aufgabe erfüllen ... Damit wir uns nicht mißverstehen. Entnazifizierung ist eine absolute Notwendigkeit.“90 Das saß. Die Entnazifizierungsminister boten ihren Rücktritt an, der aber weder von der Militärregierung noch von den Ministerpräsidenten angenommen wurde ${ }^{91}$. Selbst in den Städten und Kreisen horchte man auf. Regierungspräsident Schregle hielt die Landräte und Oberbürgermeister seines Regierungsbezirks sofort zu einem schärferen Entnazifizierungskurs an: „General Clay hat uns sechs Wochen Frist gesetzt. Wenn wir diese Frist mit Nachdruck auswerten, dann ... wird nach sechs Wochen die Situation für uns alle grundlegend besser werden. Es muß denazifiziert werden ..."92

Tatsächlich aber verpuffte die Wirkung von Clays Philippika bald. Die Presse hatte zugkräftige Schlagzeilen, in der Praxis aber blieb alles beim alten: Die Spruchkammern widmeten sich auch weiterhin vor allem der Rehabilitierung der kleinen Pgs. Als die Intelligence Division der Militärregierung Anfang Dezember 1946 eine erste Bilanz der seit dem denkwürdigen 5. November unternommenen Entnazifizierungsanstrengungen zog, mußte sie feststellen, daß sich auch an den Rahmenbedingungen der politischen Säuberung nichts geändert hatte: „... Die deutsche Öffentlichkeit ist aber auch nicht immer zur Mitarbeit bereit. Aus Angst vor späteren Vergeltungsmaßnahmen ist man sehr reserviert, wenn es gilt, als Zeuge auszusagen; außerdem sind kirchliche Würdenträger und weltliche Honoratioren im allgemeinen schnell bereit, ,Persilscheine' auszustellen. Manchmal sitzen Sympathisanten auf den Richterstühlen; manchmal versuchen die Parteien die Urteile zu beeinflussen. Einige Urteile waren viel zu milde, in verschiedenen Orten weichen die Urteile sehr voneinander ab, von Einheitlichkeit der Verfahren kann keine Rede sein und fast überall dauern die Verfahren viel zu lange. Wie man uns erneut berichtet ... wird die Arbeitsweise der Spruchkammern in etwa so bezeichnet: gleichgültig, desinteressiert, zögerlich, gemächlich, unfähig; einmal zu sehr vom Klerus beeinflußt, ein andermal zu sehr zum Vorteil der früheren Nazis." ${ }^{\text {"93 }}$

Natürlich hatte Clays Strafpredigt auch dem desolaten Zustand der Spruchkammer Ansbach-Stadt nicht aufzuhelfen vermocht. Um die Jahreswende 1946/47 war die Stelle des Vorsitzenden noch immer vakant. Im Dezember glaubte der Stadtrat zwar drei Kandidaten gefunden zu haben, aber alle drei winkten schließlich ab, so daß die

90 Clays Ausführungen vom 5. November 1946, in: AVBRD, Bd. 1, S. $1016 \mathrm{f}$.

91 Vgl. AVBRD, Bd. 1, S. 1017; Hoegner, Außenseiter, S. $236 \mathrm{f}$.

92 Besprechung des RegPräs mit den OB und LR, 11. November 1946, Prot. in: StA Nürnberg, LRA Scheinfeld, Nr. 367.

93 Wochenbericht der Intelligence Division von OMGB, 6. Dezember 1946, in: NA, RG 260, 10/85-3/2; vgl. auch Wochenbericht vom 25. Dezember 1946, in: NA, RG 260, 10/85-2/1. 
Suche von neuem beginnen mußte ${ }^{94}$. Kurz vor Weihnachten erlitt zu allem Unglück auch noch die stellvertretende Vorsitzende, Eva Reiner, einen Unfall und mußte das Bett hüten. Mitte Januar konnte sie ihre Tätigkeit wenigstens mit halber Kraft wieder aufnehmen $^{95}$. Ein Witz, der damals gerne erzählt wurde, schien sich in Ansbach zu bewahrheiten: „Hitlers 1000jähriges Reich kann rein rechnerisch so aufgeteilt werden: zwölf Jahre Hitler und 988 Jahre Entnazifizierung. ${ }^{\text {"96 }}$ Es kam aber noch schlimmer für die Ansbacher Spruchkammer. Im Februar 1947 ruhte die Arbeit fast ganz. Der erste Kläger, Julius Gäbel von der KPD, befand sich in Urlaub, und man begann zu munkeln, daß er sich wegen der Niederlage seiner Partei in der Landtagswahl vom 1. Dezember 1946 vielleicht ganz aus der Entnazifizierung zurückziehen werde. Sein Stellvertreter Josef Otta, Sozialdemokrat und 1. Vorsitzender der VVN in Ansbach, enthielt sich aus „Protest gegen die unqualifizierbaren Urteile der Berufungskammer in Ansbach ... jeder Mitarbeit ${ }^{\text {“97 }}$. Otta, der im Dritten Reich vielen Verfolgungen ausgesetzt gewesen war und als ein energischer Entnazifizierer galt, wollte mit seinem Streik auf einen in seinen Augen unhaltbaren Zustand aufmerksam machen, daß nämlich im Stadtkreis Ansbach noch keiner der größeren Nationalsozialisten vor der Spruchkammer gestanden hatte, während die wegen ihrer Milde bekannte Ansbacher Berufungskammer schon damit beschäftigt war, die in erster Instanz hart bestraften Pgs aus dem ganzen Regierungsbezirk Ober- und Mittelfranken zu rehabilitieren.

Kaum hatte man Otta zum Weitermachen überredet, schied Gäbel tatsächlich aus. Auch in vielen anderen Spruchkammern Bayerns legten um diese Zeit kommunistische Kläger und Beisitzer ihre Ämter nieder, weil sie befürchteten, ohne Fraktion im Landtag keinen Einfluß mehr auf die Entnazifizierungspolitik zu haben. „Es ergibt sich dadurch für jeden Kommunisten, der in den Apparat der Entnazifizierung unten eingespannt ist, die Gefahr", so schrieb ein Beisitzer der Spruchkammer AnsbachLand, „daß er zu Maßnahmen, die ihm von oben her aufgezwungen werden, mißbraucht wird, auf die er bzw. seine Partei jedoch von oben her keinen Einfluß, nicht einmal ein Mitspracherecht hat.“98 Dieser Standpunkt war in der KPD freilich sehr umstritten, wie sich auf einer Tagung am 19. Januar 1947 in Nürnberg gezeigt hatte. Manche der KPD angehörenden öffentlichen Ankläger hielten es für falsch, den Dienst zu quittieren. Angesichts dieser gegensätzlichen Ansichten in den eigenen Reihen gab die KPD-Landesleitung die Devise aus, so lange in den Spruchkammern zu bleiben, wie eine erträgliche Zusammenarbeit mit den anderen Parteien möglich sei99.

Wesentlich besser als um die Spruchkammer Ansbach-Stadt war es um die übrigen Spruchkammern in der Region Ansbach und Fürth bestellt. Die Kammern in Fürth funktionierten sogar relativ gut, wenn auch die Fürther Ausgabe der Nürnberger Nachrichten immer wieder mahnen mußte, doch endlich die schweren Fälle anzupak-

94 Vgl. Prot. der Sitzung des Stadtrats von Ansbach vom 6. Dezember 1946, in: Stadtverwaltung Ansbach, Registratur des $\mathrm{OB}$.

95 Vgl. OB Ansbach an MilReg, Stimmungsberichte vom 15. Januar 1947 und 24. Dezember 1946, in: Stadtverwaltung Ansbach, EAP 022-95/19.

96 Wochenbericht der Intelligence Division von OMGB, 4. Oktober 1946, in: NA, RG 260, 10/85-3/1.

$97 \mathrm{OB}$ Ansbach an MilReg, Stimmungsbericht vom 18. Februar 1947, in: Stadtverwaltung Ansbach, EAP 022-95/19.

98 Fritz Zenger, Beisitzer der Spruchkammer Ansbach-Land, an Vorsitzenden der Spruchkammer AnsbachLand, 24. März 1947, in: Amtsgericht Ansbach, Registratur S: Verwaltungsakten.

99 Vgl. Denazification Field Inspection Report, Det. Ansbach, 12. Februar 1947, in: NA, RG 260, 15/119-1/7. 
ken $^{100}$. Die Spruchkammer Ansbach-Land hatte hingegen Ende 1946 eine ihrer Stützen, den ersten Kläger, verloren; ein Ersatzmann war im August 1947 noch nicht gefunden worden ${ }^{101}$.

Daß Clays Ermahnung vom November 1946 in Bayern weitgehend folgenlos blieb, lag zum Teil auch an dem neuen Mann an der Spitze des bayerischen Sonderministeriums, dem WAV-Vorsitzenden Alfred Loritz, der seit dem 21. Dezember 1946 das Befreiungsministerium leitete. Das war bereits die dritte Besetzung dieses Postens. Der KPD-Minister Heinrich Schmitt, der von Oktober 1945 bis Juli 1946 das Sonderministerium führte, hatte sich mit seinem Konzept einer von gesellschaftlicher Umschichtung begleiteten antifaschistischen Säuberung gegen die Widerstände der Bürokratie und der Militärregierung nicht durchsetzen können. Sein Nachfolger Anton Pfeiffer von der CSU war bestrebt gewesen, die Entnazifizierung zu entpolitisieren und in die Hände von unabhängigen Juristen zu legen. Beide hatten zwar im Ministerium den Ton anzugeben vermocht, zu den Spruchkammern vor Ort waren sie jedoch nicht durchgedrungen ${ }^{102}$. Zu Zeiten von Schmitt und Pfeiffer waren die Kammern aber wenigstens mit den neuesten Richtlinien ausgestattet worden. Beide hatten auBerdem zumindest versucht, die Tätigkeit der Kammern zu überwachen. Unter Loritz wurde dagegen vieles anders. Dem eigenwilligen Minister, der bei seinem Amtsantritt verkündet hatte, daß die Nationalsozialisten nun nichts mehr zu lachen hätten, fehlte jegliche Voraussetzung für die Leitung einer so gewaltigen Unternehmung wie die Entnazifizierung. Innerhalb weniger Wochen verwandelte er alles, was bisher noch leidlich funktioniert hatte, in ein vollständiges Chaos.

Vor allem in der Ära Loritz vollzog sich der „kleinmütige Rückzug“ vom Befreiungsgesetz ${ }^{103}$. Die Weichen dafür hatte die Militärregierung schon vor dem Amtsantritt von Loritz durch den Erlaß zweier Amnestien selbst gestellt, die ein „großes Loch in das Gewebe des Befreiungsgesetzes" rissen, „durch das Berufene und Unberufene schlüpften “104. Dabei handelte es sich einmal um die am 6. August 1946 auf Drängen der Ministerpräsidenten genehmigte "Jugendamnestie“, die alle nach dem 1. Januar 1919 Geborenen von Sühnemaßnahmen befreite, sofern nicht Hauptschuldige, Belastete oder Minderbelastete davon profitierten ${ }^{105}$. Ferner hatte der Oberbefehlshaber der amerikanischen Zone, General Joseph McNarney, kurz vor dem Heiligen Abend 1946 in einer Ansprache vor dem Frankfurter Römer eine „Weihnachtsamnestie“ verkündet, die Körperbehinderte und einkommensschwache Personen von der Entnazifizierung ausnahm, vorausgesetzt sie waren vom Kläger nicht in die Gruppen I-III eingestuft worden.

Ohne daß es so-geplant gewesen wäre, konnte damit ein Riesenschritt in Richtung auf die Rehabilitierung der vielen kleinen, aber auch zahlreicher größerer Nationalsozialisten getan werden. Loritz forderte die Landräte und Oberbürgermeister Mittelund Oberfrankens am 2. März 1947 unter Hinweis auf die Absichten der Militärregierung sogar eigens dazu auf, den Anklägern und Vorsitzenden ihrer Spruchkammer

\footnotetext{
${ }^{100} \mathrm{Vgl}$. Nürnberger Nachrichten, Fürther Ausgabe, vom 12. März 1947.

${ }^{101} \mathrm{Vgl}$. Annual Hist. Rep., 11. August 1947, Det. Ansbach, in: NA, RG 260, 10/80-3/6.

${ }^{102}$ Vgl. Woller, Loritz-Partei, S. 53.

${ }^{103}$ Niethammer, Entnazifizierung, S. 436. Vgl. auch Korman, Denazification Policy, S. $113 \mathrm{f}$.

${ }^{104}$ Niethammer, Entnazifizierung, S. 440.

${ }^{105}$ Vgl. Justus Fürstenau, Entnazifizierung. Ein Kapitel deutscher Nachkriegspolitik, Neuwied 1969, S.83.
} 
mitzuteilen, daß sie es mit den Paragraphen der Weihnachtsamnestie nicht allzu genau nehmen sollten. Die Amerikaner wollten, so interpretierte Loritz die Absichten der Besatzungsmacht, „mit möglichst guten Zahlen aufwarten gegenüber den Russen, damit sie ihnen sagen können, in unserer Zone sieht es in dieser Beziehung bereits am besten aus“. Folglich solle nicht lange an „Problemen herumgedoktert" werden. "Wenn es sich um einen kleinen Bauern handelt, dann steht es fest, daß der Mann unter die Amnestie fällt. Es ist nicht lange zu entscheiden bei Fällen, wo die Grenze ein wenig überschritten wird, diese können auch noch amnestiert werden ... " Man solle ja „nicht so kleinlich (sein) bei der Bearbeitung der Weihnachtsamnestie“"106. Zugleich mit der Durchführung der Weihnachtsamnestie wollte man die immer wieder auf die lange Bank geschobene Jugendamnestie endlich abschließen, und außerdem sollten eine Arbeit, die längst fällig war - alle Nichtbetroffenen "durchgeschleust“" werden. Die ganze Blitzaktion werde Ende April 1947 abgeschlossen sein, prophezeite der optimistische Sonderminister.

Mit den bescheidenen Kräften der Spruchkammern war dieses ehrgeizige Ziel jedoch nicht zu erreichen. Im bayerischen Kabinett einigte man sich deshalb darauf, den Spruchkammern aus anderen Verwaltungszweigen kurzfristig soviel Personal wie nur irgend möglich zur Verfügung zu stellen. Die Stadtverwaltungen von Fürth und Ansbach legten vorübergehend sogar einige Dienststellen fast völlig still, um die Entnazifizierung vorantreiben zu können ${ }^{107}$. Die abgestellten Beamten, so erklärte Loritz den Oberbürgermeistern und Landräten Ober- und Mittelfrankens dieses Patentrezept, „arbeiten von 8-12 Uhr für die Aufgaben des Landrats, Amtsgerichts, Finanzamts usw. und nachmittags für die Aufgaben des öffentlichen Klägers oder Spruchkammer-Vorsitzenden ... Es ist die Aufgabe der abgestellten Beamten, die Sachen vorzubereiten, die Sache vorzukauen ... die grobe Arbeit zu leisten. 90 oder 95 Prozent der Fälle, die leicht zu bearbeiten sind, sind selbständig zu bearbeiten, so daß der öffentliche Kläger einfach unterschreiben kann. Die restlichen schwierigen Fragen, die wird er sich selbst ansehen, die müssen ihm vorgelegt werden, die leichten Fälle müssen zuerst weggearbeitet werden." ${ }^{108}$

Das großzügige Verfahren zur Durchführung der Amnestien verlegte die politische Säuberung in der Praxis auf die Schreibtische von Beamten, die darauf getrimmt waren, die einzelnen Fälle nicht lange zu prüfen, sondern gewissermaßen für die Statistik zu arbeiten. Dutzende von Fällen gingen so täglich über die Schreibtische der Kläger, die höchstens noch einen kurzen Blick in die Akten warfen. Eine politische Kontrolle dieser im Schnellverfahren gefällten Sprüche war nicht mehr möglich. Sowohl die Öffentlichkeit als auch die Parteien, die bis dahin durch die Beisitzer an der Entnazifizierung mitgewirkt hatten, waren von der Spruchkammerarbeit nun weitgehend ausgeschlossen. So war es kein Wunder, daß auch zahlreiche Unbefugte in den Genuß der Amnestien kamen. Bei vielen Pgs wäre die Belastung eigentlich zu groß gewesen, bei anderen wiederum war das Einkommen zu hoch. Und schließlich ließen sich auch

${ }^{106}$ So Loritz in der Besprechung des RegPrās mit den OB und LR, 20. März 1947, Prot. in: StA Nürnberg, Reg von Mittelfranken (1978, Zusatz), Nr. 25.

${ }^{107} \mathrm{Vgl}$. OB Fürth an RegPräs, 22. Mai 1947, in: Stadtverwaltung Fürth, EAP 4; OB Ansbach an MilReg, Stimmungsbericht vom 19. März 1947, in: Stadtverwaltung Ansbach, EAP 022-95/19.

${ }^{108}$ So Loritz in der Besprechung des RegPrās mit den OB und LR, 20. März 1947, Prot. in: StA Nürnberg, Reg von Mittelfranken (1978, Zusatz), Nr. 25. 
viele durch dubiose medizinische Atteste zu Schwerbeschädigten erklären. Ihnen allen konnte, wenn man nur die Paragraphen weit genug auslegte, die Weihnachtsamnestie gewährt werden. Besonders großzügig wurde beispielsweise der vielfache NS-Funktionär (u.a. Pg seit 1933 und stellvertretender Blockleiter, seit 1933 SA-Mitglied und Truppführer) und Strafvollzugsbeamte Michael Zaglauer aus Ansbach „entnazifiziert“. Auf ihn hätte die Weihnachtsamnestie keinesfalls Anwendung finden dürfen; allein schon seine langjährige Parteizugehörigkeit erforderte ein öffentliches Verfahren. Außerdem war Zaglauer in den Verdacht geraten, als Gefängniswärter einige Gefangene mißhandelt zu haben - womöglich also sogar ein Fall für den Staatsanwalt. Die Kammer stellte das Verfahren ein mit der Begründung, Zaglauer sei zu 40 Prozent kriegsbeschädigt. Selbst dabei verstieß die Spruchkammer noch gegen die Buchstaben der Amnestie, denn eigentlich sollte die Weihnachtsamnestie nur „Körperbeschädigte(n), die ... zu 50 und mehr Prozent als versehrt gelten“, zugute kommen ${ }^{109}$.

Dem Ankläger der Spruchkammer Fürth-Stadt gingen die dauernden Verstöße gegen Geist und Buchstaben der Weihnachtsamnestie zu weit. Er wandte sich vor allem gegen die skandalös großzügige Interpretation der Bestimmung, daß „Körperbeschädigte, die aufgrund der bestehenden Versorgungs- und Unfallfürsorgegesetze zu 50 und mehr Prozent als versehrt gelten“, unter die Amnestie fielen ${ }^{110}$. Der 50-ProzentParagraph, so teilte er der Intelligence Division mit, „erlaubt fast jedem Nazi, sich von seinem Arzt das erforderliche ärztliche Attest zu verschaffen. Die Amtsärzte, die die Atteste prüfen, nennen die 50-Prozent-Regelung und deren gängige Auslegung eine offene Hilfe für die Nazis. “"11 Das war keine Fürther Spezialität. Alle amerikanischen Detachments in den Landkreisen und Städten berichteten übereinstimmend, „daß die Anweisung von Loritz an die Spruchkammern, die Amnestien großzügig anzuwenden, zu Mißbrauch und Fehlurteilen geführt" habe ${ }^{112}$.

Wen kümmerten aber diese kritischen Bemerkungen? Was zählte war einzig, daß im Mai 1947 die Amnestien durchgeführt waren. Die Spruchkammer Ansbach-Land meldete schon in der zweiten Aprilwoche 1947, daß die Weihnachts- und Jugendamnestie abgeschlossen sei und jeder vom Befreiungsgesetz Nichtbetroffene seine „weiße Karte“113 - eine Postkarte mit der Unterschrift des Ministers - bekommen habe. Damit waren 86 Prozent aller Fälle erledigt ${ }^{114}$. Zur Behandlung waren noch geblieben: 25 der ursprünglich 39 Fälle der unter Klasse I ( = Hauptschuldige) angeklagten, 3510 Aktivisten der Gruppe II und 1563 Betroffene der Gruppen III und IV ${ }^{115}$. Die Spruchkammern in Fürth konnten auf ähnlich prachtvolle Erfolgsbilanzen verweisen. Am 14. Mai 1947 berichtete die Fürther Ausgabe der Nürnberger Nachrichten stolz: „93,4 Prozent aller Fürther entnazifiziert.“ Selbst das Sorgenkind unter den Spruchkammern der Region, die Spruchkammer Ansbach-Stadt, hatte mit Unterstützung der

${ }^{109}$ Vgl. Amtsgericht Ansbach, Registratur S: Nr. 17. Zu den Bestimmungen der Weihnachtsamnestie vgl. Schullze (wie Anm. 10).

${ }^{110} \mathrm{Vgl}$. dazu Schullze, Ausführungsvorschrift 48 (wie Anm. 10).

11 Wochenbericht der Intelligence Division von OMGB, 11. Juni 1947, in: NA, RG 260, 10/85-2/8.

112 Ebenda.

${ }^{113}$ Niethammer, Entnazifizierung, S. 452.

${ }^{114}$ Vgl. Fränkische Landeszeitung vom 12. April 1947.

115 Ebenda. 
Stadtverwaltung die Amnestie im April 1947 durchgeführt $^{116}$. Damit war der erste große Schritt, die Rehabilitierung der großen Masse der kleinen Pgs, getan. Daß auch viele stärker Belastete von den Amnestien profitierten, ging im allgemeinen Papierkrieg fast völlig unter. Das Gröbste war geschafft, das war die Hauptsache. Nun konnten sich die Spruchkammern an die Behandlung der schweren Fälle machen, obgleich die prominentesten Nationalsozialisten noch immer in den Internierungslagern saßen und wenig Hoffnung bestand, sie vor das Tribunal der Heimatspruchkammern ziehen zu können.

In Fürth erlebte die Entnazifizierung nach der Abwicklung der Amnestien tatsächlich einen Aufschwung. Die Redaktion der Fürther Ausgabe der Nürnberger Nachrichten hatte nun keinen Anlaß mehr für ihre fast schon obligatorische Klage, es würden nur die kleinen Pgs vor die Spruchkammer zitiert. Monat für Monat konnte die Zeitung nun über schwere Fälle berichten und unverhohlen Beifall spenden, wenn die Urteile angemessen hart ausfielen ${ }^{17}$. Das Interesse richtete sich dabei hauptsächlich auf Denunzianten, die in den Augen der Öffentlichkeit gar nicht hart genug bestraft werden konnten. Als im September 1947 ein Fürther Diplom-Ingenieur in die Gruppe II eingereiht, zu einem Jahr Sonderarbeit und 20-prozentigem Vermögenseinzug verurteilt wurde, schrieben die Nürnberger Nachrichten: „Hätte sich der 61jährige Dipl.-Ing. Hans Markert nicht so nazistisch aufgebläht, so wäre ihm ein schwerer Lebensabend erspart geblieben. " 118

Die Spruchkammer Ansbach-Stadt hinkte hinter dieser allgemeinen Entwicklung her: Bisher war noch gegen keinen der 69 vermutlich „Hauptschuldigen“ der Stadt ein Verfahren eröffnet worden. Von den etwa 2600 Verfahren mit angeklagten Aktivisten der Klasse II waren durch die Weihnachts- und Jugendamnestie erst etwa 600 abgeschlossen worden $^{119}$. Der designierte Nachfolger Whitakers im Amt des leitenden Militärregierungsoffiziers, Oberst Frank Yardley, nahm diese Rückstände zum Anlaß, die Vertreter der Parteien, einige Spruchkammerangehörige und Behördenvertreter zusammenzurufen und ihnen seine Unzufriedenheit zu erklären. „Es entspreche nicht dem Sinne des Gesetzes“, so berichtete die Fränkische Landeszeitung am 17. Mai 1947 über die Zusammenkunft, wenn man vielleicht erst nach zwei Jahren oder noch später, „Menschen für etwas zur Verantwortung ziehe, das heute schon mehrere Jahre zurückliegt. Es müßten Maßnahmen ergriffen werden, die eine Beendigung aller Spruchkammerarbeit spätestens in Jahresfrist gewährleisten.“

So schnelle Abhilfe, wie Yardley sie verlangt hatte, war aber nach Lage der Dinge nicht zu erwarten. In der Ära Loritz hatte sich am beklagenswerten Zustand der Ansbacher Spruchkammer nichts geändert. Die Positionen des Vorsitzenden und des ersten Klägers waren nach den durchgepeitschten Amnestien im Frühjahr 1947 noch immer vakant. Außerdem hatte der stellvertretende Kläger Josef Otta, der mit der schnellen Rehabilitierung nicht einverstanden war, durchblicken lassen, daß er Ende Juli zurücktreten werde, und schließlich hatte die stellvertretende Vorsitzende Eva

\footnotetext{
${ }^{116} \mathrm{Vgl}$. OB Ansbach an MilReg, Stimmungsberichte vom 1. und 8. April 1947, in: Stadtverwaltung Ansbach, EAP 022-95/19.

${ }_{117}$ Vgl. Nürnberger Nachrichten, Fürther Ausgabe, vom 14. Juni, 20. August und 1. Oktober 1947.

${ }^{118}$ Ebenda, 10. September 1947.

${ }^{119} \mathrm{Vgl}$. Fränkische Landeszeitung vom 17. Mai 1947.
} 
Reiner, eine tapfere und resolute Frau, die sich selbst als Antifaschistin bezeichnete und bisher die Bürden der Entnazifizierung fast allein getragen hatte, einen schweren Herzanfall erlitten und war in das Krankenhaus eingeliefert worden ${ }^{120}$. Der Weggang Ottas schien nicht weiter tragisch zu sein, denn es fand sich schnell ein Nachfolger, auf den man anfangs große Stücke hielt. Schon bald zeigte sich aber, daß der neue Mann, ein 50jähriger parteiloser Kaufmann, zu allem taugen mochte, nur nicht zum öffentlichen Kläger. „Selbst nach vier Monaten“, so schrieb die Ansbacher Militärregierung in ihrem Vierteljahresbericht vom 27. Januar 1948, „kennt er das Befreiungsgesetz noch nicht, er fertigt laufend fehlerhafte Anklageschriften an. In öffentlichen Verhandlungen verliest er lediglich die Anklageschrift, danach ist er passiv. Sein einziges Interesse besteht darin, nach Beendigung der Entnazifizierung in Ansbach einen guten Posten im öffentlichen Dienst zu ergattern. “"121

Ottas Ausscheiden im Sommer 1947 fiel mit einer größeren Úberraschung zusammen. Man hatte sich in Ansbach fast schon damit abgefunden, daß die Stelle des ersten Vorsitzenden für immer unbesetzt bleiben würde, als im Juli 1947 doch ein Vorsitzender gefunden wurde: Dr. Leopold Becker, ein 1880 in Breslau geborener Rechtsanwalt, der seit 1945 im Dienst des Bayreuther Arbeitsamtes und der Regierung von Ober- und Mittelfranken gestanden hatte. Becker, ein kleiner schmächtiger Mann, hatte sich nicht freiwillig für die Spruchkammer gemeldet, sondern war aufgrund des „Gesetzes über die Staatsbürgerliche Pflicht zur Mitarbeit an Staatsaufgaben“ verpflichtet worden ${ }^{122}$. Mit seinem Dienstantritt, Anfang Juli 1947, konnten endlich auch in Ansbach öffentliche Verfahren beginnen.

Die erste Verhandlung fand am Donnerstag, den 10. Juli 1947, statt ${ }^{123}$. Verhandlungsort war das frühere Wohnhaus des Baumeisters und Begründers des Ansbacher Markgrafenstils Karl Friedrich von Zocha, das sogenannte Zochaschlößchen in der Nähe des Bahnhofsplatzes, das im Krieg schwer beschädigt worden war. Der kleine, 1946 nur notdürftig hergerichtete Sitzungssaal war gefüllt mit Schaulustigen. Die Lokalredaktion der Fränkischen Landeszeitung hatte extra einen Reporter entsandt. Die Erwartung war groß. Die Spruchkammer hatte sich vorgenommen, gleich am ersten Tag die Fälle des Steuerbetriebsassistenten Georg Deinlein und des Kontrolleurs Ernst Mübler zu entscheiden. Deinlein, Pg seit 1935, war ein armer Schlucker, der 1945 von der Militärregierung aus seinem Posten im Finanzamt entlassen worden war. Da er außerdem seit dem Ersten Weltkrieg zu 60 Prozent schwerbeschädigt war, hätte es niemanden erstaunt, wenn er in den Genuß der Weihnachtsamnestie gekommen wäre. Im Laufe der routinemäßigen Vorermittlungen im Sommer 1946 hatte sich aber der Verdacht ergeben, daß Deinlein ein Denunziant gewesen war. Der örtliche Ausschuß des Allgemeinen Deutschen Gewerkschaftsbundes hatte nämlich auf dem Arbeitsbogen des Klägers vermerkt: „Deinlein war Nationalsozialist, man mußte sich vor ihm hüten, eine andere Meinung zu bekunden. Deinlein war seinen Mitarbeitern gegenüber nicht aufrichtig." Der aus einem Sozialdemokraten und einem Kommunisten bestehende Ermittlungsdienst, der daraufhin tätig geworden war, hatte das Urteil der Ge-

\footnotetext{
${ }^{120} \mathrm{Vgl}$. OB Ansbach an MilReg, Stimmungsbericht vom 9. Juli 1947, in: Stadtverwaltung Ansbach, EAP 022-95/19. Vgl. auch die Stimmungsberichte vom 18. Juni 1947 und 30. Juli 1947, in: Ebenda.

${ }^{121}$ Quarterly Hist. Rep., 27. Januar 1948, Det. Ansbach, in: NA, RG 260, 10/80-3/6.

122 Fränkische Landeszeitung vom 12. Juli 1947.

${ }^{123} \mathrm{Vgl}$. ebenda und Amtsgericht Ansbach, Registratur S: Nr. 10.
} 
werkschaften bekräftigt. Er war aber dabei offensichtlich politischen Vorurteilen gefolgt und hatte sich mehr auf Gerüchte als auf Tatsachen gestützt. Der öffentliche Kläger stellte den Antrag, Deinlein in die Gruppe II der Belasteten einzureihen und mit zwei Jahren Sonderarbeiten und 50-prozentigem Vermögenseinzug zu bestrafen.

Die Aufgabe der Spruchkammer war nicht leicht. In der Zeugenvernehmung tauchten erhebliche Zweifel auf, ob Deinlein tatsächlich als Denunziant anzusehen war. Hielt sich die Kammer an den Satz „in dubio pro reo“, mußte sie Deinlein als Mitläufer einstufen. Andererseits war der neue Vorsitzende offensichtlich um einen guten Einstand bemüht, und auch die Spruchkammer, in der an diesem Tag die Befürworter eines energischen Säuberungskurses überwogen, stand unter einem gewissen Erwartungsdruck der Öffentlichkeit. Würde sie nicht den ohnehin nur geringen Kredit weitgehend verspielen, wenn sie ihre Arbeit mit einem Mitläufer-Urteil eröffnete? Zwischen öffentlicher Erwartung und ungenügenden Beweisen wählte die Kammer einen Mittelweg, indem sie Deinlein in die Gruppe III der Minderbelasteten einstufte und ihn zu zwei Jahren Sonderarbeit und 20-prozentigem Vermögenseinzug verurteilte - verglichen mit späteren Urteilen in ähnlich gelagerten Fällen ein bemerkenswert hartes Urteil. Im Fall Mübler zog die Spruchkammer ebenfalls harte Saiten auf. Mübler, Pg seit 1932 und Kreiswart bei KdF, konnte neben einer Denunziation an den „Stürmer" auch nachgewiesen werden, an der Zerschlagung der Gewerkschaften aktiv beteiligt gewesen zu sein. Der Spruch der Kammer lautete: Zwei Jahre Arbeitslager und Einziehung von 30 Prozent seines Vermögens ${ }^{124}$. Becker schien auf dem richtigen Weg zu sein. Daß er die Fälle der beiden Denunzianten als erste behandelt hatte, entsprach durchaus der Erwartung der Bevölkerung.

Bereits zwei Wochen später, am Donnerstag den 24. Juli, stand endlich auch einer der großen Nationalsozialisten der Stadt vor der Spruchkammer: der ehemalige zweite Bürgermeister von Ansbach, Albert Böhm (Pg seit 1926), ein fanatischer Parteigänger und Nutznießer des Dritten Reiches, der, so die örtliche Gewerkschaft, auch an der Einweisung mehrerer Personen in das KZ Dachau mitschuldig gewesen sei. Die Teilnahme der Bevölkerung war wieder außerordentlich groß, schon lange vor Beginn der Verhandlung war der Zuschauerraum überfüllt. Die Verhandlung begann um $16 \mathrm{Uhr}$ und endete erst um 22.45 Uhr. Wieder fällte die Kammer ein Urteil, das dem Geist und den Buchstaben des Befreiungsgesetzes durchaus nahe kam. Böhm wurde in die Gruppe I der Hauptschuldigen eingereiht, für $2 \frac{1}{2}$ Jahre in ein Arbeitslager eingewiesen, außerdem sollte sein gesamtes Vermögen eingezogen werden ${ }^{125}$. Der Auftakt unter dem neuen Vorsitzenden war recht vielversprechend. Die Spruchkammer nahm sich auch in den folgenden Wochen die schwereren Fälle vor, die Urteile konnten sich durchaus sehen lassen.

Das änderte sich um die Jahreswende 1947/48 nicht nur in Ansbach, sondern überall in der amerikanischen Zone. Nachdem die Spruchkammern nach Abschluß der Amnestien eine Reihe von spektakulären Fällen behandelt hatten, mußten sie sich wieder mit Zweitrangigem befassen. Die örtliche NS-Prominenz saß bis auf wenige Ausnahmen noch immer in den Internierungslagern und wartete dort auf ihre Verfahren vor den Lagerspruchkammern. Das Interesse der Öffentlichkeit an der Arbeit der 
Spruchkammern flaute wieder ab. Mehr als zwei Jahre waren inzwischen seit dem Ende der NS-Herrschaft vergangen, immer stärker drängten nun die Sorgen der täglichen Lebensbewältigung die Erinnerung an die schlimmen Vorkommnisse im Dritten Reich in den Hintergrund. „Wenn man sie nach ihrer Meinung über die Entnazifizierung fragt, reagieren viele Deutsche böse. Die meisten meinen“, berichtete die Intelligence Division der Militärregierung schon im Juli 1947, „daß die Zeit über das Entnazifizierungsgesetz hinweggegangen ist, daß die Bevölkerung nicht mehr an Nationalsozialismus und Entnazifizierung interessiert ist und daß viele Probleme vorhanden sind, die weit wichtiger sind als der Vollzug eines unseligen Gesetzes ..."126

Das soziale Geflecht zur Abwehr der überzogenen Entnazifizierung wurde nun noch dichter als schon 1946. Symptomatisch dafür war, daß immer häufiger Belastungszeugen, die dem Ermittlungsdienst 1946/47 noch bereitwillig Auskunft gegeben hatten, später „umfielen“. Über den Gelegenheitsarbeiter Hans Raßler, Pg und SS-Mann seit 1931, hatte Amtsdirektor Christian Stecher im Sommer 1947 den Ermittlern berichtet: „Aufgrund seiner Zugehörigkeit zur SS und Partei und als persönlicher Günstling der Parteigrößen wurde er bei der Stadtverwaltung Ansbach angestellt. Ohne Prüfung wurde er Beamter und schaffte es bis zum Marktmeister.“ Ein Mitglied des Ausschusses der Parteien hatte assistiert: „Er ist ein Nutznießer, da er die Partei und SS benützte, seine persönlichen Wünsche verwirklichen zu können. Bei Aufmärschen und Kundgebungen marschierte er immer mit an der Spitze und zeigte überall den großen Mann.“ In der öffentlichen Verhandlung vor der Spruchkammer im Jahre 1948 hörten sich die Aussagen dann ganz anders an. Der Amtsdirektor gab nun zu Protokoll: Raßler ,war wohl derjenige $\mathrm{Pg}$, der sich am anständigsten verhalten hat ... Seinen Dienst hat er pünktlich versehen, war immer anständig und objektiv. Mir sind keine Klagen über ihn zu Ohren gekommen ... Die Aussage im Ermittlungsbericht stammt nicht von mir.“ Das Mitglied des Ausschusses der politischen Parteien druckste in der mündlichen Verhandlung kleinlaut herum: „... Meiner Meinung nach war er ein überzeugter Nazi. Über seine Einstellung kann ich nichts sagen ... Es ist mir nicht bekannt geworden, daß er sich werbend oder propagandistisch für die Partei eingesetzt hat. Ich habe dem Ermittler nur die allgemeine Meinung gesagt. Ich kann nicht behaupten, daß der Betr. ein Nutznießer war"127.

Der lokale Filz aus Nachbar- und Freundschaften schien jetzt eine Art von Zwang zur Rehabilitierung auszuüben. Wollte man dabei nicht mitmachen, so riskierte man, schief angesehen zu werden. Selbst Opfer des Nationalsozialismus machten sich zuweilen für Pgs stark. Der Treuhänder für ehemaliges jüdisches Eigentum im Stadtund Landkreis Ansbach, Ceslanski, schrieb über einen belasteten Bankdirektor (Pg seit 1933): „Ich habe gewußt, daß Bamm Mitglied der Partei ist, konnte aber niemals feststellen, daß er für den Hitlerkurs eine gute Meinung gehabt hätte. Sein Verhalten gegen Jedermann war immer objektiv und sein freundliches und zuvorkommendes Wesen machte auf mich nur den besten Eindruck." ${ }^{128}$ Mochte für gesellschaftliche AuBenseiter wie Ceslanski das Ausstellen eines politischen Unbedenklichkeitszeugnisses eine Möglichkeit eröffnen, aus dem Abseits wieder herauszukommen, in das sie während der NS-Zeit geraten waren, so hatten Sozialdemokraten und Gewerkschaftler auch

\footnotetext{
${ }^{126}$ Wochenbericht der Intelligence Division von OMGB, 4. Juli 1947, in: NA, RG 260, 10/85-2/11

${ }^{127}$ Amtsgericht Ansbach, Registratur S: Nr. 19.

${ }^{128}$ Ebenda: Nr. 13.
} 
andere Gründe, kleinen Parteigenossen vor der Spruchkammer zu helfen. Sie waren trotz der Verfolgung nach der Machtergreifung - ein Bestandteil der örtlichen „Gesellschaft" geblieben und den Nationalsozialisten nicht nur als politische Gegner, sondern auch als Kollegen und Nachbarn begegnet; in Notfällen - das haben viele Sozialdemokraten erfahren - konnte auf sie durchaus Verlaß $\operatorname{sein}^{129}$. Das dämpfte den Willen zur Abrechnung ebenso wie die in der SPD weitverbreitete Meinung, angesichts der allgemeinen Misere den Blick nach vorne zu richten und die alten Konflikte möglichst beiseite zu schieben.

Während aber die SPD fast verstohlen um die Gunst der kleinen Pgs warb, wurden die bürgerlichen Parteien CSU und FDP zu einem immer wichtigeren Faktor der Rehabilitierung. Einige ihrer führenden Vertreter standen als Anwälte vor den Spruchkammern gleichsam an der Spitze des Widerstandes gegen die Entnazifizierung: So der zeitweilige Vorsitzende der CSU in Ansbach, Dr. Konrad Ebert und sein Parteifreund, Dr. Hans Reichard, Bürgermeister von Leutershausen und einer der Gründungsväter der CSU im Landkreis Ansbach ${ }^{130}$; auch der profilierteste Politiker des bürgerlichen Lagers in Ansbach, Justizrat Dr. Adolf Bayer, den man sich seiner politischen Vergangenheit nach gut als Vorsitzenden oder Ankläger der Spruchkammer hätte vorstellen können, verteidigte zahlreiche kleine und größere Pgs. Bayer, ein weltläufiger, finanziell unabhängiger und kunstsinniger Mann, war als entschiedener Liberaler schon frühzeitig in Gegnerschaft zum Nationalsozialismus geraten. Während das nationalgesinnte Bürgertum seiner Heimatstadt in den zwanziger Jahren mehr und mehr zu den Nationalsozialisten umgeschwenkt war, hatte der Justizrat in vielen politischen Prozessen gegen die NS-Bewegung an vorderster Front gestanden ${ }^{131} .1946$ zum Ehrenbürger ernannt, war Bayer so etwas wie die graue Eminenz von Ansbach, und es machte natürlich großen Eindruck, wenn eine Persönlichkeit von so hohem Ansehen wie der Justizrat oder auch der örtliche CSU-Vorsitzende für die Einstufung eines Betroffenen in die Klasse der Mitläufer plädierte. Vor allem aber war das Engagement der starken Männer von CSU und FDP im Dienste der kleinen und größeren Pgs ein Zeichen für viele andere. Wenn sich diese Respektspersonen nicht zu schade waren, eine große Zahl von „Ehemaligen“ vor der Spruchkammer zu verteidigen, warum sollte dann nicht jeder $\mathrm{x}$-beliebige Ansbacher zugunsten eines Betroffenen aussagen bzw. diesem einen Persilschein ausstellen?

Das soziale Geflecht wurde aber 1947/48 nicht nur dichter, sondern schützte nun auch die größeren und prominenteren Pgs. Das zeigte sich, nachdem am 8. Oktober 1947 in der Fränkischen Landeszeitung zwischen Anzeigen über Tiermärkte und Veranstaltungshinweisen folgender Aufruf erschienen war: „Gegen den Hänel Richard, ehem. Kreisleiter, Oberbürgermeister ... findet demnächst Verhandlung vor d. Lagerspruchkammer Regensburg statt. Personen, die hierzu sachdienliche Mitteilung machen können, wollen diese umgehend beim Oeffentlichen Kläger der Spruchkammer des Lagers Regensburg, Straubinger Straße, mündlich oder schriftlich vorbringen.“ Bis

${ }^{129} \mathrm{Vgl}$. S. $176 \mathrm{f}$.

${ }^{130}$ Vgl. Annual Hist. Rep., 1. September 1946, Det. Ansbach, in: NA, RG 260, 10/80-3/6. Vgl. auch Amtsgericht Ansbach, Registratur S (vor allem die Fälle der Buchstaben B und $\mathrm{H}$ ).

${ }^{131} \mathrm{Zu}$ Bayer vgl. Fränkische Landeszeitung vom 4. Juli 1952, 11. Oktober 1962, 11. Februar 1961, 11. Februar 1956, 13. Februar 1956, 11. Februar 1976 und 2. Februar 1976 sowie Weise, Justizrat Dr. Adolf Bayer zum 75. Geburtstag, Ansbach 1951. 
zum Prozeßbeginn liefen insgesamt dreißig Schreiben bei der Regensburger Lagerspruchkammer ein: zehn Belastungsschreiben und zwanzig Persilscheine. Die Entlastungsschreiben stammten fast alle von den Angehörigen der Ansbacher Honoratiorenschaft, mit denen sich der frühere Oberbürgermeister und Kreisleiter in seiner Amtszeit arrangiert hatte. Der Dekan, der Stadtpfarrer, der Rechtsrat der Stadt, Rechtsanwälte, der Schlachthofdirektor, der frühere Direktor der Stadtwerke - sie alle waren bereit, dem früheren Stadtoberhaupt zu helfen, meldeten sich aber nicht spontan von sich aus, sondern wurden vom Rechtsanwalt bzw. der Familie Hänels um diese kleine Gefälligkeit gebeten. Eine gewisse Scheu, dem schwerbelasteten Hänel beizuspringen, bestand wohl immer noch, denn nicht wenige der honorigen Entlastungszeugen wollten sich nur schriftlich, nicht aber in einem mündlichen Verfahren vor der Spruchkammer äußern ${ }^{132}$.

Angesichts des allgemeinen Nachlassens des Säuberungswillens konnte es nicht ausbleiben, daß auch der anfängliche Elan des Spruchkammerpersonals dahinschwand. Wozu sollte man sich noch anstrengen, wenn niemand mehr an Entnazifizierung interessiert war bzw. die Berufungskammer fast automatisch die Urteile der ersten Instanz revidierte? Man machte sich höchstens unbeliebt, wenn man auf eine härtere Gangart drängte. Wer wollte schon einem Nachbarn oder Bekannten, mit dem man vielleicht noch lange Jahre Haus an Haus zu wohnen hatte, allzu weh tun? Mußte der Bäcker- oder Schuhmachermeister nicht um seinen Kundenkreis fürchten, wenn er als Beisitzer auf harten Urteilen beharrte? Die Angeklagten von heute konnten schon morgen wieder in irgendeiner Behörde einen wichtigen Posten bekleiden. Die stellvertretende Vorsitzende der Ansbacher Spruchkammer, die Frau des 1945 verstorbenen Regierungsvizepräsidenten, Eva Reiner, die erst 1945 nach Ansbach zugezogen war und deshalb auf Nachbarn und Freundschaften weniger Rücksicht zu nehmen brauchte, wußte, wie wirksam der ,soziale Filz“ die Säuberung dämpfen konnte. 1947 beklagte sich die parteilose Juristin bei der Militärregierung darüber, daß sie sich mit ihrer Meinung innerhalb der Spruchkammer häufig nicht durchsetzen könne. Sie werde von den Beisitzern, die offensichtlich dazu neigten, mit Rücksicht auf die Ansbacher Verhältnisse Milde walten zu lassen, einfach überstimmt ${ }^{133}$.

Auf der anderen Seite zeigte es sich auch in Ansbach, daß bestimmte skandalöse Vorgänge aus der NS-Zeit, die vor die Spruchkammer kamen, durchaus geeignet waren, den Willen zur politischen Säuberung wieder zu beleben. Einen solchen Fall behandelte die Spruchkammer Ansbach am 26. April 1948. Es ging dabei um eine Denunziation aus dem Jahre 1944, die dem Oberleutnant Wilhelm Gareis sieben Wochen Dunkelhaft im Gestapogefängnis Nürnberg und die anschließende Verurteilung zu zehn Jahren Zuchthaus, fünf Jahren Ehrverlust und die Degradierung zum einfachen Soldaten eingebracht hatte. Im Herbst 1944 war die üble Denunziation Stadtgespräch gewesen, fast vier Jahre später verursachte sie wieder heftige Debatten. Den Vorsitz der Verhandlung führte Dr. Becker, der, wie schon dargelegt, im Sommer/ Herbst 1947 bei einer Reihe von schweren Fällen strenge Maßstäbe angelegt hatte. Inzwischen aber war der 67jährige, der eigentlich längst reif für die Pensionierung war, zunehmend bemüht, sich der Ansbacher Stimmung anzupassen. Verschiedentlich

${ }^{132}$ Amtsgericht Ansbach, Registratur S: Nr. 1.

${ }^{133}$ Vgl. Denazification Field Inspection Report, Det. Ansbach, 12. Februar 1947, in: NA, RG 260, 15/119-1/7. 
hatte er es sogar darauf angelegt, Kläger und Belastungszeugen einzuschüchtern und die Betroffenen, wo es nur ging, zu begünstigen ${ }^{134}$.

Ein Paradebeispiel für seinen Sinneswandel lieferte er unter den Augen vieler $\mathrm{Zu}$ schauer in der Verhandlung des Denunziantenfalles. Wilhelm Wiedfeld, der Herausgeber der Fränkischen Landeszeitung, griff daraufhin persönlich zur Feder und verfaßte einen geharnischten Artikel mit dem Titel „Eine blamable Spruchkammer-Angelegenheit ${ }^{\text {“135 }}$, in dem es u.a. hieß: „Der Vorsitzende ist offensichtlich unfähig, die Verhandlung zu führen. Von Konzentration keine Spur ... Der so unbeherrschte Vorsitzende fuhr wiederholt den Öffentlichen Kläger grob an und dieser den Vorsitzenden. Die Akten klatschten und die Hände knallten auf den Tisch. Das Verhalten beider wurde immer feindseliger. Die Zuhörer lächelten, lachten, schüttelten die Köpfe. Der Spott wurde immer offensichtlicher, die Schadenfreude mancher immer offenkundiger ... Ein einarmiger Belastungszeuge, ungewandt, der Kompliziertheit des Falles und der Situation geistig nicht gewachsen, wurde derart angefahren und mit der Androhung einer zehnjährigen Zuchthausstrafe eingeschüchtert, daß dieser vollends die Sprache verlor. Frau M., die der Denunziation Beschuldigte, nannte er (d. i. Becker) voller Mitgefühl die ,arme Frau', und für diese, arme Frau' setzte er sich offensichtlich immer wieder ein. Ungezählte Suggestivfragen hatten nur das Ziel, sie zu entlasten. Der Zeuge G., den die Denunziation größtes Leid und um ein Haar den Kopf kostete, wurde von dem Vorsitzenden ohne jeden Anlaß geradezu angebrültt, so daß dieser mit Recht fragte, ob er vielleicht vor dem Tribunal stünde. Die Beisitzer der Spruchkammer mußten einmal, zweimal öffentlich von ihrem Vorsitzenden abrücken.“

Oberbürgermeister Ernst Körner, der sich mit den ungeheuerlichen Vorkommnissen ebenfalls zu befassen hatte, schrieb in seinem Stimmungsbericht vom 5. Mai 1948 an die Militärregierung, daß sich Becker soweit verstiegen habe, „den als Zeugen auftretenden ehem. Kreisleiter der NSDAP und früheren Oberbürgermeister Hänel nicht nur ständig als Oberbürgermeister, sondern in einem Fall, wie durch Zeugenaussagen bewiesen werden kann, sogar als Kreisleiter zu titulieren “ ${ }^{136}$. Die „ohnehin schon im allgemeinen umstrittene Tätigkeit der Spruchkammer" habe durch das Verhalten Bekkers, so Körner weiter, „einen weiteren ganz bedenklichen Stoß erhalten“. In der Presse wurde die Forderung erhoben: „Wir hoffen, in der auf den 10. Mai vertagten Verhandlung entweder einen gewandelten oder einen anderen Vorsitzenden zu sehen. “137

Becker sah nun wohl selbst ein, was er angerichtet hatte, und verzichtete von sich aus auf die Führung des Verfahrens. Doch damit hatte es nicht sein Bewenden. Körner bat den Staatsminister für Sonderaufgaben, Becker „sofort vom Dienste zu suspendieren, weil bei einer Fortsetzung seiner unheilvollen Tätigkeit die Gefahr besteht, daß die Ruhe und Sicherheit in der Stadt nicht unerheblich gefährdet wird“'138. Zugleich

${ }^{134}$ Vgl. dazu einen längeren Vorgang, in: Amtsgericht Ansbach, Registratur S: Nr. 1; vgl. auch August Ströhlein an Vizepräsident der Regierung von Ober- und Mittelfranken, 4. Mai 1948, in: NA, RG 260, 9/124-3/18.

135 Fränkische Landeszeitung vom 30. April 1948.

${ }^{136} \mathrm{OB}$ Ansbach an MilReg, Stimmungsbericht vom 5. Mai 1948, in: Stadtverwaltung Ansbach, EAP 022-95/19.

${ }^{137}$ Fränkische Landeszeitung vom 30. April 1948.

${ }^{138} \mathrm{OB}$ Ansbach an MilReg, Stimmungsbericht vom 5. Mai 1948, in: Stadtverwaltung Ansbach, EAP 022-95/19. 
leitete die Regierung von Mittelfranken eine Untersuchung des Falles Becker ein ${ }^{139}$. Und schließlich verfaßten die vier größeren Parteien Ansbachs und der Ortsausschuß des Bayerischen Gewerkschaftsbundes am 7. Mai 1948 ein energisches Schreiben an den Sonderminister, in dem sie hervorhoben: „Die Entnazifizierung, ohnehin zur Farce herabgewürdigt, wird durch Vorgänge, wie sie sich in der Verhandlung vor der Spruchkammer Ansbach-Stadt am 26. 4.1948 unter dem Vorsitz von Herrn Dr. Leopold Becker abspielten, völlig entwürdigt ... Wenn drei Jahre nach dem Zusammenbruch des Naziregimes der Vorsitzende einer Spruchkammer den aus dem Internierungslager Regensburg als Zeugen herbeigeholten berüchtigten ehemaligen NaziOberbürgermeister Hänel mit diesem Amtstitel anspricht, dessen Verwahrung gegen den Wortgebrauch ,nazistisch' widerspruchslos zur Kenntnis nimmt und duldet, daß dieser ehemalige Nazi-Oberbürgermeister sich in Positur setzt und arrogant erklärt: ,Ich bin kein Nazi, sondern Nationalsozialist', so hat sich ein solcher Vorsitzender damit von selbst gerichtet und unmöglich gemacht.“ Sie hielten die sofortige Abberufung Beckers für dringend erforderlich. Und weiter hieß es in dem Schreiben: „Eine Überprüfung der von Herrn Dr. Becker bisher gefällten Sprüche erscheint unbedingt geboten." 140

Angesichts einer so breiten Mißstimmung war Becker nicht mehr zu halten. Im Juni 1948 war die Stelle des Vorsitzenden der Spruchkammer Ansbach-Stadt wieder frei. Das schon begonnene Verfahren, das Becker schließlich seinen Posten kostete, wurde in der zweiten Mai-Woche unter der Leitung des Vorsitzenden der Dinkelsbühler Spruchkammer, der eigens deshalb nach Ansbach abkommandiert worden war, neu aufgerollt und am 12. Mai 1948 zu Ende geführt ${ }^{141}$. Trotz aller Empörung wollten aber nur die wenigsten ernsthaft eine neue Entnazifizierungsanstrengung unternehmen und alle in der Ära Becker gefällten Urteile überprüfen lassen. Nachdem sich die allgemeine Aufregung gelegt hatte, begann sich in allen politischen Lagern die Meinung durchzusetzen, daß man mit einer Generalrevision weitere Verzögerungen verursachen würde und schließlich auch die Glaubwürdigkeit der Spruchkammern nur noch weiter herabgesetzt hätte.

\section{c. Das letzte Stadium der Entnazifizierung 1948/49}

Durch die Amnestien der Jahre 1946/47 war zwar das Problem der Mitläufer weitgehend gelöst worden, zugleich hatten aber die Spruchkammern die Fälle der Hauptschuldigen und Belasteten weiter und weiter vor sich herschieben müssen. In ganz Bayern waren Mitte 1947 erst 14 Prozent der großen Fälle behandelt worden ${ }^{142}$. Die Länderchefs, die Clay seit 1946 zu Änderungen des Befreiungsgesetzes veranlassen wollten, verstärkten deshalb mit Unterstützung der Landtage ihre Bemühungen, den

${ }^{139} \mathrm{Vgl}$. Reg von Ober- und Mittelfranken an bay. Staatsministerium für Sonderaufgaben, 4. Mai 1948, in: NA, RG 260,9/124-3/18.

${ }^{140}$ Schreiben der Parteien und Gewerkschaften vom 7. Mai 1948, in: Amtsgericht Ansbach, Registratur S: Nr. 1.

${ }^{141}$ Die beiden Hauptdenunziantinnen wurden in die Gruppe II der Belasteten eingestuft und auf je drei Jahre in ein Arbeitslager eingewiesen. Die beiden Mitschuldigen kamen mit der Einreihung in Gruppe III und IV und geringfügigen Geldstrafen glimpflich davon. „Damit findet eine Spruchkammerverhandlung ihren Ab-

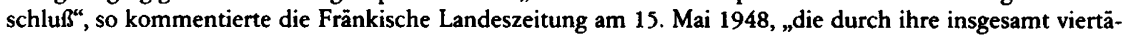
gige Verhandlungsdauer, die rege Anteilnahme der Bevölkerung, die große Zahl der Zeugen und nicht zuletzt durch den Wechsel des Vorsitzenden ohne Vorbild war.“

${ }^{142} \mathrm{Vgl}$. Niethammer, Entnazifizierung, S. 506. 
Militärgouverneur von seinem starren Festhalten am Befreiungsgesetz abzubringen und ihn für weitere Amnestien zu gewinnen. Clays Widerstand gegen eine Änderung des Gesetzes hatte sich tatsächlich abgeschwächt, seit sich nach dem Fiasko der Moskauer Außenministerkonferenz vom März/April 1947 in Washington die Tendenz durchzusetzen begann, die Westzonen als wirtschaftliche und politische Partner zu gewinnen. Die Entnazifizierung, der bisher im Zielkatalog der Militärregierung höchste Priorität zugekommen war, hatte in diesem Konzept keinen Platz mehr, sie sollte bis zum 1. April 1948 beendet sein. Das Klima hatte also umgeschlagen, und Clay konnte jetzt das Befreiungsgesetz lockern, ohne eine Entnazifizierungsdebatte in den Vereinigten Staaten zu provozieren.

Das erste Änderungsgesetz wurde nach einer Reihe von Kontroversen zwischen Deutschen und Amerikanern am 7. Oktober 1947 erlassen. Es enthielt neben einer Lockerung des Beschäftigungsverbots für Personen, die nicht unter den Klassen I und II angeklagt worden waren, vor allem eine wichtige Verfahrenserleichterung: Von nun an konnten diejenigen, die nominell unter die Gruppe der Belasteten fielen, ohne öffentliches Verfahren von den Klägern als Mitläufer eingestuft werden ${ }^{143}$. Die Befreiungsminister begrüßten diese neuen Regelungen $z w a r$, rechneten der Militärregierung aber vor, daß damit keine wesentliche Beschleunigung bei der Aburteilung der Hauptschuldigen erreicht werde ${ }^{144}$. Das Ende der Entnazifizierung sei vor Ende 1949 nicht zu erwarten. Der Druck aus Washington nahm aber nach dem Scheitern der Londoner Konferenz vom November/Dezember 1947 zu. Theo Hall, der Chef der Public Safety Division von OMGUS, sagte den Befreiungsministern Anfang 1948 offen: „Der Kongreß hat 800 Millionen Dollar in die Zone geschickt ... Der Kongreß kann diesen Ausgaben nicht zustimmen, solange noch ein Programm [Entnazifizierungsgesetz] besteht, welches diesen Haushalt [Budget der USA] noch mehr belastet ... Deshalb muß das Gesetz geändert werden, daß kein Verdacht aufkommen kann, daß hier noch eine der Gesundung der Verhältnisse entgegenstehende Maßnahme durchgeführt wird.“ Künftig sollten nach dem Willen der Amerikaner für Personen, deren Entnazifizierungsverfahren noch nicht abgeschlossen waren, in der privaten Wirtschaft und in den freien Berufen keine Beschäftigungsbeschränkungen mehr bestehen ${ }^{145}$.

Diese abrupte Kursänderung wollten die Befreiungsminister nicht mitmachen. Sie hielten es für nicht vertretbar und ungerecht, das Verfahren nun, nachdem die kleinen Parteigenossen zur Verantwortung gezogen worden waren, „mehr oder minder abzubrechen, bevor die wirklich Belasteten vor der Spruchkammer gestanden " hatten ${ }^{146}$. Der Stein, der ins Rollen gekommen war, ließ sich aber durch „einige Bedenken“147 der Befreiungsminister nicht mehr aufhalten. Am 25. März 1948 wurde ein zweites Änderungsgesetz zum Befreiungsgesetz durchgepaukt, das erneut große Löcher in die ursprüngliche Säuberungskonzeption riß. Das Beschäftigungsverbot, noch vor einem Jahr gewissermaßen die Geißel der kleinen Pgs, galt jetzt nur noch für Hauptschuldige. Den Amerikanern konnte es nun nicht schnell genug gehen. Die Spruchkammern hatten alle Mühe, dem Tempo zu folgen, das die Militärregierung anschlug. Sie

\footnotetext{
${ }^{143} \mathrm{Vgl}$. Fürstenau, Entnazifizierung, S. 91.

${ }^{144}$ Vgl. ebenda, S. 92.

${ }^{145}$ Vgl. Entnazifizierungsausschuß des Länderrats, 19. März 1948, zit. nach Niethammer, Entnazifizierung, S. 513 .

${ }^{146}$ Niethammer, Entnazifizierung, S. 513.

${ }^{147}$ Entnazifizierungsausschuß des Länderrats, 30. Januar 1948, zit. nach Niethammer, Entnazifizierung, S. 513.
} 
hatten nun immer weniger Zeit, die einzelnen Fälle gründlich zu durchleuchten. Vier Fälle pro Tag bearbeiteten die Spruchkammern im Durchschnitt. Wer konnte schon die Akten von vier Fällen bewältigen, geschweige denn, sich ein gerechtes Bild von den Angeklagten machen?

So breitete sich weiter die Neigung aus, Gnade vor Recht ergehen zu lassen. Die Vorsitzenden, Kläger und Richter waren froh, wenn wieder ein Aktenbündel vom Tisch war. Einer Reihe von mittleren und größeren Nationalsozialisten kam das zweifellos zugute, wie die folgenden zwei Beispiele aus Ansbach zeigen: Hans Bebel, Angehöriger des Freikorps „Oberland“ und Pg seit 1923, war nach den Erkenntnissen des Ermittlungsdienstes „ein begeisterter Anhänger der NSDAP“ gewesen. In seinem Arbeitsbereich „ließ er keine andere politische Meinung aufkommen ... Er war ein Idealist, der bis zum Zusammenbruch an den Endsieg glaubte. Aufgrund seiner alten Parteizugehörigkeit wurde er vom Obersekretär zum Steueroberinspektor befördert. “ Die Ansbacher Spruchkammer brachte den Fall in aller Eile zu Ende; sie ließ Zeugen nur ganz kurz befragen und schusterte dann ein Urteil zusammen, in dem es hieß: „Der Betroffene ist Mitläufer ... er hat nicht mehr als nominell am Nationalsozialismus teilgenommen ... Ein einmaliger Sonderbeitrag zu einem Wiedergutmachungsfond in Höhe von 500,- (fünfhundert) RM wird angeordnet." ${ }^{148}$ Auch Heinrich Weichmann, Pg seit 1935 und Ortsgruppenleiter seit 1939, war in den Augen des Ermittlungsdienstes ein begeisterter Nationalsozialist gewesen, der sich mit allen Kräften für den $\mathrm{Na}$ tionalsozialismus engagiert hatte. Das Urteil vom 7. Juli 1948 lautete dennoch: Mitläufer und 100,- DM Sühnebeitrag ${ }^{149}$.

Der Wille zur Entnazifizierung war allerdings noch nicht ganz erloschen. Während die Militärregierung ihre alten Vorsätze völlig umstieß, war in der deutschen Bevölkerung anscheinend doch noch etwas vom Geist der gerechten Säuberung lebendig. Wenigstens die wirklich prominenten Pgs sollten, so dachten wohl die meisten, ihrer gerechten Strafe nicht entgehen. Man empörte sich beispielsweise darüber, daß die Fälle der ehemaligen „NS-Diktatoren“, der „Nazis mit Leib und Seele“ und der „typischen Schergen der Hitler-Diktatur“ vor den Lagerspruchkammern behandelt werden sollten, die in dem Ruf standen, keine allzu strengen Maßstäbe anzulegen. Der Ansbacher Landrat Neff ließ diese Empörung deutlich anklingen, als er sich im Januar 1948 mit folgendem Schreiben an das bayerische Staatsministerium für Sonderaufgaben wandte: „Schon wiederholt habe ich mich bei den zuständigen Stellen dafür eingesetzt, daß der ehemalige Ortsgruppenleiter und Kreisbauernführer Friedrich Strobel aus Flachslanden, der schon seit längerer Zeit im Lager Langwasser untergebracht ist, nicht vor der dortigen Lagerspruchkammer, sondern vor der zuständigen Spruchkammer Ansbach-Land zur Aburteilung kommt. Nun erfahre ich, daß trotz dieser wiederholten Anträge doch eine Aburteilung durch die Lagerspruchkammer in Aussicht genommen sei und daß die Hauptverhandlung unmittelbar bevorstehe. Daraufhin hat sich gestern der Kreisausschuß des Landkreises Ansbach mit der Angelegenheit befaßt. Der Kreisausschuß fordert einstimmig, daß dem Sinne des Säuberungsgesetzes entsprechend der Betroffene Strobel dort zur Aburteilung kommt, wo er als mehrfacher Amtswalter viele Jahre hindurch sich im besonderen Maße aktivistisch betätigt 
hat, nämlich vor der Spruchkammer Ansbach-Land. Indem ich von diesem Beschluß Kenntnis gebe, darf ich noch hinzufügen, daß es von der Bevölkerung des Landkreises, bei der Strobel als führender Nationalsozialist des Landkreises allgemein bekannt ist, in keiner Weise verstanden würde, wenn dieser Mann seinem zuständigen Richter entzogen und womöglich eine Einstufung erfahren würde, die seinem hiesigen Wirken nicht gerecht würde. Wie dieser Mann einzustufen ist, kann nur hier an Ort und Stelle beurteilt werden. ${ }^{\text {"150 }}$

Neff hatte nicht nur im Fall Strobel Erfolg mit seiner Initiative, und so konnten immerhin einige der prominenten Pgs an der Stätte ihres Wirkens vor die Spruchkammer zitiert werden. Die Heimatspruchkammern gaben dann auch kein Pardon. Strobel bekam es vor der Spruchkammer Ansbach-Land deutlich zu spüren, daß seine „große Zeit“ als Ortsgruppenleiter von Flachslanden noch nicht vergessen war. Als die Spruchkammer am 27. Juli 1948 das Verfahren gegen ihn eröffnete, fanden sich noch genügend Belastungszeugen. Einige waren zwar durchaus geneigt, Strobels Untaten nun in etwas milderem Licht zu sehen. Die Kammer wußte aber nur zu gut, daß sich „infolge Zeitablauf und Einflußnahme auf Zeugen“ allgemein die Tendenz bemerkbar machte, die „Schuld des Betroffenen zu bagatellisieren“. Sie ließ sich davon nicht beirren und hielt es für erwiesen, daß Strobel im Landkreis Ansbach als der „schlimmste Vertreter der nationalsozialistischen Gewaltherrschaft allgemein bekannt und gefürchtet" gewesen war. Entsprechend hart fiel das Urteil aus, das der Vorsitzende Dr. Voretzsch nach einer ganztägigen Verhandlung gegen 20.00 Uhr verlas: „Der Betroffene ist Belasteter (Gruppe II) ... Der Betroffene wird auf die Dauer von 5 Jahren in ein Arbeitslager eingewiesen, um Wiedergutmachungs- und Aufbauarbeiten zu verrichten ... Sein Vermögen ist als Beitrag zur Wiedergutmachung ganz einzuziehen. Es ist nur der Betrag zu belassen, der unter Berücksichtigung der Familienverhältnisse und der Erwerbsfähigkeit zum notdürftigsten Lebensunterhalt erforderlich ist." ${ }^{151}$

Die in ganz Nordbayern wegen ihrer Schärfe bekannte Spruchkammer AnsbachLand schoß in ihrem Säuberungseifer bisweilen auch etwas übers Ziel hinaus, wie aus folgendem Fall ${ }^{152}$ ersichtlich ist: Der ehemalige Ortsgruppenleiter des östlich von Ansbach gelegenen 1500 Seelen-Dorfes Eyb wurde im Sommer 1947 nach mehr als zweijähriger Haft aus dem Internierungslager Moosburg entlassen und fiel damit in den Zuständigkeitsbereich der Ansbacher Spruchkammer, die mit ihren Ermittlungen denn auch sofort begann. Allzu große Mühe wollte man sich offenbar nicht machen: Johann Stich, Pg seit 1931 und Mitglied der SS seit 1932, galt als einer der aggressivsten Nationalsozialisten im Landkreis. Der Fall war klar, wozu sollte man also noch langwierige Ermittlungen anstellen? Die Aussagen der wenigen Belastungszeugen, die sich beim Ermittlungsdienst gemeldet hatten, waren eindeutig. „Stich ist als Ortsgruppenleiter mit aller Schärfe vorgegangen“, sagte etwa der Bürgermeister von Brodswinden. Ein früherer Kollege von Stich erwähnte: „Ich bin von Stich nach allen Regeln der Kunst schikaniert worden.“ Ein anderer Zeuge erzählte dem Ermittlungsdienst, Stich habe immer gegen die Pfarrer „losgezogen“. Einmal habe er den Ausdruck ge-

${ }^{150}$ LR Ansbach an bay. Staatsministerium für Sonderaufgaben, 31. Januar 1948, in: Amtsgericht Ansbach, Registratur S: Nr. 16.

${ }^{151}$ Ebenda.

152 Ebenda: Nr. 21 
braucht: „Die Kirche gehört weg, da ist ein schöner freier Platz, da gehört ein Theater hingebaut."

Am Morgen des 16. Januar 1948 stand Stich vor der Spruchkammer. Den Vorsitz führte wie immer der energische Botschafter a. D. Ernst-Arthur Voretzsch (CSU), zwei Sozialdemokraten und zwei CSU-Mitglieder assistierten ihm als Beisitzer. Die Anklage vertrat Leo Sessler, ein Vertreter der Linksparteien, der eine Klageschrift angefertigt hatte, in der es hieß: „Der Betroffene ist Hauptschuldiger, und ihn hat die ganze Härte des Gesetzes zu treffen ... Er ist auf die Dauer von 8 Jahren in ein Arbeitslager einzuweisen." Ein hartes Urteil war zu erwarten, dies umso mehr, als Stich, anders als der frühere Kreisleiter und Oberbürgermeister von Ansbach, Richard Hänel, zu dessen Gunsten fast die halbe Ansbacher Honoratiorenschaft ausgesagt hatte, kaum jemanden auf seiner Seite hatte. Stich, politisch naiv und alles andere als wortgewandt, war gelernter Bauschlosser, der sich im Laufe der Jahre zum Werkmeister hochgedient hatte. Im Dritten Reich war er aufgrund seiner Zugehörigkeit zur NSDAP zum hauptamtlichen Kreisleiter und Kreisobmann der DAF aufgestiegen. Für die Kollegen noch immer der unbeliebte Vorarbeiter und Antreiber, der offenbar häufig zur lautstarken Demonstration seiner Macht geneigt hatte, in den Augen der Honoratioren der kleine Bauschlosser, saß Stich damit zwischen allen Stühlen. Sieben Zeugen (unter ihnen nur ein Entlastungszeuge) waren erschienen - ein Spruchkammerverfahren auf Sparflamme. Das kam auch darin zum Ausdruck, daß nur vier Stunden verhandelt wurde, ehe Voretzsch das Urteil verkündete: „Der Betroffene ist Hauptschuldiger ... Er wird auf die Dauer von 5 Jahren in ein Arbeitslager eingewiesen." Am nächsten Tag wurde Stich wieder in das Lager Moosburg eingeliefert.

Das Verfahren gegen Stich war ein Beispiel für ein politisches Tribunal gegen einen Exponenten des NS-Regimes im Landkreis. Für die Spruchkammer stand das Urteil gewissermaßen schon vor der Verhandlung fest. Die Urteilsbegründung war nur gut eine Seite lang und bestand überwiegend aus Zitaten aus der Anklageschrift. U.a. hieß es: „Er hat als Kreisredner eine starke politische Tätigkeit entfaltet und unter seinen Arbeitsgenossen den Einpeitscher für die Partei abgegeben und durch Zwang und Drohung und ungerechte Maßnahmen, durch seine Beteiligung an der Zerschlagung von Genossen- und Gewerkschaften sich als ein vorbildlicher Vertreter der nationalsozialistischen Gewaltherrschaft und ihrer Methoden erwiesen ... Es kann nicht dem geringsten Zweifel unterliegen, daß die Tätigkeit des Betroffenen für die nationalsozialistische Gewaltherrschaft eine ungewöhnliche, dazu auf Überzeugung gestützte, energische und begeisterte und damit eine außerordentliche gewesen ist ... Geschlossen und gefertigt ...“ Entlastende Aussagen, die im Rahmen der Ermittlungen aufgetaucht waren, wurden nicht weiter berücksichtigt, obwohl sich in einer ganzen Reihe von Zeugenaussagen Hinweise darauf gefunden hatten, daß Stich zwar ein Rabauke und Schreier, aber doch kein Hauptschuldiger war. Das Urteil konnte wohl nur deshalb so hart ausfallen, weil Stich durch die Maschen des sozialen Protektionsnetzes fiel, die bei gesellschaftlich angeseheneren Pgs enger waren als bei dem ehemaligen Bauschlosser.

Während in der ersten Instanz selbst 1948 noch ein ausgeprägter Säuberungswille zum Ausdruck kommen konnte, setzte die Berufungskammer ihren schon 1946/47 eingeschlagenen Rehabilitierungskurs fort. Noch mehr als das schon 1946/47 deutlich geworden war, trat nun eine schroffe Kluft zwischen der ersten und zweiten Instanz in 
der Auslegung des Befreiungsgesetzes auf. Das zeigte sich auch im Fall von Richard Hänel $^{153}$, der sich vom 15. bis 17. September 1948 in erster Instanz vor der Lagerspruchkammer Regensburg und neun Monate später in zweiter Instanz vor der Berufungskammer ins Ansbach verantworten mußte. Hänel, 1895 in Ansbach geboren, im deutschnationalen Milieu groß geworden und Freiwilliger im Ersten Weltkrieg, hatte sich bereits Anfang der zwanziger Jahre zur NSDAP hingezogen gefühlt. Er war stolz darauf - und ließ später keine Gelegenheit aus, es zu betonen -, daß er 1923 die Ortsgruppe der NSDAP als Schriftführer mitgegründet hatte. Laut, vital und außerordentlich aktiv, war er bei vielen kleinen und politisch unbequemen Leuten als Diktator und Großtuer gefürchtet gewesen, mit der Honoratiorenschaft und den leitenden Herren der Stadtverwaltung hatte sich der kleine Angestellte dagegen selten angelegt. Der Ermittler bezeichnete Hänel „als 100prozentigen und äußerst fanatischen Nazi seit 1923 ... darüber hinaus will er ja auch noch heute Nationalsozialist sein ...“

Das Urteil vom 17. September 1948 lautete: Hauptschuldiger. Hänel „wird auf die Dauer von 4 Jahren und 6 Monaten in ein Arbeitslager eingewiesen ... Sein Vermögen ist als Beitrag zur Wiedergutmachung einzuziehen ... Er verliert seine Rechtsansprüche auf eine aus öffentlichen Mitteln zahlbare Pension oder Rente.“ In der knappen Urteilsbegründung wurde deutlich, daß die Spruchkammer das Verfahren gegen Hänel in erster Linie als ein politisches Verfahren ansah. Ihr ging es nicht so sehr darum, die Beteiligung Hänels an einzelnen Denunziationen und sonstigen Missetaten zu beweisen, als vielmehr darum, die politische Verantwortung des ehemaligen Kreisleiters und Oberbürgermeisters festzuhalten. Entlastende Momente, wie etwa der durchaus korrekte Umgang mit seinen Untergebenen im Ansbacher Rathaus, blieben weitgehend außer Betracht. U.a. hieß es in der Urteilsbegründung: „Der Betr. hat als Kreisleiter, Oberbürgermeister und gleichzeitig als Polizeichef der Stadt Ansbach die unumschränkte Macht in seinen Händen gehabt. Sowohl die Aktenlage als auch das Geständnis des Betr. beweisen, daß er sich als überzeugter Anhänger der nat. soz. Gewaltherrschaft betätigt hat. Auf seinen Befehl hin wurde in der Nacht vom 9. zum 10. November 1938 die Synagoge von Ansbach in Brand gesteckt, auf seinen Befehl mußte die SA sämtliche Juden dieser Stadt verhaften, auf seinen Befehl hin wurden die Wohnungseinrichtungen der Juden durch die SA beschädigt. Als weitere Folge dieser Maßnahmen veranlaßte er die Ausweisung der Juden aus seinem Kreis terminmäßig bis zum Dezember 1938 und als Folge davon auch gleichzeitig die Arisierung jüdischen Besitzes ... Wenn auch nicht erwiesen ist, daß der Betr. sich direkt als Denunziant betätigt hat, so steht jedoch andererseits fest, daß er durch die Weiterleitung der Anzeigen an die Gestapo zur Verfolgung von Gegnern der NSDAP beigetragen hat und sich damit als überzeugter Anhänger der n. s. Gewaltherrschaft erwiesen hat.... Zusammenfassend wird festgestellt: Der Betr. hat durch seine Stellung und Tätigkeit als Kreisleiter und Oberbürgermeister die Gewaltherrschaft der NSDAP wesentlich gefördert, hat seine Stellung als Kreisleiter zu Drohungen ausgenützt und sich als überzeugter Anhänger der nationalsozialistischen Gewaltherrschaft, insbesondere auch ihrer Rassenlehre erwiesen ... Er ist im Dienste des Nationalsozialismus hetzerisch und gewalttätig gegen Kirchen und Religionsgemeinschaften aufgetreten, hat sich aktiv bei der Zerschlagung der Gewerkschaften beteiligt und wurde nur aufgrund seiner

${ }^{153}$ Ebenda: Nr. 1. 
Zugehörigkeit zur NSDAP in das Amt eines Oberbürgermeisters berufen. Er ist verantwortlich für Ausschreitungen, hat sich in einer führenden Stellung der NSDAP und einer ihrer Gliederungen betätigt und hat auch sonst der nationalsozialistischen Gewaltherrschaft eine außerordentliche Unterstützung gewährt.“

In der Berufungsverhandlung vom 1. bis 3. Juni 1949 war von einem politischen Tribunal nichts mehr zu spüren. Die Berufung ähnelte einem gewöhnlichen Gerichtsverfahren. Vor allem aber änderte sich die Art der Urteilsbegründung grundlegend. Die Berufungskammer bestätigte zwar viele Einschätzungen der ersten Instanz ausdrücklich, so etwa, daß Hänel der nationalsozialistischen Gewaltherrschaft außerordentliche politische und propagandistische Unterstützung gewährt, sich als überzeugter Anhänger der Gewaltherrschaft erwiesen und seine Stellung zu Drohung und Druck ausgenützt habe oder daß er an der Zerschlagung der Gewerkschaften aktiv beteiligt gewesen war. In wesentlichen Punkten wich die Berufungskammer aber von der Begründung der ersten Instanz beträchtlich ab. Insbesondere hob sie mehrmals hervor, daß Hänel nur ein schwaches Glied in einer Kette gewesen sei, so daß man ihm kaum etwas vorwerfen könne. „Die Feststellung der Erstkammer“, so ist in der Begründung zu lesen, „der Betr. habe sich in einer, führenden Stellung der NSDAP betätigt und sei auch deshalb Hauptschuldiger, ist rechtsirrig ... " Die Berufungskammer konnte auch in der Beteiligung Hänels an Denunziationen bzw. der Weiterleitung von Denunziationen keine Belastungen sehen. Hier, wie auch bei der Zerschlagung der Gewerkschaften, habe der Betroffene nur im Rahmen seiner Dienstpflicht bzw. auf Befehl gehandelt. Und schließlich sei auch die Beurteilung des Betroffenen als Nutznießer („Nutznießer ist ... wer nur aufgrund seiner Zugehörigkeit zur NSDAP in ein Amt berufen ... wurde“) zu Unrecht erfolgt. „Die Posten eines Oberbürgermeisters wie der eines Landrats sind sowohl im Weimarer Staat, wie im sog. 3. Reich politische Posten gewesen, wie sie dies auch heute in der jungen deutschen Demokratie wiederum sind, d.h. diese Posten waren und werden überwiegend unter politischen Gesichtspunkten besetzt. Es wäre unverständlich und ungerechtfertigt, wollte man heute ... etwas als politische Belastung ansprechen, was gleichzeitig im politischen Leben der Jetztzeit tagtäglich geübt wird.“

War mit dieser streckenweise sehr eigentümlichen Argumentation das Urteil der ersten Instanz schon stark erschüttert, so mußte es vollends ins Wanken geraten, als die Berufungskammer, anders als die Lagerspruchkammer, die Persilscheine für Hänel als sachdienlich und durchaus glaubhaft bezeichnete. Der Betroffene vermochte zu beweisen, so die Urteilsbegründung, „daß er, sei es als Kreisleiter der NSDAP, sei es als Oberbürgermeister der Stadt Ansbach, menschlich gehandelt hat, sich bemühte objektiv zu sein, in seiner Haltung großzügig war und für seine Person manches, eingesteckt hat, was andere Kreisleiter sicher zum Einschreiten veranlaßt hätte, seine Beamten und Angestellten keinem Druck aussetzte ... Darüberhinaus hat sich der Betr. nachweislich sogar für Leute, die aus polit. Gründen straffällig geworden waren, eingesetzt und seinen Einfluß aufgeboten, um diese vor Bestrafung zu bewahren." Seine Einreihung in die Gruppe I der Hauptschuldigen stehe in keinem Verhältnis zu seiner „tatsächlichen Gesamthaltung“. Seine „Gesamthaltung aber, die so viele ansprechende und menschliche Züge aufzuweisen hat, berechtigt ... zu einer Milderung hinsichtlich der Einreihung “. Hänel wurde somit Belasteter (Klasse II). Er verlor zwar alle Rechtsansprüche auf „eine aus öffentlichen Mitteln zahlbare Pension oder Rente“, das Wahl- 
recht und das Recht, sich ,irgendwie politisch zu betätigen“. Aber er mußte nicht wieder in das Internierungslager zurück, denn auf die zwei Jahre Arbeitslager, zu denen ihn die Berufungskammer verurteilte, wurde die seit dem 19. Mai 1945 erlittene politische Haft voll angerechnet ${ }^{154}$.

Die Praxis der Berufungskammer, das Befreiungsgesetz wie ein gewöhnliches Strafgesetz auszulegen, konnte, wie am Beispiel Hänels gezeigt, für schwerbelastete Nationalsozialisten durchaus von Vorteil sein. Darauf war wohl auch die vielleicht etwas überspitzte Bemerkung des Ansbacher Oberbürgermeisters Körner gemünzt, der Ende 1948 an die Militärregierung schrieb: „Eine rasche Beendigung (der Entnazifizierung) muß als dringend geboten erachtet werden, da die Spruchkammern in der Meinung der Bevölkerung zutiefst gesunken sind. Zurückzuführen ist dies in erster Linie darauf, daß hauptsächlich in der Berufungsinstanz die Tätigkeit ... scheinbar ausschließlich darauf ausgerichtet war, selbst die schwerstbelasteten Nazis reinzuwaschen und zu mindestens zu harmlosen Mitläufern zu machen." ${ }^{155}$

Das war es aber nicht allein. Die Berufungskammern wurden auch zum Ärgernis wegen ihrer skandalösen Behandlung von minimalbelasteten Pgs, die sich mit dem Mitläufer-Etikett nicht abfinden wollten. Nicht wenige dieser „Karteigenossen“ sahen es als Beleidigung an, mit zahlreichen, ebenfalls zu Mitläufern gestempelten „Alten Kämpfern“, Multi-Funktionären, Nutznießern und Denunzianten, die in den Dörfern und Städten das NS-Regime repräsentiert hatten, auf eine Stufe gestellt zu werden. Sie gingen deshalb in die Berufung mit dem Ziel, als Entlastete eingestuft zu werden. Während aber die Berufungskammern Belastete und Minderbelastete sehr großzügig behandelten und fast automatisch um eine oder zwei Klassen zurückstuften, hatten sie für die Anliegen der Mitläufer wenig Verständnis. Sie hielten sich genauestens an die Bestimmungen des Befreiungsgesetzes und legten Art. 13 („Entlastet ist: wer trotz seiner formellen Mitgliedschaft oder Anwartschaft ... sich nicht nur passiv verhalten, sondern nach dem Maß seiner Kräfte aktiv Widerstand gegen die nationalsozialistische Herrschaft geleistet und dadurch Nachteile erlitten hat") so restriktiv wie nur möglich aus.

Der frühere Sozialdemokrat und Gewerkschafter Rudolf Beil ${ }^{156}$ beispielsweise mußte von Pontius zu Pilatus laufen, ehe er von der Berufungskammer im Juni 1949 als Nichtbetroffener eingestuft wurde. Eigentlich hätte er schon 1946 darüber informiert werden können, daß er vom Befreiungsgesetz nicht betroffen sei, denn die einzige braune Stelle in seinem ansonsten weißen Fragebogen bezog sich auf seine SAMitgliedschaft vom November 1933 bis Dezember 1934, die, so Beil, auf Druck seiner Vorgesetzten zustandegekommen war. Daß er sich darüber hinaus nicht engagiert hatte, war ihm während der NS-Zeit häufig als "Lauheit" angekreidet worden und auch der Grund gewesen, daß Beil nicht befördert wurde, obwohl er längst an der Reihe gewesen wäre. Aus dem Kreise seiner Kollegen wurde ihm bescheinigt, daß er „stets ein großer Gegner der Nazi“ gewesen war. Einer versicherte eidesstattlich, Beil sei öfter mit der Gestapo „zusammengerückt“, weil er sich für einige russische Fremdarbeiter eingesetzt hatte, die bei der Reichsbahn beschäftigt gewesen waren.

Die Spruchkammer Ansbach wollte sich mit dem Fall nicht lange aufhalten und ${ }^{154}$ Ebenda.

${ }^{155}$ OB Ansbach an MilReg, Stimmungsbericht vom 9. Dezember 1948, in: Stadtverwaltung Ansbach, EAP $022-95 / 19$.

${ }^{156}$ Vgl. Amtsgericht Ansbach, Registratur S: Nr. 22. 
stufte Beil im Dezember 1947 in die Gruppe der Mitläufer ein und belegte ihn mit 300,- RM Geldsühne. Diese starre Auslegung des Befreiungsgesetzes erregte Beil sehr. Er wollte es nicht auf sich sitzen lassen, Mitläufer zu sein, „genauso wie die vielen anderen, die bis zuletzt bei der Partei oder ihren Gliederungen oder bei beiden waren und es auch heute noch wären, wenn der Krieg nicht verloren wäre“. Er beantragte deshalb Berufung: „Dafür, daß ich so standhaft blieb und zu Nazis Zeiten wegen meiner nichtnationalsozialistischen Haltung nicht befördert wurde, und dafür, daß ich als bekannter Nichtnazi an den gefährdetsten Punkten eingesetzt wurde, während die Herren Parteigenossen daheim auf sicheren Posten saßen oder wenn es hoch kam im sog. Generalgouvernement sich ein angenehmes Leben machten, und dafür, daß ich so viele Demütigungen erdulden mußte, soll ich mich heute als Mitläufer einstufen lassen. Das spricht nicht nur jeder Gerechtigkeit Hohn, sondern trägt auch sehr viel zur Genugtuung der wirklichen Nazis bei, die sich ins Fäustchen lachen ... Ich empfinde es empörend, daß man mich, der ich stets meine aufrechte, freiheitliche und demokratische Gesinnung bewahrte und noch keine Minute mit den Nazis sympathisierte, mit alten Nazis und mit alten Kämpfern, die ja auch zum Teil als Mitläufer herauskamen, auf die gleiche Stufe stellt." Sein Ziel, als Entlasteter eingestuft zu werden, erreichte er auch vor der Berufungskammer, die sich im Juni 1949 mit seinem Fall beschäftigte, nicht. Letztlich mußte sich Beil damit zufriedengeben, Nichtbetroffener zu sein.

Solche Fälle sorgten natürlich für Gesprächsstoff und trugen dazu bei, daß die Autorität der Spruchkammern schließlich ganz verfiel. Ansbachs Oberbürgermeister Körner stand mit seiner Meinung sicherlich nicht allein, als er 1949 an die Militärregierung berichtete: „... Heute muß festgestellt werden, daß die verheerende Tätigkeit der Spruchkammer eines der größten Hemmnisse in der demokratischen Entwicklung Bayerns überhaupt darstellt. “157

Während man in der Öffentlichkeit über Sinn und Unsinn der Entnazifizierung debattierte, war das Personal der Spruchkammern von ganz anderen Sorgen geplagt. Den Vorsitzenden und Klägern war bei ihrem Dienstantritt mehrfach vor Augen gehalten worden, wie wichtig ihre Tätigkeit im Dienste einer politischen Erneuerung sei. Zugleich war ihnen zugesichert worden, daß nach Beendigung der Entnazifizierung selbstverständlich in angemessener Weise für sie gesorgt würde. Dies waren aber nur schöne Worte gewesen. Die meisten Spruchkammerangehörigen mußten schon nach kurzer Zeit erfahren, daß die Mitarbeit an einer erstrangigen staatspolitischen Aufgabe wie der Entnazifizierung keine Lorbeeren einbrachte. Im Gegenteil, die meisten waren in den Städten und Dörfern isoliert, zuweilen einem "regelrechten sozialen Boykott“ ausgesetzt ${ }^{158}$. Kaum jemand verstand, wie man sich für so eine Tätigkeit „hergeben“ konnte. Einige Spruchkammerangehörige bangten sogar um ihr Leben. Sie fürchteten, das Beispiel von Nürnberg, wo Anfang 1947 eine Reihe von Attentaten auf die dortige Spruchkammer verübt worden war, könne Schule machen. In Ansbach war die Stimmung zeitweise so aufgeheizt, daß Oberbürgermeister Körner einen Polizeibeamten vor dem Sitz der Spruchkammer postieren mußte ${ }^{159}$. Auch Voretzsch, der beherzte

${ }^{157}$ OB Ansbach an MilReg, Stimmungsbericht vom 5. März 1949, in: Stadtverwaltung Ansbach, EAP 022-95/19.

${ }^{158}$ Dirks, Folgen der Entnazifizierung, S. 461.

${ }^{159} \mathrm{Vgl}$. OB Ansbach an MilReg, Stimmungsbericht vom 12. Februar 1947, in: Stadtverwaltung Ansbach, EAP 022-95/19. 
Vorsitzende der Spruchkammer Ansbach-Land, fühlte sich zeitweilig bedroht; eines Tages waren nämlich - als Zeichen des dörflichen Protestes gegen seine Mitwirkung in der Spruchkammer - seine Hühner abgeschlachtet, die Hühnerköpfe am Gartenzaun aufgespießt worden ${ }^{160}$. Das Personal der Spruchkammern wurde deshalb immer unzufriedener. Vor allem wollte es endlich Sicherheit über seine berufliche Zukunft haben. Die stellvertretende Vorsitzende der Spruchkammer Ansbach-Stadt, Eva Reiner, schrieb am 12. November 1947 an den Präsidenten der Berufungskammer: „Die Stimmung und damit die Arbeitsfreudigkeit der in der Entnazifizierung für AnsbachStadt tätigen Personen wird wesentlich gesteigert, wenn der betroffene Personenkreis eine feste und verbindliche Zusage für eine spätere Weiterführung im öffentlichen Dienst erhält.“"161

Die Befreiungsminister der amerikanischen Zone kannten die gedrückte Stimmung in den Spruchkammern. Aus Sorge, das Personal der Spruchkammern könne einfach auseinanderlaufen, drängten sie schon seit längerem auf eine rasche gesetzliche Regelung der Versorgungsansprüche. Aber erst am 27. März 1948 wurde in Bayern das „Gesetz zur Überführung der bei der politischen Befreiung tätigen Personen in andere Beschäftigungen“" verabschiedet, das den Angehörigen der Spruchkammern die Übernahme in den öffentlichen Dienst in Aussicht stellte bzw. ihnen einen Rechtsanspruch auf die Hilfe des Staates bei der Suche nach einem Arbeitsplatz in der freien Wirtschaft einräumte ${ }^{162}$.

Als dann im Sommer 1948 die meisten Kammern ihre Arbeit getan hatten und das Spruchkammerpersonal auf seine Rechte pochte, erlebte es eine herbe Enttäuschung. Die Amtschefs in den Städten und Landkreisen zeigten nur wenig Neigung, die größtenteils ungeschulten Kräfte in ihren Behörden aufzunehmen. Die Entnazifizierung sei eine Aufgabe des Staates gewesen, so betonten sie, dieser, nicht die Städte und Kommunen, sei nun in erster Linie verpflichtet, „diese Leute jetzt einzubauen“163. Die Entnazifizierten waren ihnen allemal lieber als die Entnazifizierer ${ }^{164}$. Außerdem waren nach der Währungsreform vom 20. Juni 1948 die Kassen leer. Eine Reihe von Ämtern mußte sogar Stammpersonal entlassen. Regierungspräsident Schregle berichtete am 11. Januar 1949 an die bayerische Staatsregierung nach München: „... seitdem die Spruchkammern ihre Tätigkeit größtenteils eingestellt haben, (vergeht) kein Tag, an dem nicht früher bei der Spruchkammer Beschäftigte bei der Regierung um Übernahme in den Verwaltungsdienst nachsuchen. Sie führen Klage darüber, daß sie nach ihrer mehrjährigen Tätigkeit im Dienste der Entnazifizierung ,stempeln gehen “ müssen oder auf die Fürsorge angewiesen sind. Ferner weisen sie darauf hin, daß die Stellen in der öffentlichen Verwaltung zwischenzeitig mit den von ihnen entnazifizierten Personen besetzt sind. Hiergegen muß den Stellenbewerbern in Erinnerung gebracht werden, daß aufgrund der Tatsache, daß keine Stellen frei sind und der Abbau des vorhandenen Personals um 20 Prozent angeordnet ist, eine Einstellung unmöglich ist ..."165

\footnotetext{
${ }^{160}$ Mündliche Mitteilungen von Dr. Ludwig Schönecker und Wilhelm Eichhorn vom 17. August 1983.

${ }^{161}$ Eva Reiner, stellv. Vors. der Spruchkammer Ansbach-Stadt, an Präsidenten der Berufungskammer, 12. November 1947, in: Amtsgericht Ansbach, Registratur S: Verwaltungsakten.

162 Vgl. BGVB1. 8/1948.

${ }^{163}$ So OB Ansbach in der Besprechung des RegPräs mit den OB und LR, 7. März 1949, Prot. in: StA Nürnberg, LRA Scheinfeld, Nr. 367.

${ }^{164} \mathrm{Vgl}$. Niethammer, Entnazifizierung, S. 534.

${ }^{165}$ RegPrãs an bay. Staatsregierung, 11. Januar 1949, in: BayHStA, MWi 11715
} 
Die wiederholten Klagen des Spruchkammerpersonals fruchteten nur wenig. Auch der Aufruf der Regierung von Mittelfranken an die Oberbürgermeister und Landräte des Regierungsbezirks vom März 1949, „mitzuteilen, wieviel sie von diesen Leuten bei der Selbstverwaltung oder größeren Stadtverwaltungen unterbringen könnten“, endete mit einem Fiasko ${ }^{166}$. Es meldete sich nämlich nur ein Landkreis, der eventuell bereit war, einen Mann aufzunehmen. Die relativ größten Chancen, im öffentlichen Dienst unterzukommen, hatten die Vorsitzenden und Ankläger, für die sich manche Landräte und Oberbürgermeister stark machten. In der freien Wirtschaft aber waren ihnen die Türen verschlossen. Es sei völlig klar, so äußerte sich der Landrat von Nürnberg in der Besprechung des Regierungspräsidenten mit den Oberbürgermeistern und Landräten von Mittelfranken am 7. März 1949, „daß, wer Vorsitzender oder Kläger war, keine Anstellung in der Privatindustrie findet“. Noch schlechter erging es dem Personal der Ermittlungsdienste, dem nach dem Ende der Spruchkammertätigkeit oft nichts anderes übrig blieb, als um öffentliche Fürsorge einzukommen. Darüber hinaus mußten sie sich auch noch sagen lassen, daß sie an ihrem Schicksal selbst Schuld hätten. Die schönen Worte von 1946 über die ehren- und verantwortungsvolle Mitarbeit an der politischen Säuberung waren vergessen. Schon beinahe zynisch wies der Ansbacher Oberbürgermeister ihre Ansprüche $1949 \mathrm{ab}$ : „Die meisten Leute sind nur wegen der anständigen Bezahlung in diese Stellung gegangen. Ich habe kein Verständnis dafür, wenn irgendeiner seine Stellung als Fachmann aufgab, um einen Ermittler zu machen."167 Ihre Tätigkeit war alles andere als ein „Sprungbrett für eine Nachkriegskar-

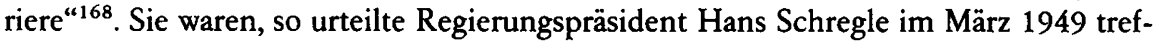
fend, das „peinliche Erbe“ der Entnazifizierung ${ }^{169}$.

Als die Spruchkammer Ansbach-Stadt kurz vor Weihnachten 1948 ihre Pforten schloß, konnte sie an das Bayerische Staatsministerium für Sonderaufgaben berichten, daß in Ansbach die Meldebogen von ca. 22000 Personen bearbeitet worden waren. Über 19000 (=86 Prozent) hatten im Laufe der Jahre 1946 und 1947 die Mitteilung erhalten, daß sie vom Gesetz zur Befreiung von Nationalsozialismus und Militarismus nicht betroffen waren ${ }^{170}$. Lediglich gegen 2500 Personen hatte die Spruchkammer überhaupt ein Verfahren eröffnet, die meisten davon waren schriftlich abgewickelt worden. Nur etwa 20 Prozent aller Beschuldigten $(=500)$ hatten sich in öffentlicher Verhandlung zu verantworten. Die Masse der Verfahren war also eine reine Schreibstubenangelegenheit gewesen. Von den 2500 Personen wurden eingestuft in die Gruppen

$\begin{array}{llr}\text { I } & \text { (= Hauptschuldige }) & 3 \\ \text { II } & \text { (= Belastete }) & 31 \\ \text { III } & \text { (= Minderbelastete }) & 280 \\ \text { IV } & \text { (= Mitläufer }) & 1294 \\ \text { V } & \text { (= Entlastete }) & 59 .\end{array}$

\footnotetext{
${ }^{166}$ So die Ausführungen von Oberregierungsrat Ziegler in der Besprechung des RegPrās mit den OB und LR, 7. März 1949, Prot. in: StA Nümberg, LRA Scheinfeld, Nr. 367.

${ }^{167}$ So Körner in der Besprechung des RegPräs mit den OB und LR, 7. März 1949, Prot. in: Ebenda.

${ }^{168}$ Niethammer, Entnazifizierung, S. 536.

${ }^{169}$ So Schregle in der Besprechung des RegPräs mit den OB und LR, 7. März 1949, Prot. in: StA Nürnberg, LRA Scheinfeld, Nr. 367.

${ }^{170}$ Vgl. die einzelnen Fälle in: Amtsgericht Ansbach, Registratur S.
} 
Unter die Weihnachtsamnestie fielen 317, unter die Jugendamnestie 270. In 213 Fällen wurde das Verfahren eingestellt oder der Angeklagte erhielt das Prädikat „nicht betroffen“ bzw. „nicht belastet“. 49 Personen kam die Heimkehreramnestie zugute ${ }^{171}$.

Nach Lage der Dinge konnte die Bilanz der Spruchkammer Ansbach-Stadt kaum grundlegend anders aussehen, denn auch sie war - wie dargelegt - nur ein Spezialist für „Zweitrangiges“172. Unter den 2500 Fällen finden sich hauptsächlich einfache Parteigenossen, kleine Funktionäre wie z. B. DAF-Obmänner, Schar-, Trupp- und Rottenführer oder SA- und BDM-Führerinnen sowie niedrigere SS-Chargen. Die NS-Prominenz kam nicht oder nur selten vor die Ansbacher Spruchkammer. Die wenigen Pgs mit größerer Belastung wurden in der ersten Instanz durchaus hart angefaßt und zu Arbeitslager, Vermögenseinzug oder Sonderarbeiten verurteilt. Ihnen stand aber noch der Weg in die Berufung offen, den sie auch beschritten - meist mit Erfolg, wie die folgende Tabelle zeigt, die auf einer Stichprobe von 240 Fällen des Buchstaben $\mathrm{H}$ basiert.

Bilanz nach der zweiten Instanz (in Klammern die Entscheidungen nach der ersten Instanz):

Gruppe I

Gruppe II

Gruppe III

Gruppe IV

Gruppe V

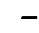

1

2

130

4

52

36

Jugendamnestie \\ Sonstige}

Im Endeffekt - in Ansbach wie im gesamten amerikanischen Besatzungsgebiet fast nur eine Bilanz der Rehabilitation ${ }^{173}$. Das hat Lutz Niethammer in seinem großen Buch über die Entnazifizierung in Bayern dazu verleitet, die Spruchkammern als „Mitläuferfabriken“ $\mathrm{zu}$ bezeichnen und den historisch-politisch so bedeutsamen Versuch einer politischen Säuberung in Deutschland insgesamt als gescheitert anzusehen. Wenn aber gilt, daß wir der Geschichte der Entnazifizierung nicht weniger schuldig sind als jeder anderen Vergangenheit, nämlich genau hinzusehen und vom Gesehenen so gerecht wie möglich zu berichten, so wird man Niethammers Ergebnisse in zweierlei Hinsicht wesentlich korrigieren müssen. Die Rehabilitierung zahlloser kleiner Par-

${ }^{171}$ Mit „Nichtbelastete“ bzw. „Nichtbetroffene“ sind alle jene Fälle gemeint, bei denen sich erst nachträglich herausstellte, daß eigentlich kein Verfahren hätte eröffnet werden brauchen. Unter „Sonstige“ fallen beispielsweise Verstorbene, deren Verfahren eingestellt wurde, oder von Ansbach Weggezogene. Alle Urteilssprüche der Spruchkammer Ansbach-Stadt finden sich im Amtsgericht München, Registratur S.

172 Niethammer, Entnazifizierung, S. 549.

${ }^{173}$ Die Bilanz der Spruchkammer Ansbach-Stadt wäre anders ausgefallen, wenn die Kammer ihr Augenmerk mehr auf zwei, im Befreiungsgesetz ausdrücklich hervorgehobene Tatbestände gerichtet hätte, nämlich auf den Tatbestand der Nutznießerschaft und auf den Tatbestand der langjährigen Parteizugehörigkeit. „Nutznießer ist“, so hieß es in Art. 9 des Gesetzes zur Befreiung von Nationalsozialismus und Militarismus, „wer aus der Gewaltherrschaft der NSDAP, aus der Aufrüstung oder aus dem Kriege durch seine politische Stellung oder seine politischen Beziehungen für sich oder andere persönliche oder wirtschaftliche Vorteile in eigensüchtiger Weise herausgeschlagen hat." Diese Bestimmung war in das Befreiungsgesetz aufgenommen worden, um auch solche Personen erfassen zu können, die keiner NS-Organisation angehört hatten, ihre Einkünfte aber dem NS-Regime zu verdanken hatten. Vgl. dazu auch Niethammer, Entnazifizierung, S. 591. In der Praxis spielte der Vorwurf der Nutznießerschaft nur eine geringe Rolle. Er wurde allenfalls neben an- 
teigenossen war - wie gesehen ${ }^{174}$ - in vielen Fällen berechtigt und machte oft vorher begangenes Unrecht wieder gut. Außerdem gingen der schließlichen Rehabilitierung häufig Strafen voraus, die eine materiell fühlbare Wirkung hatten: Unter den 240 Personen unserer Stichprobe des Buchstaben H finden sich immerhin 87 (=36 Prozent), die nach Kriegsende z.T. drastische Sanktionen zu erleiden hatten; abgesehen vom zeitweisen Verlust aller politischen Rechte wurden sie aus ihren beruflichen Stellungen entlassen oder durften ihr Geschäft bzw. ihren Handwerksbetrieb nicht mehr weiterführen; 21 (=9 Prozent) saßen im Interniertenlager. Erst seitdem sie den Mitläuferoder Amnestierungsbescheid in der Tasche hatten, war die Entnazifizierung vorbei, und sie konnten wieder ihren früheren Berufen nachgehen. Das dauerte allerdings meistens zwei bis drei, in einigen Fällen sogar vier Jahre. Darin bestand der eigentliche „Denkzettel“ für die Mitläufer und Minderbelasteten. In seiner Mischung aus fühlbarer Strafe und großzügiger Gnade war er so dosiert, daß er die Gefahr der Herausbildung eines Heeres von Entnazifizierungsgeschädigten weitgehend bannte, die spätere Bildung neuer Loyalitäten an den demokratischen Staat nicht übermäßig erschwerte und eher das kritische Nachdenken über antidemokratische Experimente und Ideologien förderte.

Einen Denkzettel anderer Art erhielten die prominenten Parteigenossen der Region. Sie waren nach dem Einmarsch der Amerikaner verhaftet worden und mußten bis zu drei Jahre im Internierungslager verbringen. Im Herbst 1948 befanden sich alle wieder auf freiem Fuß. Lediglich der ehemalige Ansbacher Oberbürgermeister Richard Hänel und der ehemalige Ortsgruppenleiter von Windsbach, Hans Hagelauer, mußten noch eine neunmonatige bzw. zweijährige Haftstrafe absitzen, zu denen sie von ordentlichen Gerichten wegen ihrer maßgeblichen Rollen bei der Reichskristallnacht 1938 verurteilt worden waren ${ }^{175}$. Aber keiner aus der alten Garde der hohen NS-Funktionäre fand nach Abschluß der politischen Säuberung Anschluß an die neuen Verhältnisse. Richard Hänel, als Ansbacher Oberbürgermeister und Kreisleiter früher die Nummer Eins in Ansbach und Umgebung, mußte nach seiner Haftentlassung im Oktober 1949 ganz von vorne anfangen. Bis 1952 konnte er keine Anstellung finden, so daß er auf öffentliche Fürsorge angewiesen war. Danach arbeitete er als klei-

deren schweren Vorwürfen erhoben. Dabei zeigte sich deutlich, daß die Spruchkammern nicht in der Lage waren, diesen sehr komplexen Tatbestand entsprechend zu würdigen. Die Betroffenen genossen meist beträchtliches Ansehen in der Öffentlichkeit und verkehrten in den Kreisen der örtlichen Honoratiorenschaft. Sie hatten es in der NS-Zeit zu etwas gebracht, das machte ihnen keiner zum Vorwurf. In den Akten der Ansbacher Spruchkammer finden sich die Fälle von 79 der rund 110 örtlichen Träger des Goldenen Parteiabzeichens, das durch Verfügung des Führers an alle Parteimitglieder verliehen wurde, die die Mitgliedsnummern 1 bis 100000 trugen. Unter den 79 waren viele, die die Ansbacher Ortsgruppe der NSDAP aus der Taufe gehoben hatten. Die wenigsten von ihnen hatten in der Ortsgruppe irgendwelche Positionen bekleidet. Die Spruchkammer sah in der langen Parteizugehörigkeit keine besondere Belastung und behandelte die „Goldenen“ ebenso wie die Märzgefallenen oder die Pgs, die 1937 in die NSDAP eingetreten waren.

Einstufung der Träger des Goldenen Parteiabzeichens in der ersten Instanz in die Klassen I bis V:

Klasse I -

Klasse II 5

Klasse III 32

Klasse IV 23

Klasse V 1

Weihnachtsamnestie, Jugendamnestie und sonstige Amnestien 18.

174 Vgl. S. 102.

${ }^{175}$ Vgl. Amtsgericht Ansbach, Registratur S: Nr. 1, 17. 
ner Handelsvertreter bei einer ortsansässigen Sperrholzgroßhandlung ${ }^{176}$. Sein früherer Stellvertreter, Bürgermeister Albert Böhm, stand nach seiner Entlassung aus dem Internierungslager vor dem Nichts ${ }^{177}$. Böhm war, wie dargelegt, in erster Instanz in die Gruppe I eingestuft worden. Außerdem hatte er alle Ansprüche auf Rente und Pension verloren. $\mathrm{Zu} 70$ Prozent erwerbsunfähig, bereits weit über 60 Jahre alt und völlig mittellos, mußte auch er von der Fürsorgeunterstützung der Stadt Ansbach leben. 1948 legte Böhm mit folgender Begründung Berufung gegen das Urteil der Spruchkammer Ansbach ein: „Meine Frau ist halbtägig bei zwei alten Frauen im Haushalt tätig und verdient dort monatlich 20,- RM wovon 8,- RM für Krankenkasse abgezogen werden. Das sind unsere ganzen Einnahmen ... Es ist für mich lebensnotwendig, daß ich die Rente aus der Angestelltenversicherung erhalte, die ich nun 35 Jahre lang eingezahlt habe." In diesem Punkt kam ihm aber die Berufungskammer nicht entgegen. Daraufhin richtete Böhm ein Gnadengesuch an das Sonderministerium, dem im September 1949 stattgegeben wurde. Der ehemalige Bürgermeister von Ansbach erhielt damit eine kleine staatliche Angestelltenrente, die ihm ein kärgliches Auskommen sicherte. Bis zu seinem Tod im Jahre 1957 versuchte er vergeblich, eine Revision des Urteils der Berufungskammer zu erzwingen. Er sah sich selbst als „Paria II. Klasse“, ohne bürgerliche Rechte und der „seelischen und wirtschaftlichen Verelendung“ überlassen und steigerte sich schließlich in einen fast grenzenlosen $\mathrm{Haß}$ auf den demokratischen Staat, der nicht den Mut fände, „hinter dieser so verunglückten Spruchkammer-Angelegenheit ... einen Strich zu ziehen“.

Böhm und Hänel bemühten sich in den fünfziger Jahren mehrmals, ihre Pensionsansprüche gegenüber der Stadt Ansbach durchzusetzen. Der Stadtrat blieb aber in beiden Fällen hart; 1953 beschloß er, ,alle Ansprüche des fr. Bürgermeisters Albert Böhm grundsätzlich abzulehnen“"178. 1956 wies er einen Antrag Hänels auf finanzielle Unterstützung zurück, weil beim Alt-Oberbürgermeister „weder unverschuldete Notlage gegeben“ sei, noch ein „besonderer Härtefall“ vorläge ${ }^{179}$. Den ehemaligen „Herren" der Stadt hatte man also noch lange nicht vergeben. Nicht viel anders als Hänel und Böhm erging es dem früheren Ortsgruppenleiter von Ansbach/Hofgarten und Zeilberg, Leonhard Rübig ${ }^{180}$, und dem früheren Ortsgruppenleiter von Eyb, Johann Stich $^{181}$. Rübig, dessen Frau während der langen Haftzeit ihres Mannes gestorben war und der außerdem im Krieg zwei Söhne verloren hatte, war nach Kriegsende völlig verarmt. Seine Ansbacher Wohnung, die 1945 demoliert und ausgeraubt worden war, mußte er an Flüchtlinge abtreten, so daß er buchstäblich auf der Straße stand, bis ihn schließlich eine Schwägerin in München aufnahm. Stich war nach der Haft im Internierungslager gesundheitlich schwer angeschlagen, und es dauerte geraume Zeit, bis er eine Anstellung als Autoschlosser fand. Seine geringen Einkünfte mußte er zum größten Teil sofort seinem Anwalt zuleiten, der ihm während seines langwierigen Spruchkammerverfahrens beigestanden hatte.

\footnotetext{
${ }^{176}$ Vgl. dazu ebenda: Nr. 1.

177 Vgl. Amtsgericht München, Registratur S: Nr. 1.

${ }_{178}$ Stadtrat Ansbach an Minister für politische Befreiung, 28. Juli 1953, in: Ebenda.

${ }^{179}$ Stadtrat Ansbach an bay. Staatsministerium für Justiz, 26. Juni 1956, in: Amtsgericht Ansbach, Registratur S: Nr. 1.

${ }^{180}$ Vgl. Amtsgericht München, Registratur S: Nr. 4.

${ }^{181}$ Vgl. Amtsgericht Ansbach, Registratur S: Nr. 21.
} 
In den fünfziger Jahren lebten die ehemaligen Ortsgruppen- und Kreisleiter in ihren Dörfern und Städten meist sehr zurückgezogen und wollten nicht mehr an ihre Vergangenheit erinnert werden. Der soziale Verkehr mit den Nachbarn und Kollegen blieb auch nach dem Ende der Entnazifizierung für sie schwierig. Der Haß, dem die meisten von ihnen nach 1945 begegnet waren, flaute zwar später ab, aber in gewisser Weise blieben sie am Rande der Gesellschaft. Bemerkenswerterweise konnte auch keiner ein politisches Comeback feiern, als in den sechziger Jahren mit der NPD eine politische Partei die Bühne betrat, die zumindest teilweise an die Tradition des Dritten Reiches anzuknüpfen versuchte und damit gerade im protestantisch-deutschnationalen Milieu Mittelfrankens beträchtlichen Zulauf erhielt ${ }^{182}$. Im Zuge der politischen Säuberung war die alte Garde der prominenten NS-Aktivisten also für immer ausgeschaltet worden. 